\title{
Thermal Exposure Sensor for Fire Fighters- Full-Scale Performance Experiments
}

\author{
Atul Deshmukh \\ John G. Casali \\ Jeff A. Lancaster \\ Nelson P. Bryner \\ Roy A. McLane
}

This publication is available free of charge from:

http://dx.doi.org/10.6028/NIST.TN.1804 


\title{
Thermal Exposure Sensor for Fire Fighters- Full-Scale Performance Experiments
}

\author{
Atul Deshmukh \\ John G. Casali \\ Jeff A. Lancaster \\ Auditory Systems Laboratory \\ Grado Department of Industrial and Systems Engineering \\ Virginia Polytechnic Institute and State University \\ Nelson P. Bryner \\ Roy A. McLane \\ Fire Research Division \\ Engineering Laboratory
}

This publication is available free of charge from:

http://dx.doi.org/10.6028/NIST.TN.1804

July 2016

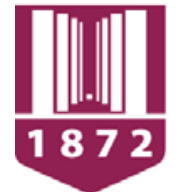

\section{VirginiaTech}

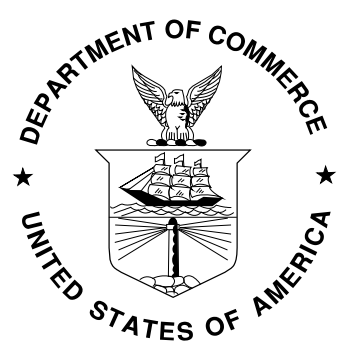

U.S. Department of Commerce

Penny Pritzker, Secretary

National Institute of Standards and Technology Willie May, Under Secretary of Commerce for Standards and Technology and Director 
Certain commercial entities, equipment, or materials may be identified in this document in order to describe an experimental procedure or concept adequately. Such identification is not intended to imply recommendation or endorsement by the National Institute of Standards and Technology, nor is it intended to imply that the entities, materials, or equipment are necessarily the best available for the purpose.

National Institute of Standards and Technology Technical Note 1804 Natl. Inst. Stand. Technol. Tech. Note 1804, 61 pages (July 2016) CODEN: NTNOEF

This publication is available free of charge from: http://dx.doi.org/10.6028/NIST.TN.1804 


\title{
Thermal Exposure Sensor for Fire Fighters- Full-Scale Performance Experiments
}

\begin{abstract}
During structural fire fighting suppression operations, fire fighters wear protective gear to insulate them from the high temperature environment including hot combustion gases, burning surfaces, and thermal radiation. Current turnout gear insulates the fire fighter to such an extent, basically encapsulating his/her entire body that it is more difficult for each individual fire fighter to understand how hazardous or hot the thermal environment is. A fire fighter's body is usually covered with protective gear during search and rescue operations. Therefore, the natural heatsensing mechanism of the body is incapable of sensing the ambient temperature, possibly putting firefighters at risk. A thermal sensing device that attaches to the visor of the head gear is designed to restore situational awareness of the firefighter by showing varying heat intensity through different colored warning indicators in the firefighter's line of sight. Human factors evaluation of the performance of the warnings in the thermal sensing device was conducted in laboratory-scale (i.e., climatic chamber experiments) and in full-scale (i.e. fire experiments in ISO room) environments. While a previous report discussed the laboratory-scale experiments, this report describes the full-scale fire exposure experiments. The evaluation involved tracking the performance of multiple thermal sensors within a standard room during live fire tests.
\end{abstract}




\section{LIST OF ACRONYMS}

a

ANSI

ASTM

A/D

$\mathrm{Al}$

BFRL

$\mathrm{BTU} / \mathrm{ft}^{3}$

$\mathrm{cm}$

$\mathrm{Cr}$

${ }^{\circ} \mathrm{C}$

DAQ

DV

Exp \#

$\mathrm{ft}$

${ }^{\mathrm{o}} \mathrm{F}$

FP

FEE

FT

$\mathrm{Ft}^{3} / \mathrm{min}$

$\mathrm{gal} / \mathrm{min}$

$\mathrm{Hg}$

$\mathrm{Hz}$

HRR

$\mathrm{kHz}$

in

IE

ISO

$\mathrm{kW}$

$\mathrm{kJ} / \mathrm{L}$

NFPA

NG

$\mathrm{Ni}$

NIST

$\mathrm{L} / \mathrm{s}$

$\mathrm{L} / \mathrm{min}$

$\min$

$\mathrm{m}$

$\mathrm{mm}$

$\mathrm{m} / \mathrm{s}$

$\mathrm{mV}$

mAh

MW

$\mathrm{M}$ \#

Ampere

American National Standards Institute

American Society for Testing and Materials

Analog-to-Digital

Alumel

Building Fire Research Code

BTU per cubic feet

Centimeter

Chromel

Degrees Centigrade

Data Acquisition System

Digital Video

Experiment Number

foot/feet

Degrees Fahrenheit

Facepiece

Fire Equipment Evaluator

Front

Cubic feet per minute

Gallon per minute

Mercury

Hertz

Heat release rate

Kilohertz

Inch

Inside

International Standards Organization

Kilowatts

Kilojoules per liter

National Fire Protection Association

Natural Gas

Nickel

National Institute of Standards and Technology

Liters per second

Liters per minutes

Minute

Meter

Millimeter

Meters per second

Milli-volt

Milli Amperes hour

Megawatts

Mask number 


\begin{tabular}{|c|c|}
\hline $\mathrm{MJ} / \mathrm{kg}$ & Mega joules per kilogram \\
\hline MIDAS & MIDAS computerized data collection system \\
\hline ON & Power on the device \\
\hline OFF & Power off the device \\
\hline $\mathrm{Pa}$ & Pascal \\
\hline Rep & Repetition \\
\hline ROM & Read Only Memory \\
\hline $\mathrm{RP}$ & Radiant Panel \\
\hline $\mathrm{RR}$ & Rear \\
\hline RTD & Resistance-Temperature Device \\
\hline $\mathrm{s}$ & Second \\
\hline SO & Static Oven \\
\hline TC & Thermocouple \\
\hline TC \# & Thermocouple number \\
\hline TI & Temperature Inside \\
\hline TO & Temperature Outside \\
\hline TSU & Thermal Sensing Unit \\
\hline UBC & Uniform Building Code \\
\hline $\mathrm{V}$ & Volt \\
\hline$\%$ & Percent \\
\hline
\end{tabular}




\subsection{INTRODUCTION}

Firefighters and first responders wear protective gear to insulate them from high temperature conditions including hot combustion gases, burning surfaces, and thermal radiation. While it is critical to protect fire fighters from adverse fire conditions, it is also important that fire fighters be able to continuously assess the fire environment in which they are working. A rapid increase in temperature may alert a fire team to worsening conditions or a cooling of the environment may indicate successful suppression. Being able to constantly assess their environment allows fire fighters to work more safely and more effectively. Current turnout gear, including boots, pants, coat, hood, helmet, and gloves, effectively insulates a fire fighter from their environment. This gear encapsulates their entire body and that makes it more difficult for fire fighters to sense or understand how hot or intense the conditions are that envelop them. A smoke filled room prevents a fire fighter from visually evaluating their environment. Before the current personal protective equipment was widely available, fire fighters often utilized exposed skin, such as ears, to sense or track the fire conditions around them. While current protective equipment may have reduced the number of burns, especially to the ears, fire fighters still need to be able to assess fire conditions.

Thermal sensing technology can provide fire fighters with the ability to monitor their thermal surroundings. However, in order to be effective, this technology must first be able to detect the thermal environment, and second must make the fire fighter aware of the thermal conditions in a manner that is timely and understandable. At this time, it is not clear whether tracking gas temperatures will provide better data than monitoring heat flux rates. While measuring temperatures or heat fluxes will provide important information, it may also be necessary to track the gradient or change in these quantities. In other words, the specific temperature may be important, but how quickly that temperature is achieved may provide additional insight into the developing fire environment.

Thermal sensing technology including thermocouples or thermistors, and heat flux gauges can be incorporated into existing protective equipment or as stand-alone monitors. Multiple manufacturers of Personal Alert Safety System (PASS) devices offer models with thermal sensors incorporated into each device. If the temperature being monitored exceeds preset limits, the alarm signal is activated. At this time, thermal sensors have only been incorporated into non-integrated PASS devices and are not available on PASS devices that have been integrated into self-contained breathing apparatus (SCBA). Other fire safety equipment manufacturers offer stand-alone thermal sensing units which can be utilized to monitor temperatures in several different location inside or outside turnout gear. Early stand-alone systems such as Life Vest** or Life Shirt, appeared to focus on temperature inside a fire fighter's turnout coat. While these sensing units may provide warning of potential burn injuries or heat stress, these temperature monitors do not provide much data on changing conditions surrounding a fire fighter.

\footnotetext{
${ }^{*}$ Certain trade names and company products are mentioned in the text or identified in an illustration in order to specify adequately the experimental procedure and equipment used. In no case does such identification imply recommendation or endorsement by the National Institute of Standards and Technology, nor does it imply that the products are necessarily the best available for the purpose
} 
Thermal sensors, such as the Fire-Eye (Figure 1) have been developed to track external gas temperatures and display this data directly to each fire fighter. Fire-Eye's sensing unit and display mounts directly to the clear viewing section of the SCBA mask. As the temperature monitored near the face piece exceeds pre-determined values, a series of red and green light emitting diodes (LED) alert the fire fighter to changing conditions. The Fire-Eye device can be described as a 'personal situation awareness tool' that helps firefighters to make better decisions through providing an accurate indication of the temperature in the workspace surrounding them, and which ultimately seeks to reduce heat-related injuries and damage to equipment.

While thermal sensing technology has already been included in different pieces of safety equipment, there are currently no standards or testing protocols with which to assess the performance of these thermal exposure sensors. While it is commendable that manufacturers seek to include more technology in order to increase the safety of fire fighters, the fire service does not have the resources to evaluate the thermal exposure sensor performance in stand-alone or integrated systems devices. There is a need for a well-designed testing protocol that would include different fire conditions that fire fighters typically encounter. This would allow the fire service to understand better the performance characteristics of the thermal sensors. In addition, a standardized testing protocol would allow the manufacturers to match the performance of their devices with the requirements of the fire service.

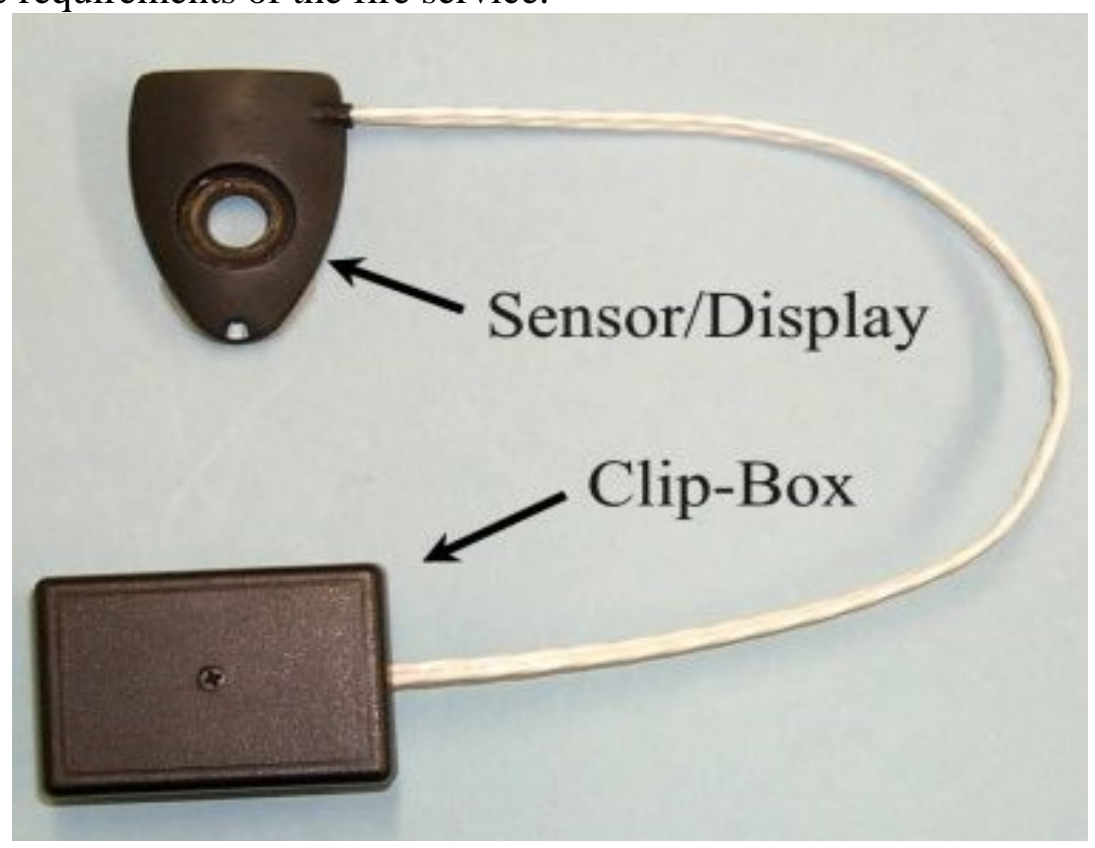

Figure 1. Example of personal awareness tool, Fire-Eye display device along with the clip-box electronics unit.

\subsection{Heat Transfer Mechanism in the Fire Fighter Environment}

The experimental series included the different thermal conditions that fire fighters typically encounter. Within a fire scenario, there are three mechanisms by which thermal energy is transported: convection, conduction, and radiation. Convection is the transfer of heat by actual movement of the warmed matter or gases in the atmosphere; it is the transfer of heat energy in a gas or liquid by movement of currents. Conduction is the transfer of energy through matter from particle to particle; it is the transfer and distribution of heat energy from atom to atom within a 
substance. Conduction is most effective in solids, but it can also happen in fluids. Radiation is the transfer of energy by electromagnetic waves that directly transports energy through space; it is the most efficient modes of transfer of heat energy across gas-filled volumes and it is the dominant mode in a typical fire.. A fire scenario may involve the transfer of heat energy with any combination of the three mechanisms. Therefore, it was necessary to evaluate the performance of a temperature-warning device in experimental conditions representing each of the three mechanisms. In order to validate the performance of the device in keeping with the elements above, the experimental matrix included examining the device in laboratory and fullscale experiments utilizing conductive, convective and radiative modes during the controlled exposure conditions.

\subsection{Situational Awareness Information Displays}

Timely display of fire ground data such as gas temperature, thermal flux values, and gas concentrations, is as important as collecting the data itself. This situational information must be displayed to the fire fighter quickly and in an understandable form. Firefighters and emergency responders are covered with protective gear while conducting firefighting or response activities; therefore, one possible method is to provide a visual warning which is directly in their line of sight. One method for providing this information to the fire fighter is through a visual display on or near the face piece. Manufacturers of personal protective equipment are beginning to introduce equipment with head mounted displays (HMDs) in which the information is conveyed to them through a Head-Up Display (HUD) or Head-Down Display (HDD). HUD is most prominently used in PPE for emergency responders. HUD has the potential to increase firefighter's safety and make their work more efficient without interfering with their primary task of fighting a fire. Some of the typical devices in which HUDs are installed include display of thermal imaging data to locate a fire victim or fellow firefighter, or tactical information, such as maps or navigational information. The HUD warning system has also been used in the Fire-Eye device. The Fire-Eye device utilizes the location of the head visor to indicate various warning indicators, directly in the line of sight of the firefighter. There have been multiple applications of HMDs in fire department operations. HMDs are being effectively used by showing images recorded by a thermal imaging camera, and by displaying maps and the status of the equipment and the environment to the firefighters while they are inside the structure. The advantage of a HMD is that it is "hands-free." HMDs can also be used in hazardous material operations, search and rescue after accidents, and also for detecting hot spots when the fire is extinguished. In the future, the amount of available electronic information from several sources (e.g., the firefighter himself, from sensors or external information from the command post) will highly increase the need for a "hands-free" device such as a HMD to display the relevant information (Bretschneider et al., 2006).

\subsection{Performance of Thermal Sensing Units Under Full-Scale Conditions}

This study examines the performance of a stand-alone thermal sensing unit in a series of full-scale experiments that were designed to document the response of externally mounted monitors. The performance of several thermal sensing devices were monitored through a series of live fires inside a ISO standard room using natural gas, heptane, and upholstered furnishings as fuel packages. Prior to the completion of the full-scale experiments, these same thermal 
sensing devices were included in a series of laboratory-scale experiments which were described in a separate report (Deshmukh et al. 2013).

\subsection{Heat Release Rate and Fire Growth}

Heat Release Rate (HRR) is defined as the enthalpy change per unit of time as a result of the conversion of the chemical energy of a fuel to heat in a combustion process. Usually, the fuel is carbon-based and the combustion process is oxidation, which utilizes the available oxygen from the air. Heat release rate is usually reported in kilowatts (kW) or megawatts (MW) and is an important value because it is a key predictor of the hazard of fire, directly controlling the rate at which heat and the toxic gases build up in an enclosed structure or are driven into more remote spaces. The heat release rate is also the most pertinent measure of the size of a fire (Babrauskas, 2002).

Many different aspects of a fire can affect the performance of a heat-sensing warning device such as Fire-Eye. Any of the three kinds of heat transfer characteristics (i.e., conduction, convection, or radiation) can affect the status of the heat-sensing sensor of the device tested here, depending upon the intensity and type of fuel burning in the fire. Therefore, it is important to validate the performance of thermal sensing devices using different types of fuels, some generating soot, whereas others burning 'cleanly' (i.e., without soot).

Fires typically grow from a small incipient fire to a large one through ignition and flame spread across the various fuels that are available in the environment. While attempting to evaluate the performance of a thermal sensing device in a realistic fire scenario, the overall size of the fire in the testing space and the fire's spread over interior furnishings can significantly affect thermal sensing device performance. One method of evaluating the performance of the thermal sensor is to conduct realistic 'room-corner' tests in standard settings (e.g., living room, bedroom). Unlike laboratory-scale experiments, devices in the room-corner test are exposed to a full-scale fire scenario. In the conduct of such testing, thermal sensing devices should be mounted in an orientation that is representative of their potential use in real fire situations. The ignition source should ideally be kept consistent with a 'naturalistic' form of ignition (i.e., not artificial) in the room-corner tests.

Several room-corner test protocols are currently in use by testing laboratories and are specified by entities such as ASTM, NFPA, the Uniform Building Code (UBC), and the International Standards Organization (ISO). The test arrangements and procedures for the specified room-corner tests are all similar, but there are some differences that can significantly affect the performance of the specimens being tested (Dillon, 1998). These differences include the size, location and energy release rate of the ignition burner as well the height and distance of the specimen from the fire. In order to produce the most representative, realistic fire scenarios, three different kinds of fuels are often used, including liquid sooty, gaseous clean, and wood and fabric (such as a couch, an end table, and a lamp). These fuels were used in the large-scale fire tests of the Fire-Eye device to be outlined below. The height and the distance of the facepieces that were mounted with the thermal sensing devices were representative of realistic fire conditions, such as the conduction-, convection-, and radiation-types of heat transfer that were described earlier. The primary measurements in the room-corner tests were temperature, the total heat flux at various locations, and the visual alarm signal performance of the thermal sensing devices. In order to avoid any structural damage to the ISO room and any other infrastructure used for the large-scale fire tests, the scenarios were designed to avoid flashover 
temperatures (usually in the range of $800^{\circ} \mathrm{C}$ to $1000^{\circ} \mathrm{C}$ ). Another valuable objective of the room-corner tests was to compare the performance of thermal sensing devices in the full scale fire tests with the previous laboratory-scale experiments.

\subsection{EXPERIMENTAL APPARATUS}

This section describes the various instruments, fuel characteristics, and the ISO room specifications. This section also describes the instrumentation used for measuring the temperatures, heat flux, and to collect the digital video recordings.

\subsection{ISO Room Specifications}

The facility used for testing the thermal sensing units was the ISO 9705 Full-scale room fire chamber (see Figure 2) at the Engineering Laboratory (EL) of the National Institute of Standards and Technology (NIST), Gaithersburg, MD. The ISO 9705-2003 room corner scenario is an internationally recognized standard test environment, and the tests conducted within it can be repeated and reproduced relatively easily. The ISO 9705 room dimensions are $2.4 \mathrm{~m}$ wide $\times 3.6 \mathrm{~m}$ deep $\times 2.4 \mathrm{~m}$ high. The door (centered at the bottom of the front wall) in the front is $2.0 \mathrm{~m}$ high $\times 0.8 \mathrm{~m}$ wide. The exhaust hood for the ISO room (in front of the door receiving the gases exhausting from the front door) is $3.0 \mathrm{~m}$ wide x $3.0 \mathrm{~m}$ deep x $1.0 \mathrm{~m}$ high and the exhaust duct diameter is $0.4825 \mathrm{~m}$.

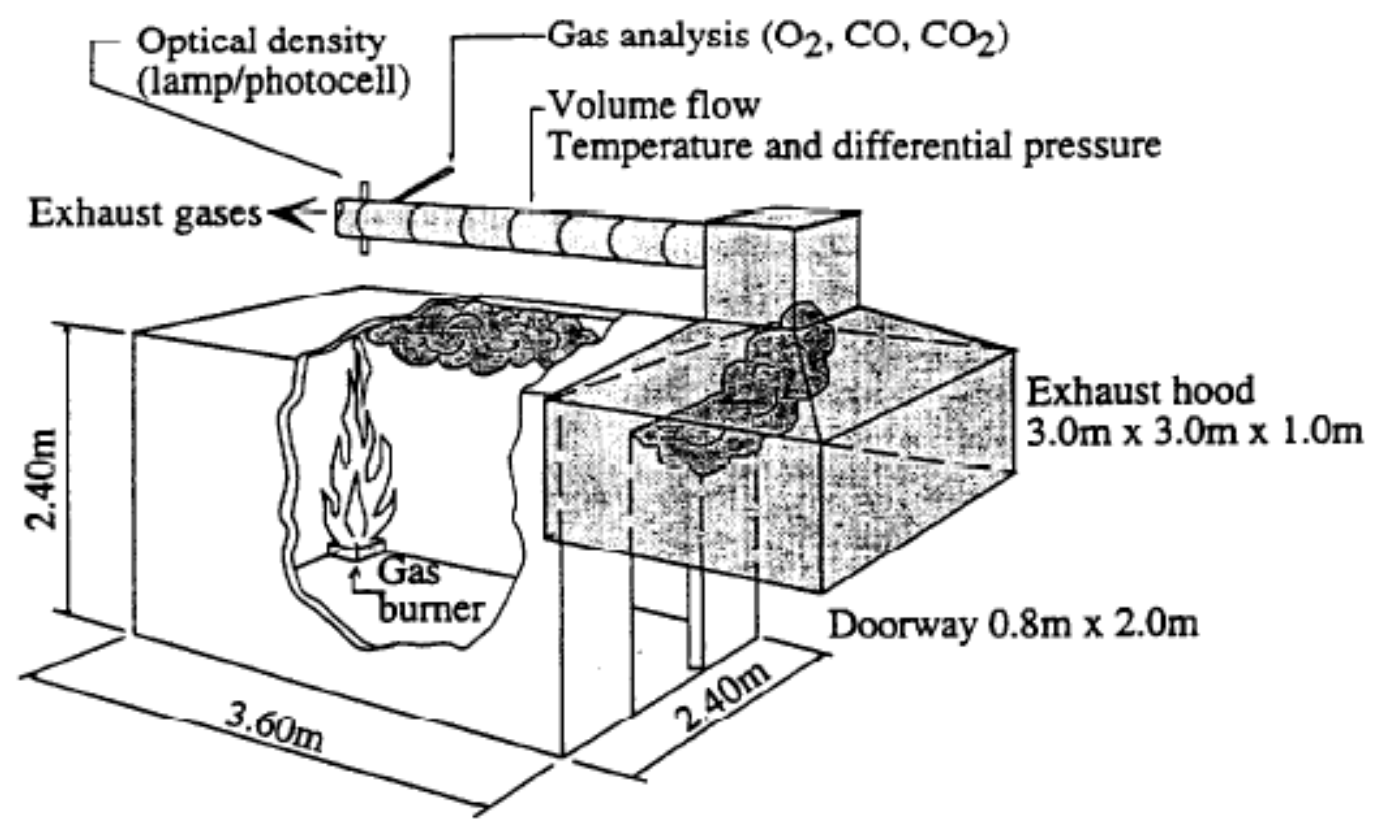

Figure 2. Schematic drawing of the ISO 9705 Room-Corner Test (Dillon, 1998). 


\subsection{ISO Room Construction}

A photograph of the ISO room is shown in Figure 3. The door in the front wall of the ISO room is the only access to the room. The room consists of a sheet metal stud framework lined with three layers of $1.27 \mathrm{~cm}$ thick gypsum wallboard and a single layer of $1.27 \mathrm{~cm}$ thick calcium-silicate board. The gypsum wall board can withstand temperatures in the range of $800{ }^{\circ} \mathrm{C}$ to $1000{ }^{\circ} \mathrm{C}$. The floor of the room is made up of cement board.

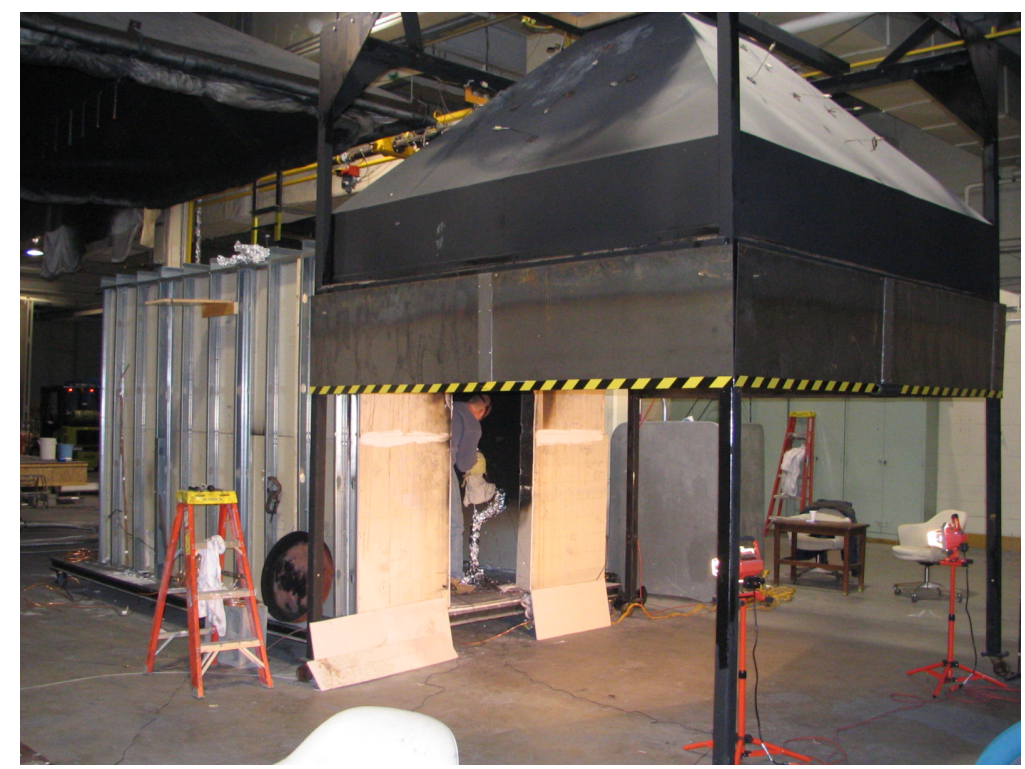

Figure 3. ISO room and its exhaust hood.

The gypsum board walls sometimes degrade when it is too hot inside the room; hence, cement flooring is used instead of gypsum board flooring. The large, instrumented exhaust hood allows for oxygen calorimetry and gas analysis to be performed on the exhaust gases originating from room fires. Oxygen consumption calorimetry consists of collecting all of the gases produced by the fire, measuring the rate of flow of the gases, sampling a small and well-mixed portion of the gases, and measuring the volume fractions of specific gas species, especially the oxygen volume fraction (Bryant et al., 2004).

The ISO room was instrumented with two thermocouple arrays whose locations and specifications are described in the thermocouple array section (Section 2.4). Three water-cooled total heat flux gauges were used to record the heat flux at the target locations where the thermal sensing units were located. The burners for the first two types of fuels used in the experiments were located in the rear left corner of the room. The fuel was supplied through pipes that were connected to fuel storage tanks. The measurements for the physical locations of the fuel burners, thermal sensing units, thermocouple arrays, and the total heat flux gauges in the ISO room were measured from the rear leftmost corner of the room. Electric matches ${ }^{1}$ were used as an ignition

\footnotetext{
${ }^{1}$ Electric match consists of looping a section of bare high-resistant wire around the match heads in a book of matches. When a slight current is applied across the wire, the wire heats up and ignites the entire book of matches in a reproducible manner.
} 
source for all experiments. The ignition spot for each large-scale experiment originated at the same place, located at the leftmost rear corner of the ISO room.

\subsection{Fuels Used for Large-Scale Fire Testing}

As stated earlier, three different types of fuels were selected to conduct the thermal sensing device performance validation in full-scale fire environment. The selection of fuel was based on the soot-production of the fuel as well as its resemblance to realistic fire scenarios in a structural fire. The first two fuels were fired using liquid fuel burners, whereas typical residential furnishings were used for the living room burn experiments.

The first fuel selected for the first two experiments was natural gas. The natural gas heat of combustion was33.73 MJ/m $\left(905.35 \mathrm{BTU} / \mathrm{ft}^{3}\right)$. The specific gravity of natural gas was assumed to be 0.6 and the flow coefficient was taken as 1.0. The heat of combustion per unit of oxygen $\left(\mathrm{O}_{2}\right)$ is $12.55 \mathrm{MJ} / \mathrm{kg}$ of $\mathrm{O}_{2}$. Natural gas burns cleanly, essentially without yielding soot. Natural gas was supplied to the burner using a pipe connected to the cylinder inserted through the rear wall (see Figure 4) of the room. The size of the burner used for the experiment was 0.30 $\mathrm{m}(1.0 \mathrm{ft})$ wide by $0.30 \mathrm{~m}(1.0 \mathrm{ft})$ long by $0.30 \mathrm{~m}(1.0 \mathrm{ft})$ high. The sand within the steel pan of the burner provided a resistance to the flow and resulted in the fuel being distributed more equally across the burner surface. The burner was spaced $15 \mathrm{~cm}(6 \mathrm{in})$ away from the left wall and $15 \mathrm{~cm}$ (6 in) away from the rear wall of the ISO room. The burner was ignited using a pilot light as shown in Figure 4.

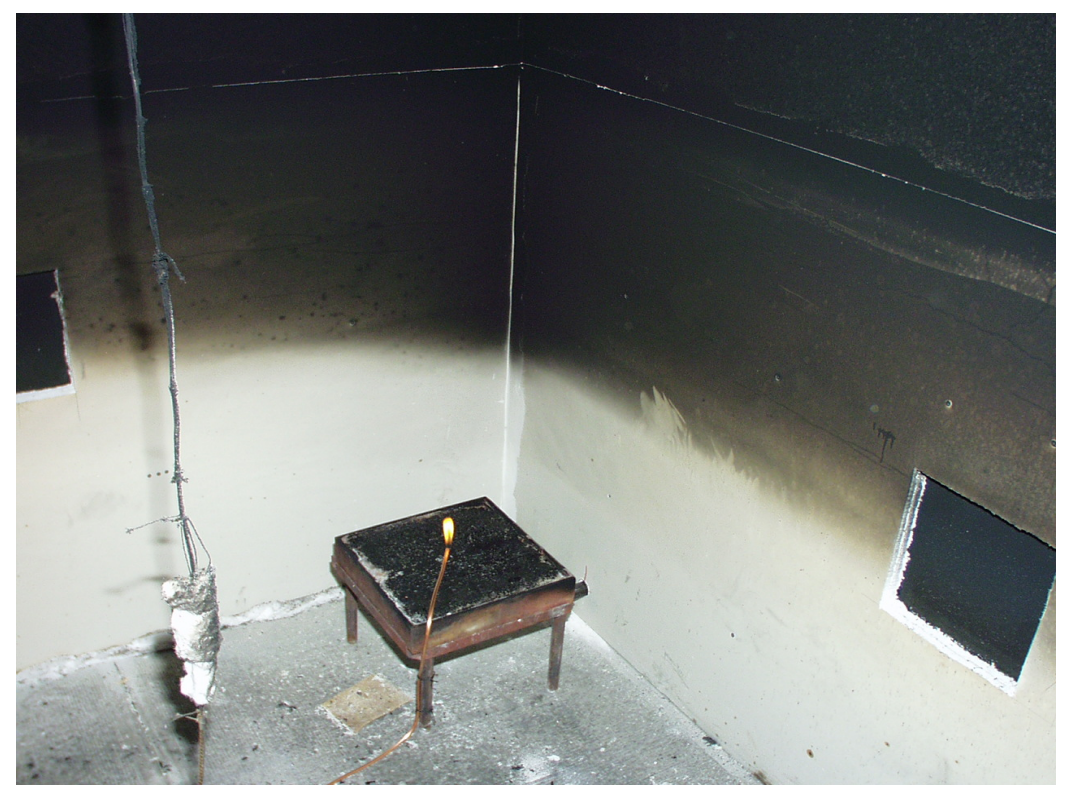

Figure 4. Natural gas burner.

The second fuel selected for the full-scale fire experiments was heptane. The heat of combustion for n-heptane is $30593 \mathrm{~kJ} / \mathrm{L}$, its flow coefficient is 1.0, and the heat of combustion 
per unit of oxygen $\left(\mathrm{O}_{2}\right)$ is $12.68 \mathrm{MJ} / \mathrm{kg}$ of $\mathrm{O}_{2}$. Heptane produces large amount of soot while burning. The type of burner used for the heptane experiment was a 'pan burner.' The diameter of the pan burner was $0.61 \mathrm{~m}$ (24 in), and it was raised to a height of $0.46 \mathrm{~m}$ (18 in) from the floor of the ISO room using two vertically-oriented concrete blocks as shown in Figure 5. The pan was placed at a distance of $7.6 \mathrm{~cm}$ (3.0 in) from the left wall and $7.6 \mathrm{~cm}$ (3.0 in) from the rear wall of ISO room.

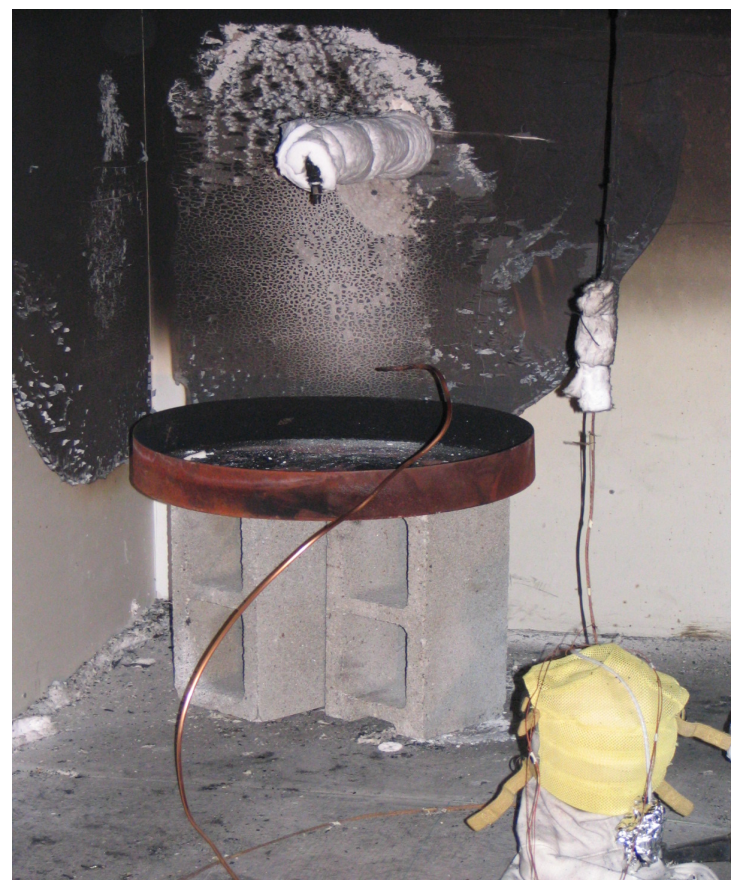

Figure 5. Steel pan burner used for the heptane experiments.

The burner was ignited via a pilot light as shown in Figure 5. The heptane was supplied from storage tanks through a pipeline that flowed through an opening in the bottom of the pan.

The third fuel selected for the full-scale fire experiments was representative of the wood and synthetic fabric typically used in living room furniture. The fuel consisted of a couch, an end table, and a table lamp. Two identical sets of these items were procured from a local furniture store that sold used furniture. The couches were Niagara blue in color and were manufactured by Klaussner ${ }^{\circledR}$ Furniture Industries located in Asheboro, NC (see Figure 6). The length of the couch was $2.18 \mathrm{~m}$ (86 in), whereas the height of the couch from the ground including the two upright cushions was $0.73 \mathrm{~m}$ (29 in). The depth of the couch from its front corner to its rear corner was $0.91 \mathrm{~m}$ (36 in), and the height of the couch (excluding the cushion height) was $0.58 \mathrm{~m}$ (25 in). There were two upright backrest cushions and two horizontal cushions placed on the couch-the cushion in the upright position against the backrest was 0.91 $\mathrm{m}$ (36 in) wide and $0.43 \mathrm{~m}$ (17 in) high. The weight of the couch without the upright cushion was $41.58 \mathrm{~kg}$, and the two upright cushions weighed $5.53 \mathrm{~kg}(12.2 \mathrm{lb})$. The total weight of the couch including the cushions was $47.10 \mathrm{~kg}(103.6 \mathrm{lb})$. The cushions were filled with foam, and the external finish was made with a mixture of polyester-vinyl type of material. 


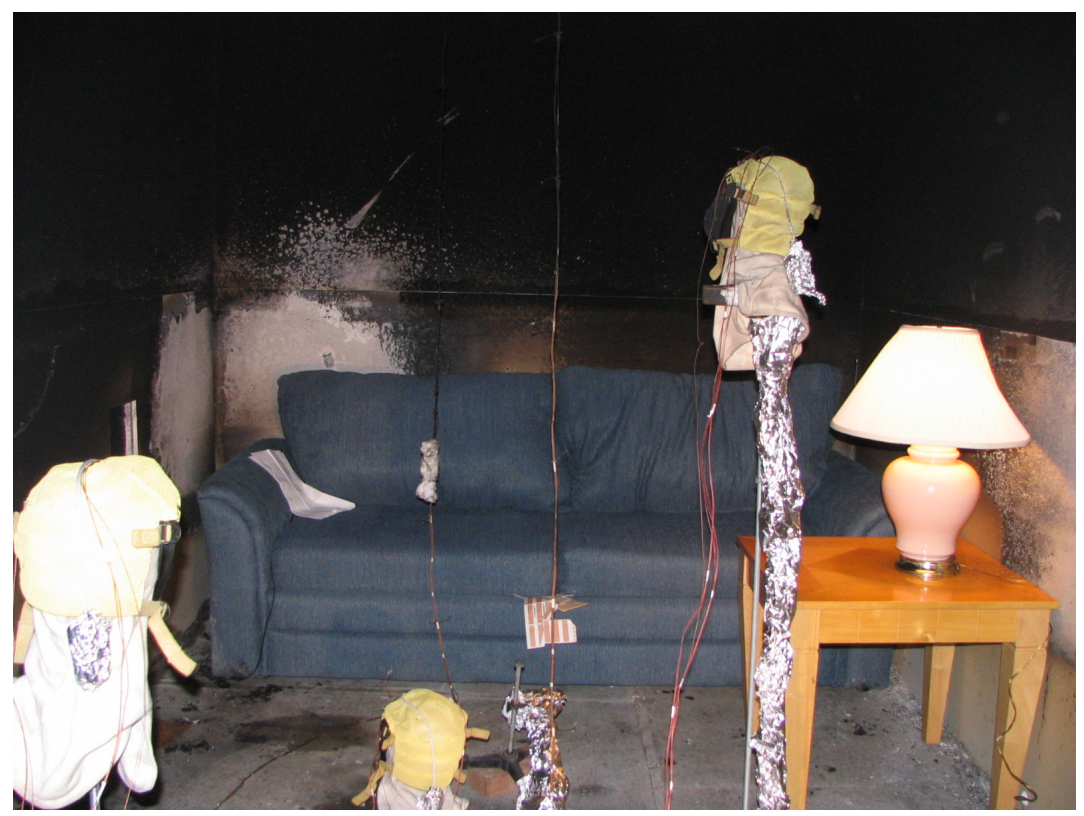

Figure 6. Couch, end table, and lamp used in furnished room burns.

The end table was $0.64 \mathrm{~m}$ (25 in) wide x $0.64 \mathrm{~m}$ (25 in) deep x $0.58 \mathrm{~m}$ (23 in) high, and weighed $13.7 \mathrm{~kg}(30.1 \mathrm{lb})$. The lamp and the shade were $0.43 \mathrm{~m}$ (17 in) high. The lamp was $0.23 \mathrm{~m}$ ( 9 in) wide at the center and $0.15 \mathrm{~m}$ (6 in) wide at the base, and its shade was $0.46 \mathrm{~m}$ (18 in) wide at the bottom, $0.18 \mathrm{~m}$ (7 in) wide at the top, and $0.28 \mathrm{~m}$ (11 in) high. The lamp and the shade together weighed $2.54 \mathrm{~kg}(5.6 \mathrm{lb})$ (Figure 6).

\subsection{Thermocouple Arrays}

Two vertical thermocouple arrays were positioned to monitor the thermal environment inside the ISO room (see Figure 6). Eight thermocouples were attached to each array at $0.30 \mathrm{~m}$ $(1 \mathrm{ft})$ intervals from ceiling to floor. The highest thermocouple on each array was $2.5 \mathrm{~cm}$ (1.0 in) below the ceiling, whereas the second thermocouple on each array was exactly $0.30 \mathrm{~m}$ $(1 \mathrm{ft})$ below the ceiling. All other thermocouples, from TC \#3 through TC \#8, were placed 0.30 $\mathrm{m}(1 \mathrm{ft})$ apart, the last thermocouple being at the floor level. The thermocouples used in the array were Type K Chromel-Alumel thermocouples, which can withstand temperatures up to $1260{ }^{\circ} \mathrm{C}$. The diameter of the sensing junction bead on each thermocouple was approximately 1 $\mathrm{mm}$. Typically, as the mass of the sensing junction bead increases, the time response of the thermocouple also increases. The time constant for these $1 \mathrm{~mm}$ diameter bare thermocouple beads was estimated at 2 seconds (Omega).

During a typical room-corner experiment in the ISO 9705 room, a hot layer of gases develops at the top, and cold air moves into the bottom of the room. The thermocouples within the upper layer at the top $0.6 \mathrm{~m}$ to $0.9 \mathrm{~m} \mathrm{(} 2 \mathrm{ft}-3 \mathrm{ft}$ ) of the room display higher temperatures than the actual temperatures due to radiation cooling. The thermocouples at a distance of $0.3 \mathrm{~m}$ to $0.6 \mathrm{~m}(1 \mathrm{ft}-2 \mathrm{ft})$ from the floor show a higher temperature than is the actual ambient temperature 
due to radiative heating effects. Corrections for radiation heating or cooling were not applied to the temperatures recorded by the thermocouples in the room.

\subsection{Instrumentation of Thermal sensing units and Facepieces}

The nomenclature used for labeling the six thermal sensing units in Table 1 was also used in the full-scale fire experiments. Each Scott AV Face Mask 2000 model was equipped with a different thermal sensing unit. Each facepiece was instrumented with two thermocouples, one attached to the inside surface and the other attached to the outside surface of the transparent polycarbonate lens of the facepiece. Each thermal sensing unit except for unit \#4 was instrumented with two thermocouples. Thermal sensing unit \#4 was instrumented with three thermocouples. Ambient temperature thermocouples were also attached to each facepiece at a distance of $2.5 \mathrm{~cm}$ (1.0 in) from the thermal sensing unit, as in the laboratory-scale experiments. Each facepiece/thermal sensing unit had a minimum of five thermocouples attached, whereas the facepiece with thermal sensing unit \#4 had six thermocouples attached. While testing the three thermal sensing units simultaneously, seven thermocouple channels were allocated to each mask in the Data Acquisition System (DAQ, discussed in detail below). Each thermocouple maintained a dedicated channel for data collection. The length of the thermocouples attached to the thermal sensing units averaged $6.1 \mathrm{~m}(20 \mathrm{ft})$. This length was not sufficient, however, to plug the other end of thermocouples in the DAQ. Therefore, thermocouple extension wires were used to plug the channels into the DAQ.

Table 1: Nomenclature for the thermal sensing devices.

\begin{tabular}{|c|c|c|}
\hline $\begin{array}{c}\text { Assigned Device } \\
\text { Number }\end{array}$ & $\begin{array}{c}\text { Manufacturer's Serial } \\
\text { Number }\end{array}$ & $\begin{array}{c}\text { Thermocouple } \\
\text { Specification }\end{array}$ \\
\hline 1 & 10001629 & TC1 and TC2 \\
\hline 2 & 10001708 & TC1 and TC2 \\
\hline 3 & 10001638 & TC1 and TC2 \\
\hline 4 & 10001623 & TC1, TC2 and TC 5 \\
\hline 5 & 10001618 & TC1 and TC2 \\
\hline 6 & 10001530 & TC1 and TC2 \\
\hline
\end{tabular}

Table 2. Facepiece (FP) serial numbers and the thermocouples associated with them.

\begin{tabular}{|c|c|c|}
\hline $\begin{array}{c}\text { Assigned Facepiece } \\
\text { Number }\end{array}$ & $\begin{array}{c}\text { Manufacturers Serial } \\
\text { Number }\end{array}$ & $\begin{array}{c}\text { Thermocouple } \\
\text { Specification }\end{array}$ \\
\hline FP 1 & $804191-08$ & TC3 and TC4 \\
\hline FP 2 & $804177-01$ & TC3 and TC4 \\
\hline FP 3 & $802240-01$ & TC3 and TC4 \\
\hline
\end{tabular}




\subsection{Heat Flux Transducers}

Three calibrated Schmidt-Boelter total heat flux transducers were used to measure heat flux at three thermal sensing unit locations. The heat flux transducers are a water-cooled thermopile type, operating between $0 \mathrm{~kW} / \mathrm{m}^{2}$ to $50 \mathrm{~kW} / \mathrm{m}^{2}$. The transducers operate with a sensitivity of approximately $10 \mathrm{mV}$ at $50 \mathrm{~kW} / \mathrm{m}^{2}$. Each heat flux gauge measured $25 \mathrm{~mm}(1.0$ in) in diameter and had a metal flange located $25 \mathrm{~mm}$ (1.0 in) down its body and away from the sensing surface. Figure 7 shows a part of the heat flux gauge attached to the left side of the mask. Table 3 shows the serial numbers and dedicated data channels for the total heat flux gauges used at three mask locations. Each serial number had an independent calibration factor to convert the $\mathrm{mV}$ sensor output signal into a total heat flux in $\mathrm{kW} / \mathrm{m}^{2}$, which was recorded by the DAQ. The three heat flux gauges were pointed towards the fire source so that they could record the heat flux at the location of each thermal sensing unit.

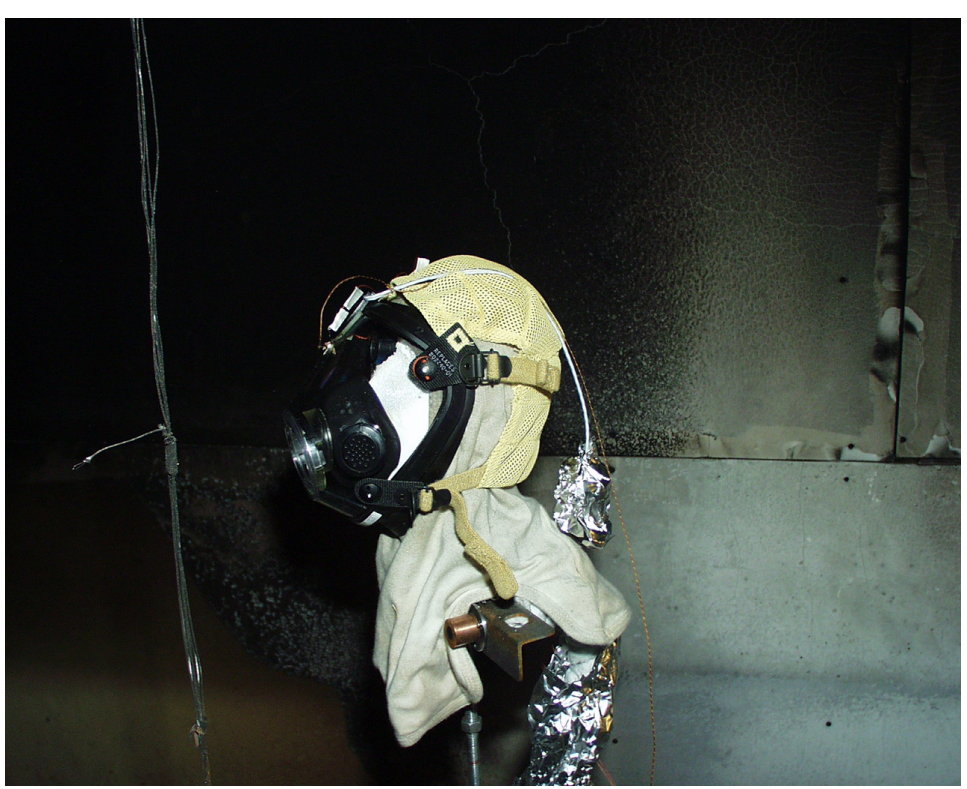

Figure 7. Heat flux gauge mounted to the left of the facepiece.

Table 3. Nomenclature for the heat flux gauges used at the three mask locations.

\begin{tabular}{|c|c|c|c|}
\hline Flux Gauge \# & $\begin{array}{c}\text { Total Heat Flux } \\
\text { Gauge Serial \# }\end{array}$ & $\begin{array}{c}\text { Data Acquisition Channel } \\
\text { Number }\end{array}$ & Wattage \\
\hline Gauge 1 & 126844 & Channel 3 & $20 \mathrm{~W}$ \\
\hline Gauge 2 & 126846 & Channel 4 & $20 \mathrm{~W}$ \\
\hline Gauge 3 & 126842 & Channel 5 & $20 \mathrm{~W}$ \\
\hline
\end{tabular}

\subsection{Data Acquisition System}

The DAQ also provided a user interface for control of the calibration burner's output and to record the subsequent response of its instruments (Bryant et. al. 2004). The primary DAQ 
board had 16 analog input channels at a 16-bit digital resolution and was capable of a sampling rate of $333 \mathrm{kHz}$. A total of 40 analog input signals were required for the calorimetry computation. Seven signal conditioning and multiplexing modules were employed and each module had a capacity for 32 input channels. The channels were scanned at a rate of $200 \mathrm{~Hz}$ and the signals were routed to a single channel on the primary DAQ board. Each multiplexed channel was electronically averaged for $1 \mathrm{~s}$ and the digital value was stored to the computer. The signal-conditioning features of the module included an electronic filter (200 Hz low-pass) and gain (amplifying up to 100 times). The gain was typically applied to low-voltage signals, such as those produced by the thermocouples (Bryant et. al. 2004). Figure 8 shows a picture of the thermocouples and heat flux gauges plugged into the data collection system.

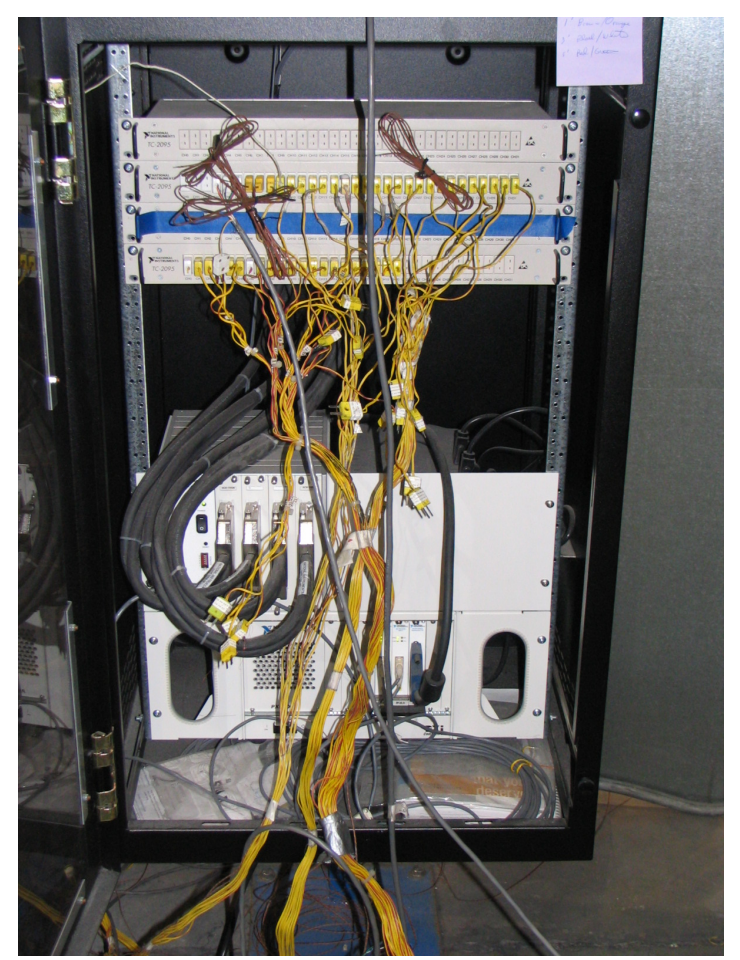

Figure 8. Data acquisition input unit for the thermocouples.

The user interface for the DAQ was written in a LabView program that computed the heat release rate and displayed user-specified data and computations. The program was run on a workstation with dual $733 \mathrm{MHz}$ processors and was located in the instrument control room of the NIST National Fire Research Laboratory. The output was displayed on the workstation monitor and was updated as the fire experiment proceeded. Figure 9 shows the two visual monitors utilized, each with three real time temperature channels and other experiment parameters displayed on the left of the screens. 


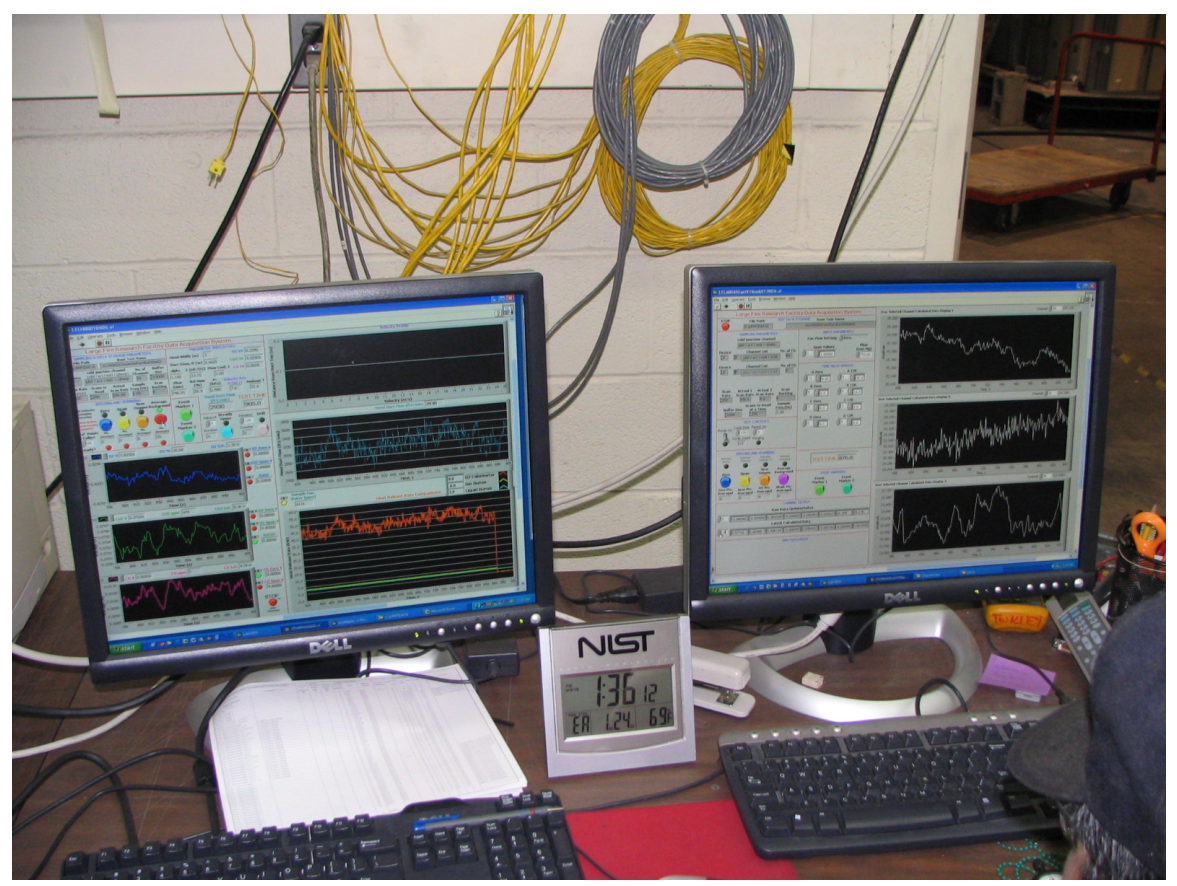

Figure 9. Visual displays showing the fuel flow rate as well as temperatures at different locations.

\subsection{Digital Video Recording System}

The performance of three thermal sensing units was recorded simultaneously using three bullet cameras fitted into the head-forms as described in the laboratory-scale experiments (Deshmukh et.al 2013). For the Full-scale fire testing, the three bullet cameras were connected to three digital video recording units, each of which was powered by individual batteries.

\subsection{EXPERIMENTAL MATRIX}

Presented below is information outlining the experimental design used for the large-scale fire experiments, including devices, instrumentation, protocol, and setup.

\subsection{Qualitative Description of Mask Location}

Three masks were located at three different locations and elevations to simulate the realistic heat transfer circumstances of conduction, convection, and radiation. The heat flux density was typically highest at the mask closest to the fire, as it received the most radiation. The mask farthest from the heat source received the least amount of radiative heat, but was subjected to conductive heat. The mask at the higher elevation in the enclosed space received the most convective heat since the burning process pushed the heated gases high up into the structure. Since the room height was just $2.43 \mathrm{~m}$ (8.0 ft), the mask at an elevation of $1.52 \mathrm{~m}$ (5.0 $\mathrm{ft}$ ) from the floor received substantial heat from the heated gases. 


\subsection{ISO Room Test Layout and Location of Masks}

The layout for the ISO room specific to each fuel experiment is displayed in Figure 10. A separate room layout was utilized for the natural gas and Heptane fuel experiments. Figure 11 displays the location of Mask 1 in the ISO room, which was located diagonally at a distance of $0.84 \mathrm{~m}$ (33 in) from the front corner of the natural gas burner, and $0.94 \mathrm{~m}$ (37 in) from the left

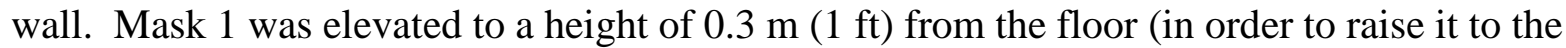
level of burner) so that the heat generated from the burner was normally incident on the thermal sensing unit. The position of Mask 1 was maintained as the same for the heptane and the living room experiments for consistency.

\section{Experimental Layout 1 - Natural gas / Heptane $\quad$ Experimental Layout 2 - Living Room Burn}
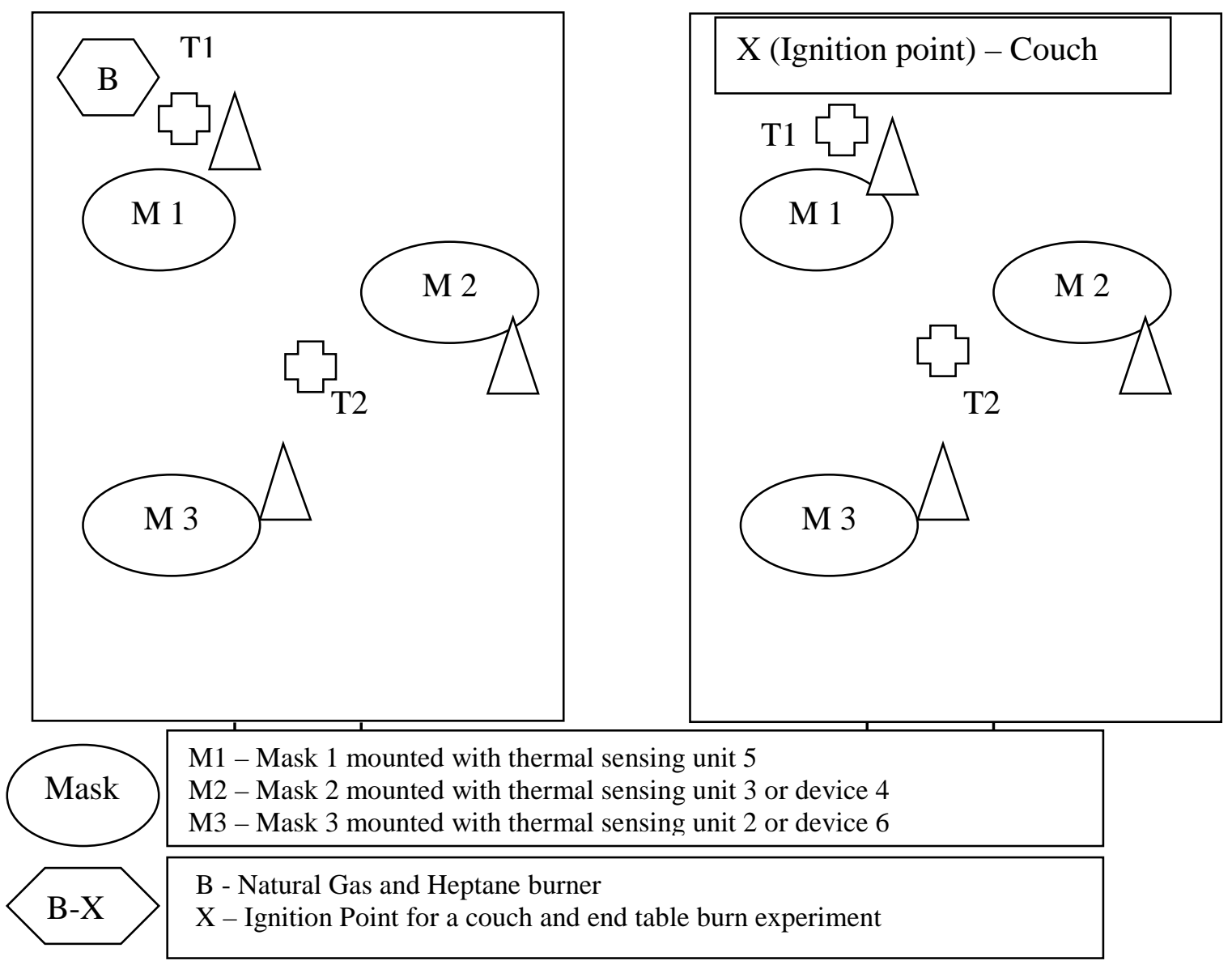

Thermocouple Tree 1 and 2
Tree $1(\mathrm{~T} 1)-0.9 \mathrm{~m}(3 \mathrm{ft})$ from the left wall and $0.9 \mathrm{~m}(3 \mathrm{ft})$ from the rear wall
Tree $2(\mathrm{~T} 2)-1.2 \mathrm{~m}(4 \mathrm{ft})$ from the left wall and $1.8 \mathrm{~m}(6 \mathrm{ft})$ from the rear wall

$\bigwedge \quad$ Three heat flux gauges next to each mask

Figure 10. Layout and arrangement of the facepiece and thermal sensing unit in the ISO room (Viewpoint is from the top down). 


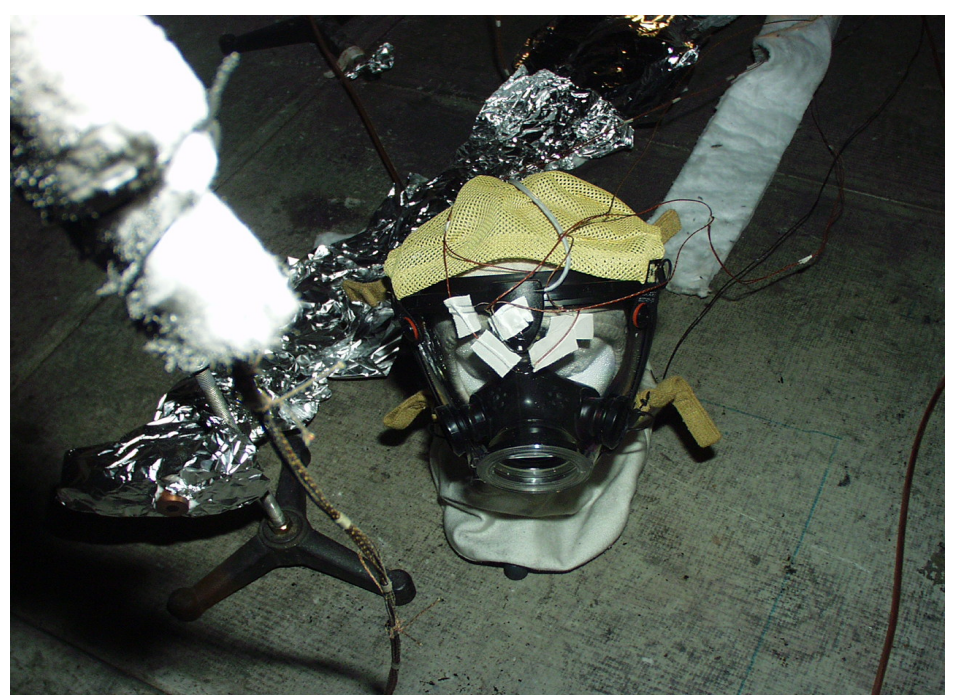

Figure 11. Mask 1 located at a height of $0.3 \mathrm{~m}(1 \mathrm{ft})$ from the ISO room floor.

A diagonal distance of $0.84 \mathrm{~m}$ (33 in) was maintained from the radiant heat source in an effort to mirror the distance of the radiant panel as in the laboratory-scale experiments in a flux of $1.6 \mathrm{~kW} / \mathrm{m}^{2}$. Heat flux gauge \#1 was located on the same arc at a distance of $0.84 \mathrm{~m}$ (33 in) from the natural gas burner and to the left side of and close to Mask 1 (see Figure 11). The Mask 1 location was representative of a firefighter operating very close to a fire source, and exposed to radiant heat generated from that source.

Figure 12 displays the location of Mask 2 in the ISO room, which was at a distance of 6 feet from the left wall and $1.8 \mathrm{~m}(6 \mathrm{ft})$ from the rear wall. Mask 2 was elevated $1.5 \mathrm{~m}(5 \mathrm{ft})$ from the room floor using an iron rod mounted on a stand. Mask 2 simulated the convective heat transfer condition of a fire. Heat flux gauge 2 was mounted on the same stand below Mask 2 as shown in Figure 12. During a real fire incident, the burnt gases and soot rise to the highest points in the enclosed structure (the space closest to the roof) while the oxygen is burning at the fire's source. The elevation of Mask 2, therefore, was representative of a firefighter moving inside a burning fire toward the fire source or toward hot smoke, and the heated air moving in the direction of firefighter.

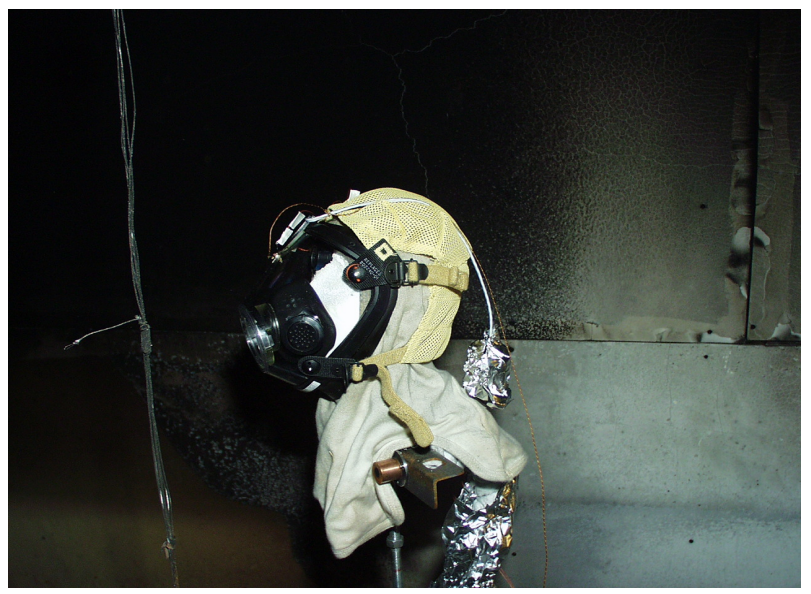

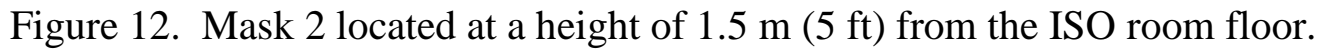


Figure 13 shows the location of Mask 3 in the ISO room. Mask 3 was located at a

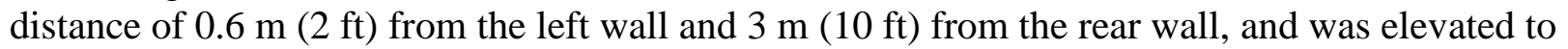
a height of $0.91 \mathrm{~m}$ (3.0 ft) from the room floor. Mask 3 simulated the conductive heat-transfer condition in a realistic fire scenario. Heat flux gauge \#3 was mounted on the same stand, and below the Mask 3 as shown in Figure 13. During a real fire incident, the location of Mask 3 would be representative of a fire fighter crawling or moving by bending his/her back in order to avoid the hot gas layer formed at a height of $1.5 \mathrm{~m}(5.0 \mathrm{ft})$ to $2.4 \mathrm{~m}(8.0 \mathrm{ft})$. At the height of 0.91 $\mathrm{m}(3.0 \mathrm{ft})$ from floor, the conductive-type of heat transfer is more prominent than is radiation or convection.

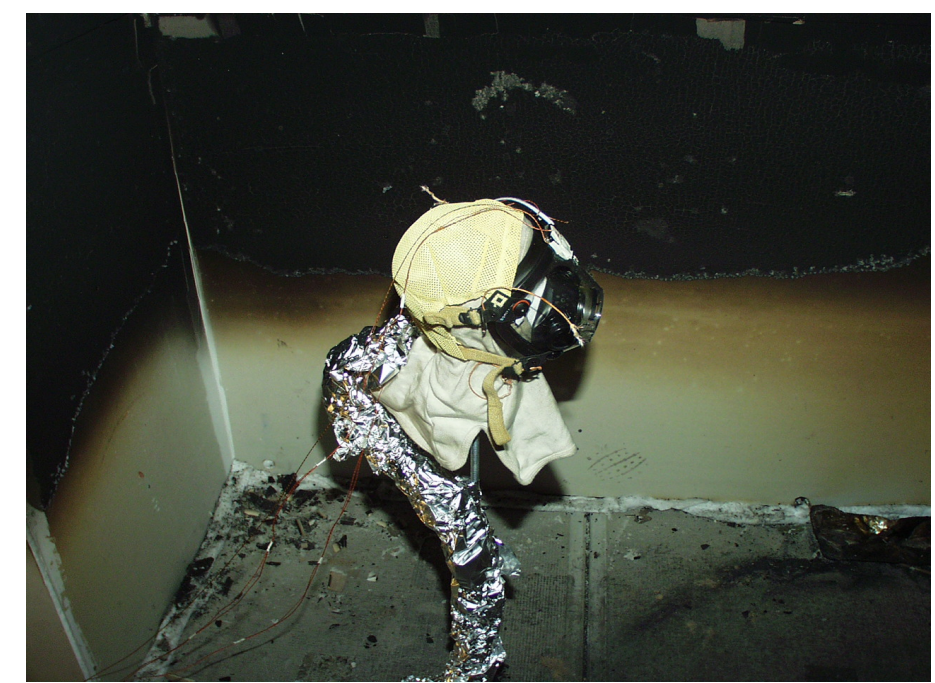

Figure 13. Mask 3 located at a height of $0.91 \mathrm{~m}(3 \mathrm{ft})$ from the ISO room floor.

\subsection{Experimental Design for the Full-scale Fire Experiments}

Figure 14 shows the experimental matrix for evaluating thermal sensing units in the fullscale fire facility. Experiment 1 and Experiment 2 were planned using natural gas fuel, whereas Experiment 3 and Experiment 4 were planned using liquid heptane fuel. Experiment 5 and Experiment 6 were conducted using living room furniture as a fuel. As per the experiment plan, two ISO room experiment burns were conducted using each type of fuel. In order to validate the performance of thermal sensing unit with different kinds of fuels, six experiments were performed over a period of two days.

In order to examine the reproducibility of the thermal sensing unit, it was decided to use device number 5 (the same as for the laboratory-scale experiments). The full-scale fire experiments maintained a protocol of two repetitions for thermal sensing unit 5 with each fuel, whereas the laboratory-scale experiments had three repetitions for thermal sensing unit 5 . In the six experiments, thermal sensing unit \#5 was characterized at the same location (i.e., with Mask 1) to help mitigate the variability that may have arisen due to a location change.

In order to examine the repeatability of the thermal sensing unit, device numbers $2,3,4$, and 6 were tested at different locations. In order to maintain consistency with the laboratoryscale experiments, these four devices were tested during two full-scale burns using the same fuel. Two devices were examined in the first burn and the remaining two devices were re-examined in the next burn using the same fuel. For example, TSU 2 and TSU 3 were at locations M3 and M2 
(respectively) during the first burn, and TSU 4 and TSU 6 were at location M2 and M3 for the second burn. In order to reduce the set-up time (e.g., re-instrumentation) between the two experiments, and to mitigate any variability that may have presented with respect to a device location change, particular devices were maintained at the same position between fuel burns. Replacement of a device's batteries and the fuel source were the only procedures undertaken between burns, which provided time for the thermal sensing units, bullet cameras, and the facepieces to cool before a subsequent experiment.

\section{FUEL 1 - NATURAL GAS}

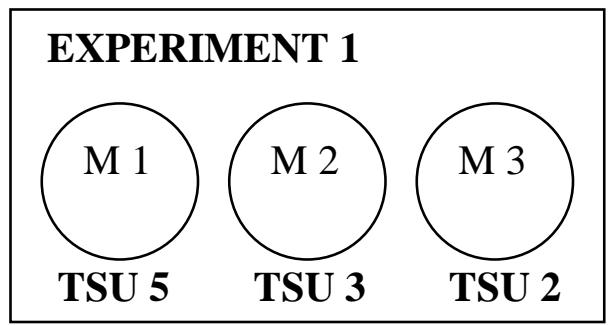

EXPERIMENT 2

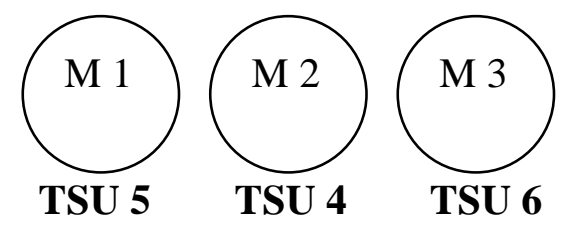

\section{FUEL 2 - HEPTANE}

\section{EXPERIMENT 3}

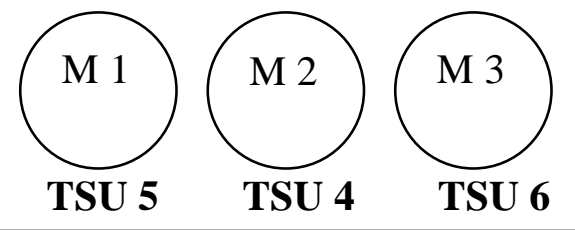

\section{EXPERIMENT 4}
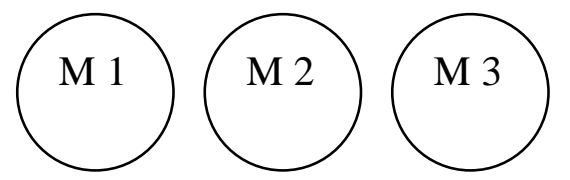

TSU 5

TSU 3

TSU 2

FUEL 3 - COUCH AND END TABLE

\section{LIVING ROOM BURN 1}

EXPERIMENT 5

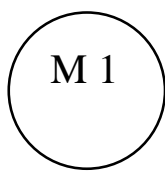

TSU 5

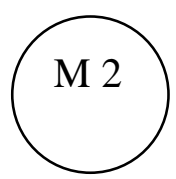

TSU 3

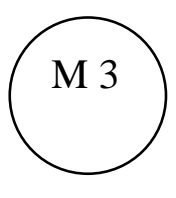

TSU 2

Figure 14. Experiment plan for the thermal sensing units in the full-scale fire facility. 


\subsection{EXPERIMENTAL PROCEDURES}

The experimental procedures followed for each of the full-scale fire experiments are presented below.

\subsection{Natural gas Experimental Procedure}

The relative humidity was $26 \%$ at the beginning of the natural gas experiment. The barometric pressure was $751 \mathrm{~mm}$ of mercury (Hg), and the ambient temperature of the space inside and outside the ISO room was $23^{\circ} \mathrm{C}$. The criterion for terminating the natural gas experiments was to reach a temperature of at least $120^{\circ} \mathrm{C}$ at TC1 for Mask 1 and Mask 2, which would mirror the laboratory-scale experimental temperature conditions. The experimental procedure was as follows:

1. Complete the instrumentation of the masks and the Thermal sensing units as per the experiment plan for natural gas experiment \#1.

2. Ready the three video recording units as well as adjust the bullet cameras to appropriately view the thermal sensing units.

3. Program the DAQ to store the details of each experiment.

4. Adjust the heat release rate (HRR) of the natural gas fuel to zero and record the time(s).

5. Start the data acquisition computer and record a reference time.

6. Ignite the gas burner inside the ISO room using the pilot light (see Figure 4).

7. Record the ignition time and start the digital video recording system.

8. Raise the HRR to $26.6 \mathrm{~kW}$ after 3 minutes from the time of ignition.

9. Raise the HRR to $50 \mathrm{~kW}$ after 6 minutes from the time of ignition.

10. Raise the HRR to $100 \mathrm{~kW}$ after 9 minutes from the time of ignition.

11. Check the mask temperatures at M1TCI and M2TC1 and confirm whether they have reached at a level of $120^{\circ} \mathrm{C}$.

12. Reduce the HRR after 12 minutes to $0 \mathrm{~kW}$ and turn off the natural gas supply.

13. Stop the HRR computer and data acquisition computer.

14. Repeat the experiment for experiment plan \#2 as per Figure 14.

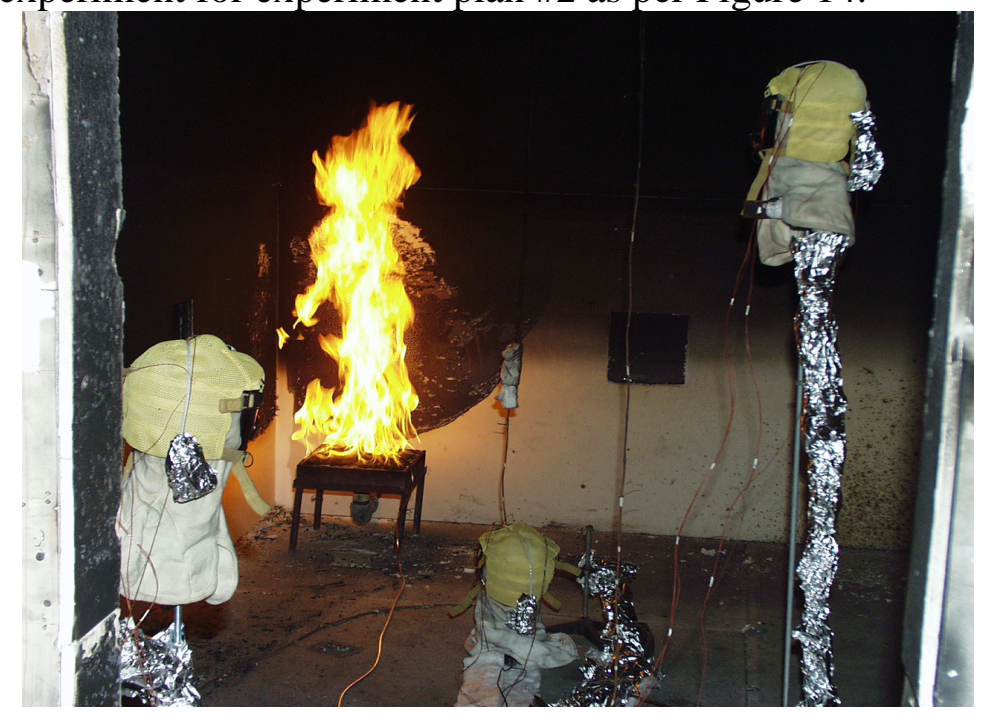

Figure 15. Full-scale fire experiment in progress using natural gas as fuel. 


\subsection{Heptane Experimental Procedure}

The relative humidity was $30 \%$ at the start of the heptane experiment. The barometric pressure was $751 \mathrm{~mm}$ of mercury $(\mathrm{Hg})$, and the ambient temperature of the space inside and outside the ISO room was $16.1^{\circ} \mathrm{C}$. The experiment terminating criteria for the Heptane experiments was to reach a temperature of $120^{\circ} \mathrm{C}$ at M1TC1 or M2TC1. The experimental procedure was as follows:

1. Complete the instrumentation of the masks and the thermal sensing units for heptane experiment \#1, per the experiment plan in Figure 14. Confirm that the data acquisition system is reading appropriate values for all 53 channels.

2. Ready the three video recording units as well as adjust the bullet cameras to appropriately view the thermal sensing units.

3. Program the DAQ to store the details of each experiment.

4. Adjust the frequency of heptane flow to zero and record the time(s).

5. Start the data acquisition computer and record a reference time.

6. Ignite the heptane flow burner inside the ISO room using pilot light (see Figure 5).

7. Record the ignition time and start the digital video recording system.

8. After 3 minutes from ignition, raise the frequency of nozzle flow to $0.5 \mathrm{~Hz}$ to reach a HRR of $70 \mathrm{~kW}$.

9. After 6 minutes from ignition, raise the frequency of nozzle flow to $0.76 \mathrm{~Hz}$ to reach a HRR of $100 \mathrm{~kW}$. Record the appropriate experiment status in lab notebook.

10. After 9 minutes from ignition, raise the frequency of nozzle flow to $0.82 \mathrm{~Hz}$ to reach a HRR of $130 \mathrm{~kW}$. Raise the frequency of nozzle flow to $0.76 \mathrm{~Hz}$ to reach a HRR of 100 $\mathrm{kW}$ after 6 minutes from the time of ignition.

11. Pull back Mask \#1 in order to protect it from high radiative heat at the location of Mask 1 , and confirming that M1TC1 has reached a temperature of $120^{\circ} \mathrm{C}$.

12. After 12 minutes from ignition, raise the frequency of nozzle flow to $1.0 \mathrm{~Hz}$ to reach a HRR of $160 \mathrm{~kW}$. Stop the liquid fuel flow one minute after reaching a HRR of $160 \mathrm{~kW}$.

13. Check the temperature at M2TC1 and confirm whether it has reached at a level of $120^{\circ} \mathrm{C}$.

14. Turn off the heptane fuel supply.

15. Stop the HRR computer and data acquisition computer. Repeat the experiment for second experiment plan as per Figure 14. 


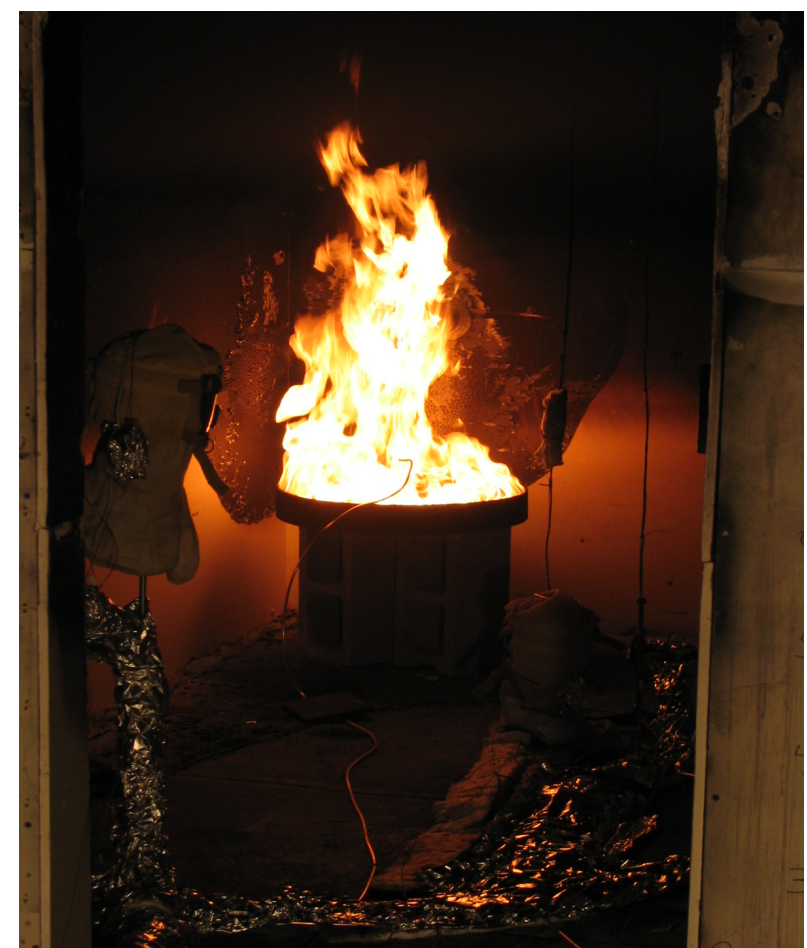

Figure 16. Full-scale fire experiment in progress using heptane as a liquid fuel.

\subsection{Living Room Fire Experimental Procedure}

The relative humidity on the day of the living room fire experiment was $27 \%$. The barometric pressure was $749 \mathrm{~mm} / \mathrm{Hg}$, and the ambient temperature of the space inside and outside the ISO room was $21^{\circ} \mathrm{C}$. The general experiment terminating criterion for the living room experiments was to avoid flashover temperatures more than $600^{\circ} \mathrm{C}$ to $800^{\circ} \mathrm{C}$ at the height of 7 to 8 feet from the floor. The specific experiment terminating criteria was to not allow the temperatures at M1TC1 and M2TC1 to rise above $160^{\circ} \mathrm{C}$. Once the temperatures at either of these two TC reaches $160^{\circ} \mathrm{C}$, then the fire would be extinguished with water sprinkler by a trained firefighter present at the time of testing. The experimental procedure was as follows:

1. Arrange the couch, corner table, and table lamp as shown in the pre-experiment scenario in Figure 17. Maintain the location of the masks constant as in the earlier four experiments.

2. Complete the instrumentation of the masks and the thermal sensing units for the living room experiment \#1, per the experiment plan in Figure 14. Confirm that the DAQ is reading appropriate values in all 53 channels.

3. Ready the three video recording units as well as adjust the bullet cameras to appropriately view the thermal sensing units.

4. Program the data acquisition system to store the details of each experiment.

5. Start the HRR computer and record the time (s).

6. Start the data acquisition computer and record a reference time.

7. Ignite the leftmost rear corner of the couch using the electric matches. A photograph of the living room experiment after ignition is shown in Figure 18. 


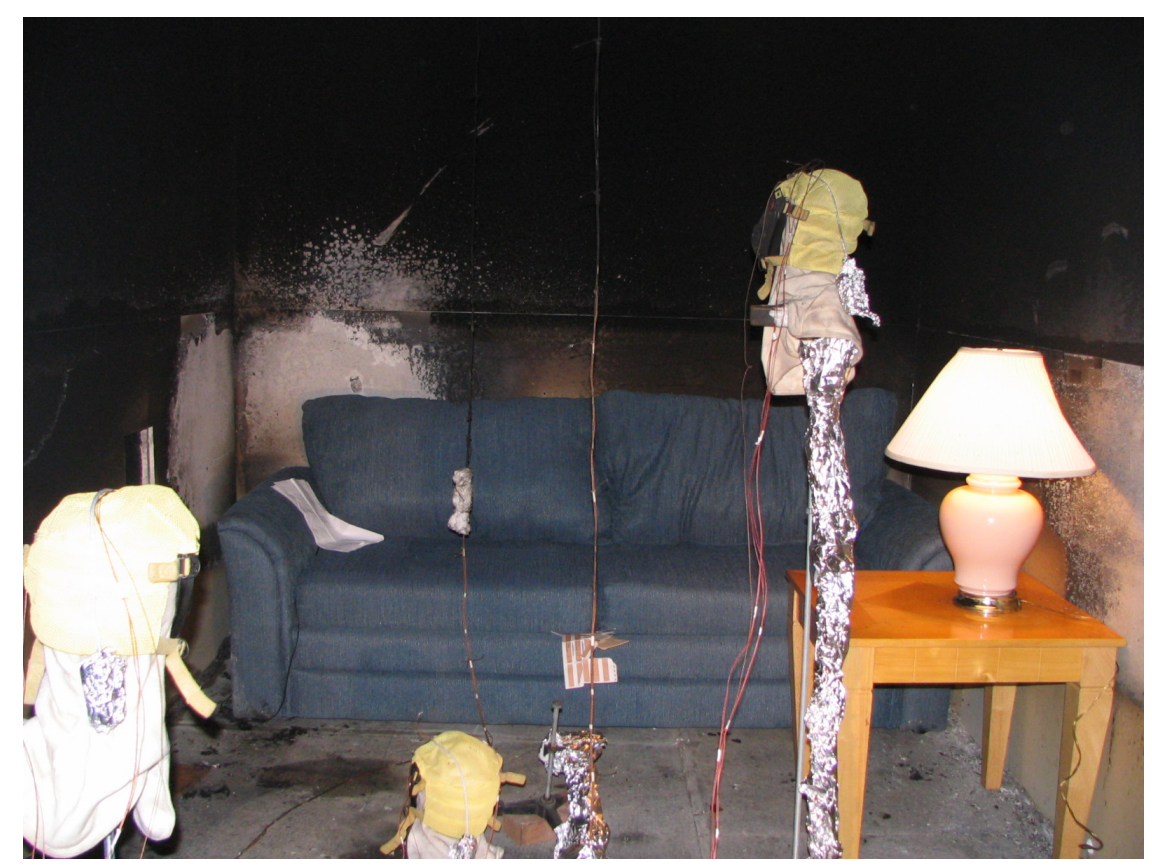

Figure 17. Full-scale living room burn set-up before ignition.

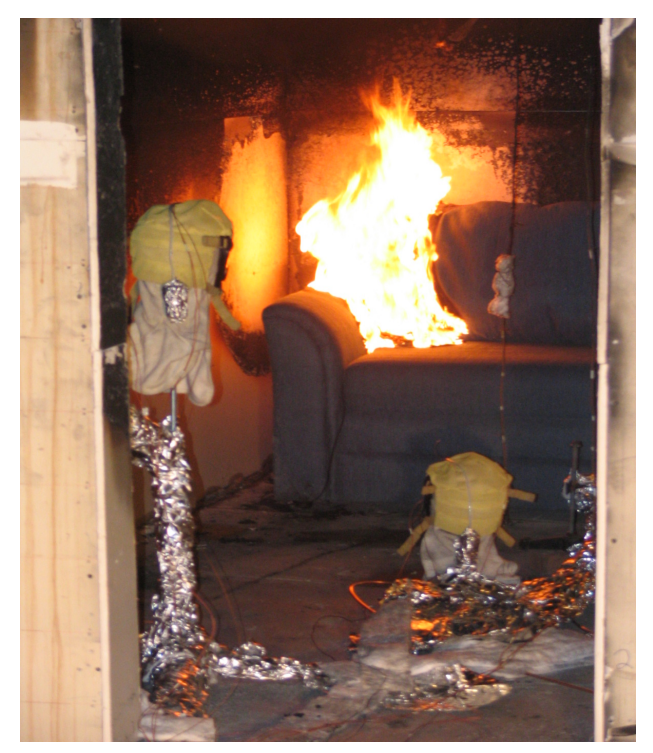

Figure 18. Living room fire experiment in progress after ignition.

8. Track the temperatures inside the room as well as outside the mask and thermal sensing units from the data acquisition computer.

9. Record the thermal sensing unit performance in the lab notebook.

10. Suppress the fire by initiating water flow through sprinkler head above the furniture as soon as the criterion for termination of the experiment was reached in terms of temperatures in the upper layer of room. 
11. Start the high-speed cooling fan to cool the ISO room and its contents.

12. Record the damage done to the masks and the thermal sensing units by taking pictures of post-experiment scenarios. A post-fire scenario is shown in Figure 19.

13. Stop the digital video recording units after recording 15 minutes of post-experiment cooling activities of thermal sensing units.

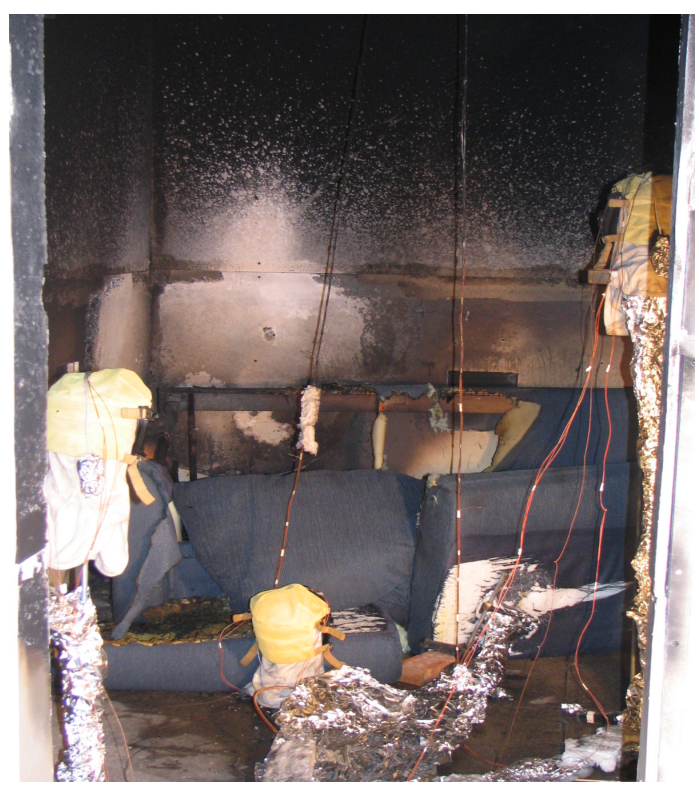

Figure 19. After- the living room fire experiment.

\subsection{RESULTS}

The gas temperatures, thermal heat fluxes, and responses of the thermal sensing units for natural gas, heptane, and living room fire experimental scenarios are presented below.

\subsection{Temperature Profiles in the ISO Room}

The temperature profiles in the ISO room at the locations of Thermocouple Array 1 and Thermocouple Array 2 are displayed in Figures 20- 29. The graphs show the range of the temperatures reached in the upper, middle, and the lower level of the ISO room during each experiment. The figures ( 20 through 29) are arranged in the order that the experiments were conducted, and demonstrate that the intensity of temperatures increased from Experiment 1 through Experiment 6. The natural gas experiment environment was the least intense temperature environment, whereas the living room fire experiment was the most intense temperature environment. The time span of a experiment was inversely proportional to the intensity of thermal environment of that experiment. Therefore, the natural gas experiments were the longest but less thermally intense experiments, whereas the living room fire experiments were the shorexperiment but most thermally intense experiments. The temperatures were recorded every second during the experiment, and each plot displays the temperature profile per second for the experiment duration. 


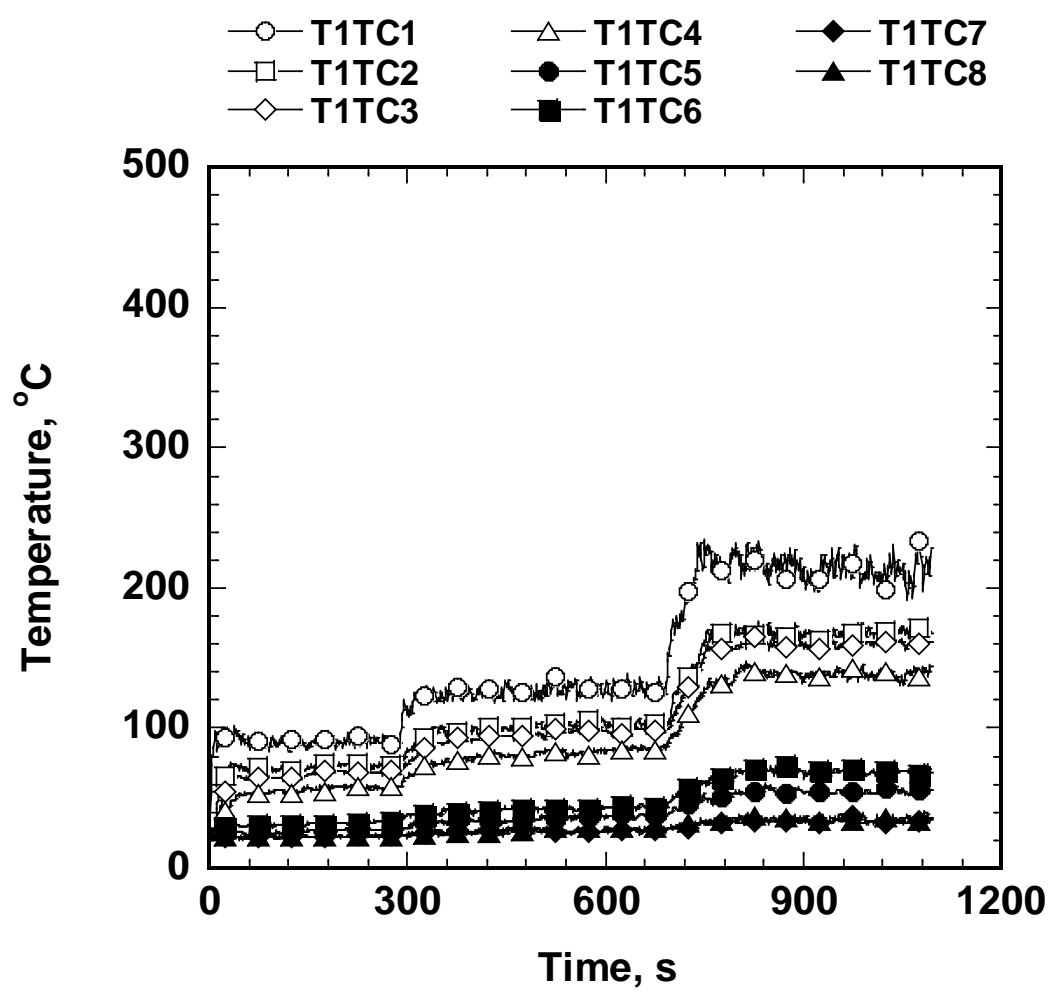

Figure 20. Gas temperatures at Thermocouple Array 1 (T1) for Natural Gas Experiment \#1.

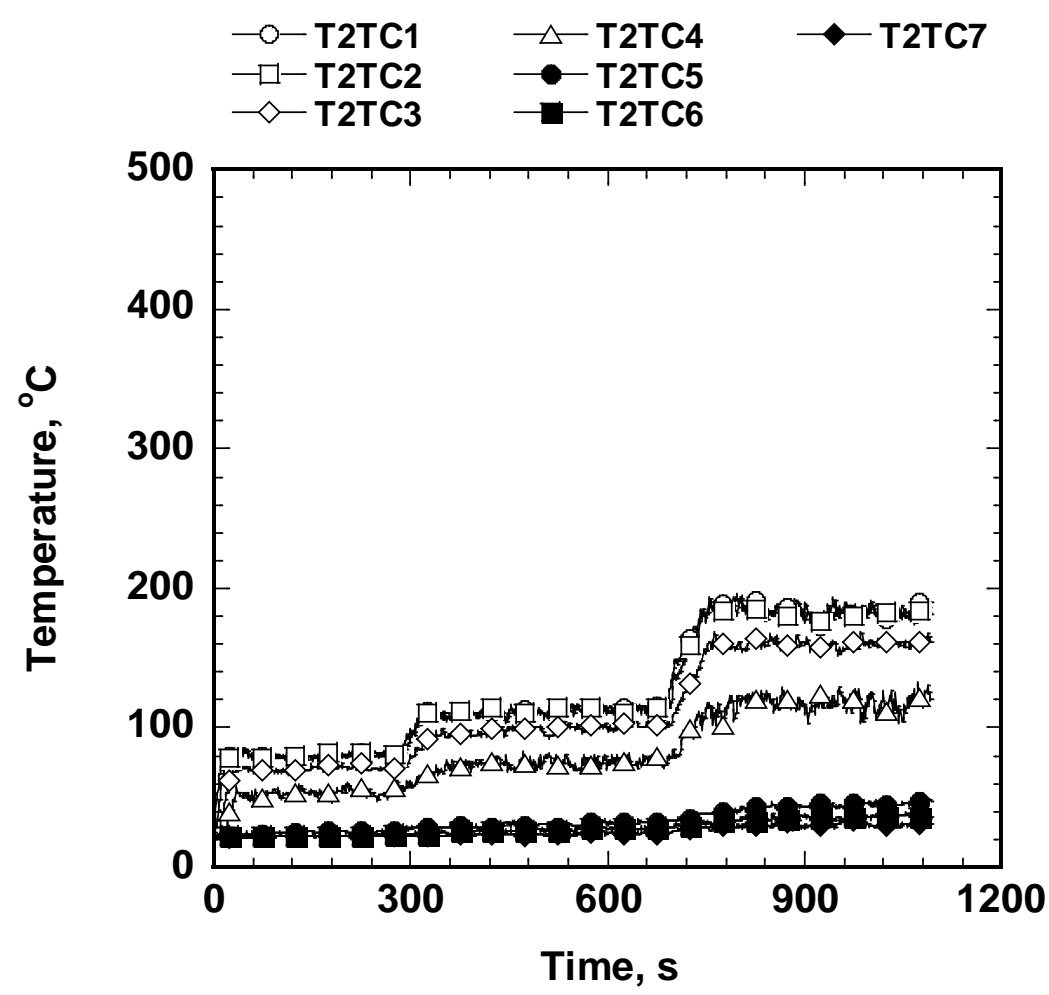

Figure 21. Temperatures at Thermocouple Array 2 (T2) for Natural Gas Experiment \#1. 


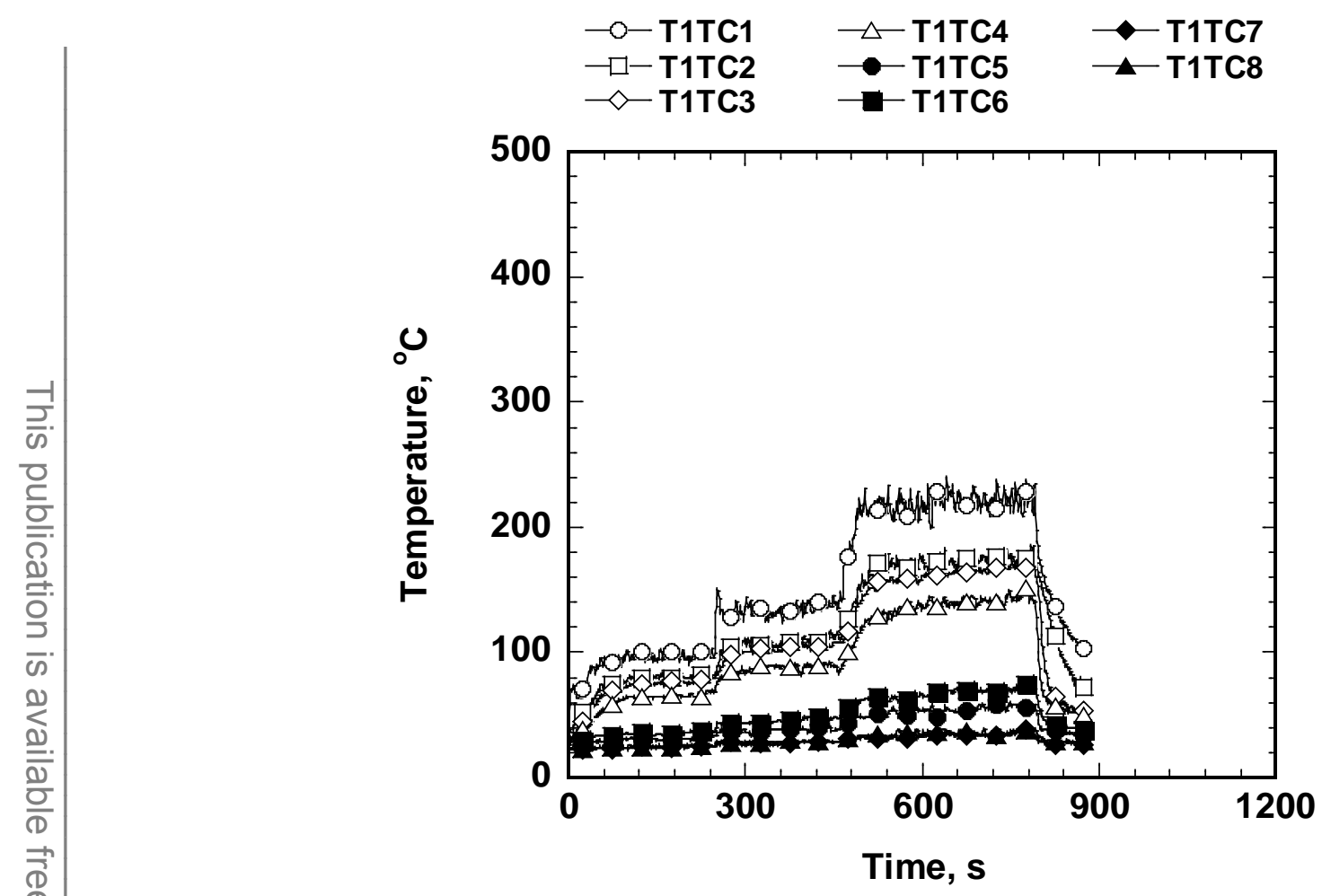

Figure 22. Temperatures at Thermocouple Array 1 (T1) for Natural Gas Experiment \#2.

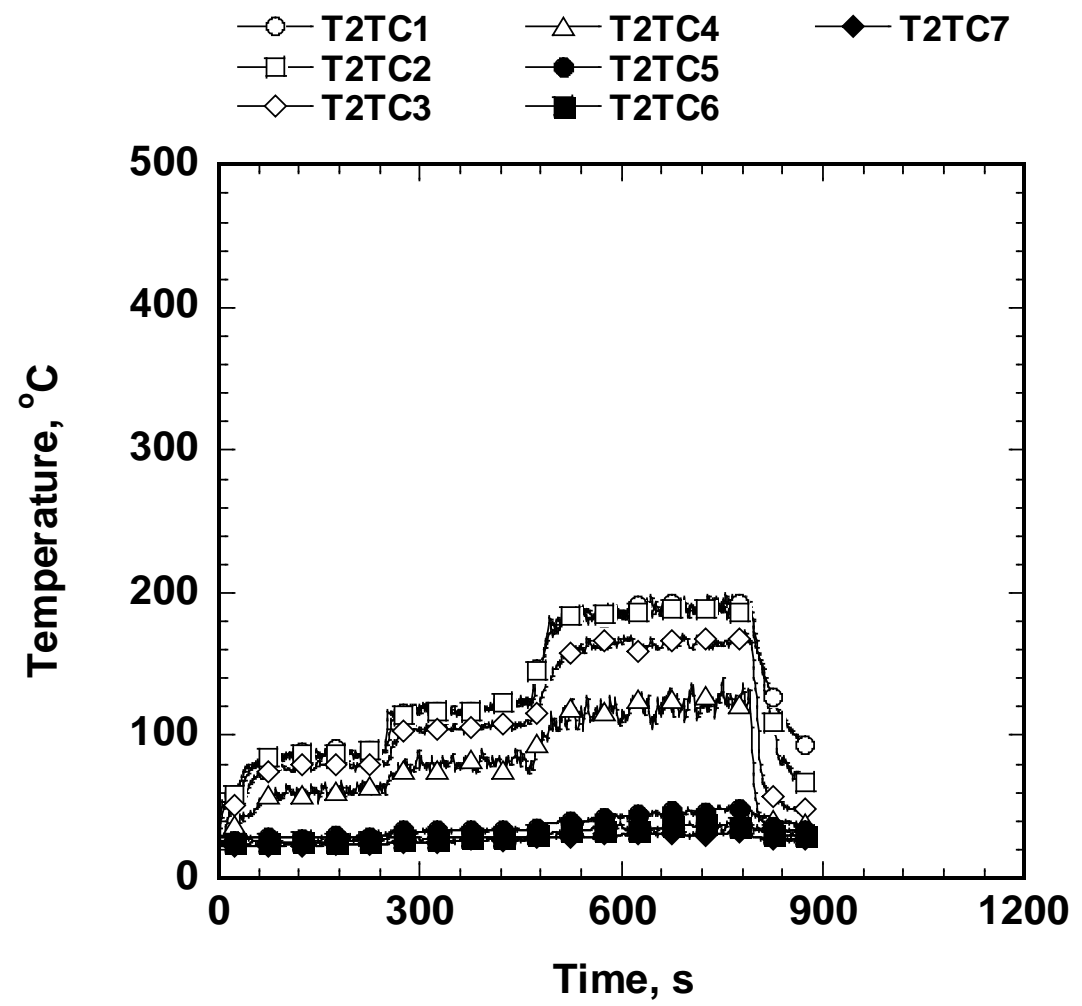

Figure 23. Temperatures at Thermocouple Array 2 (T2) for Natural Gas Experiment \#2. 


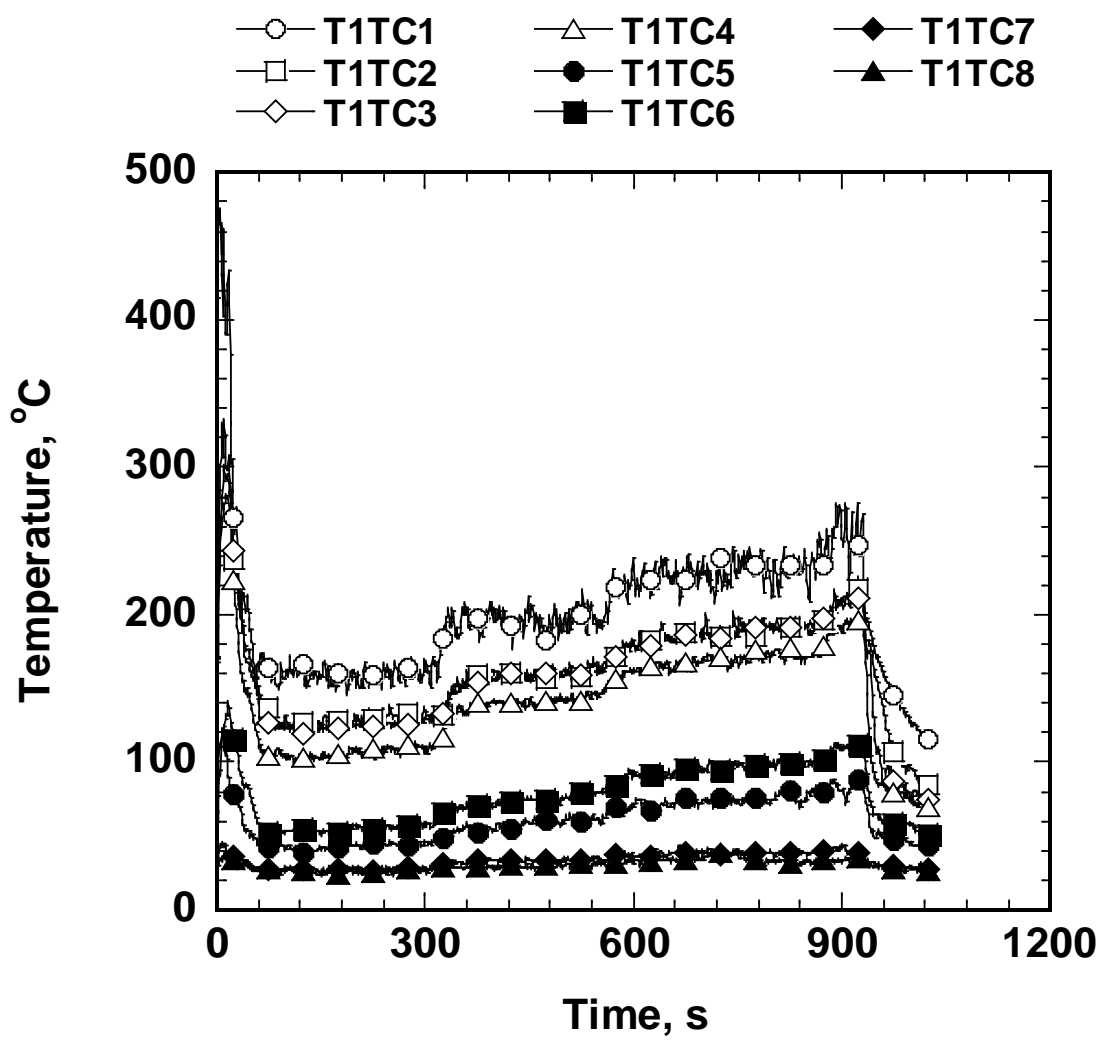

Figure 24. Temperatures at Thermocouple Array 1 (T1) for Heptane Experiment \#1.

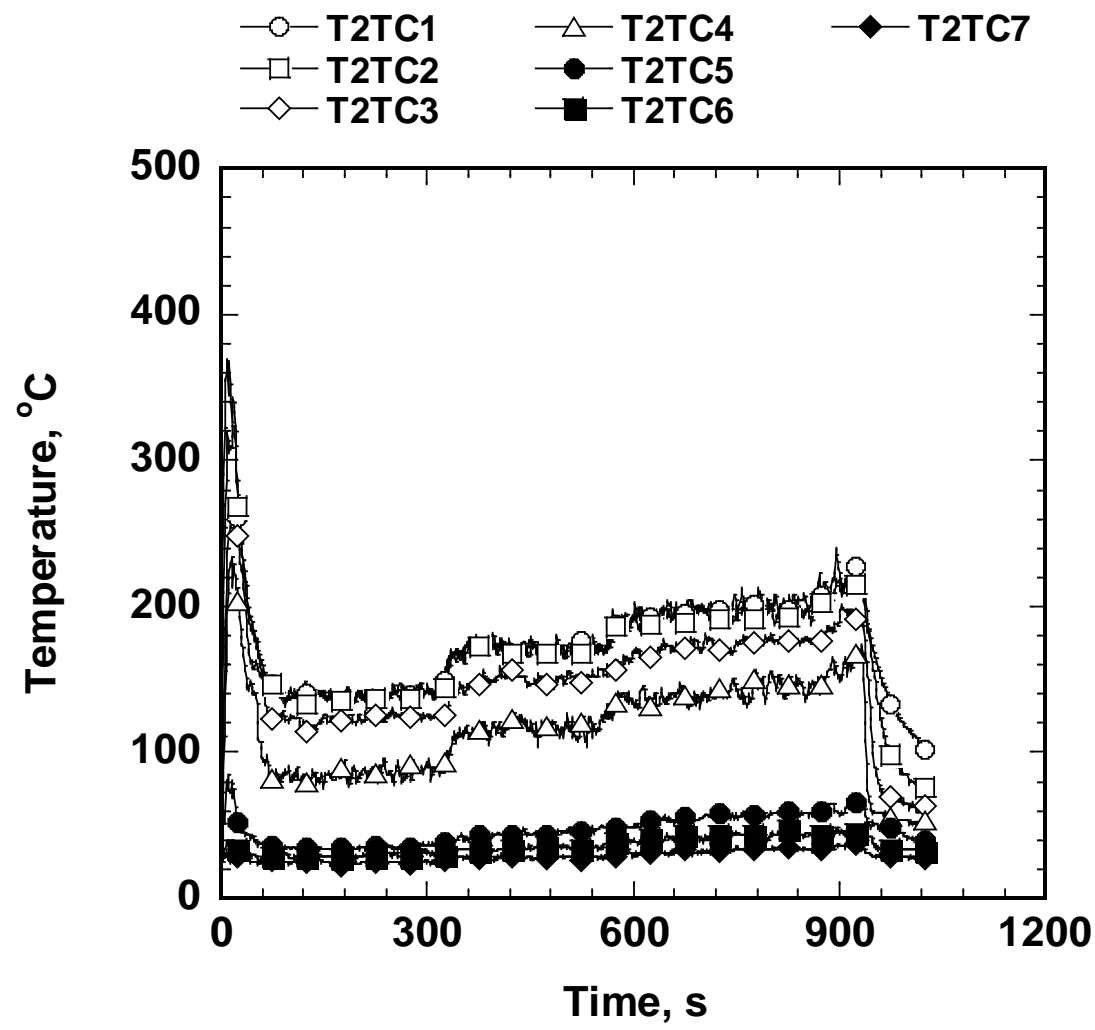

Figure 25. Temperatures at Thermocouple Array 2 (T2) for Heptane Experiment \#1. 


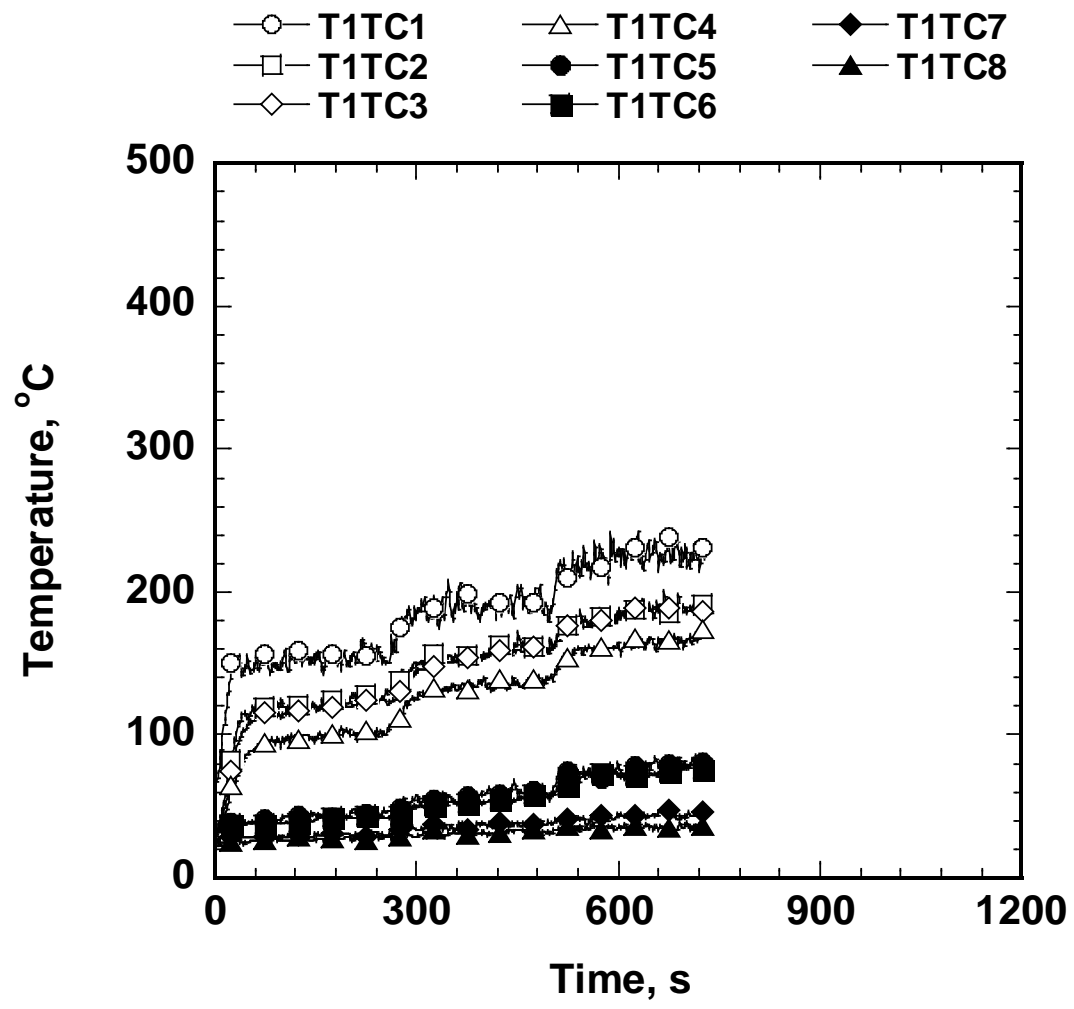

Figure 26. Temperatures at Thermocouple Array 1 (T1) for Heptane Experiment \#2.

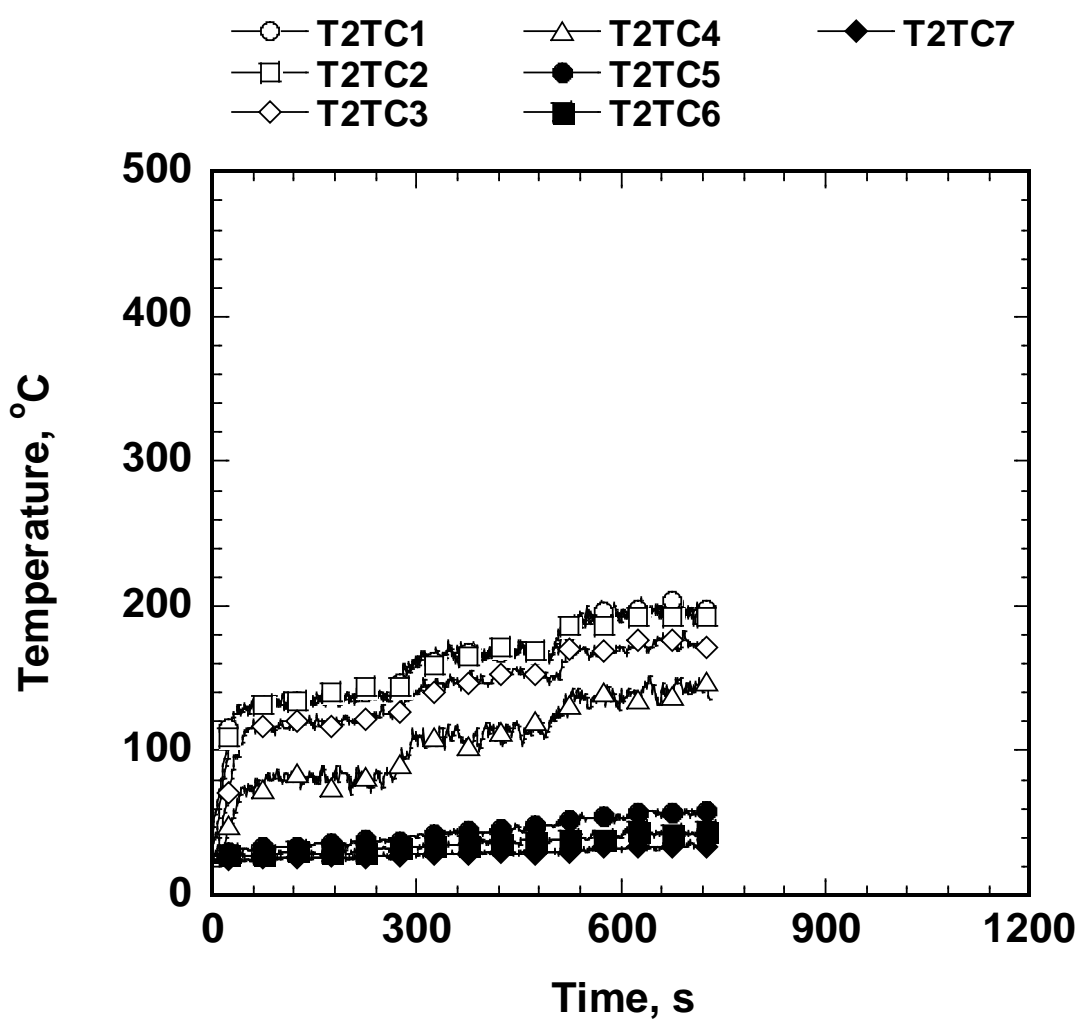

Figure 27. Temperatures at Thermocouple Array 2 (T2) for Heptane Experiment \#2. 


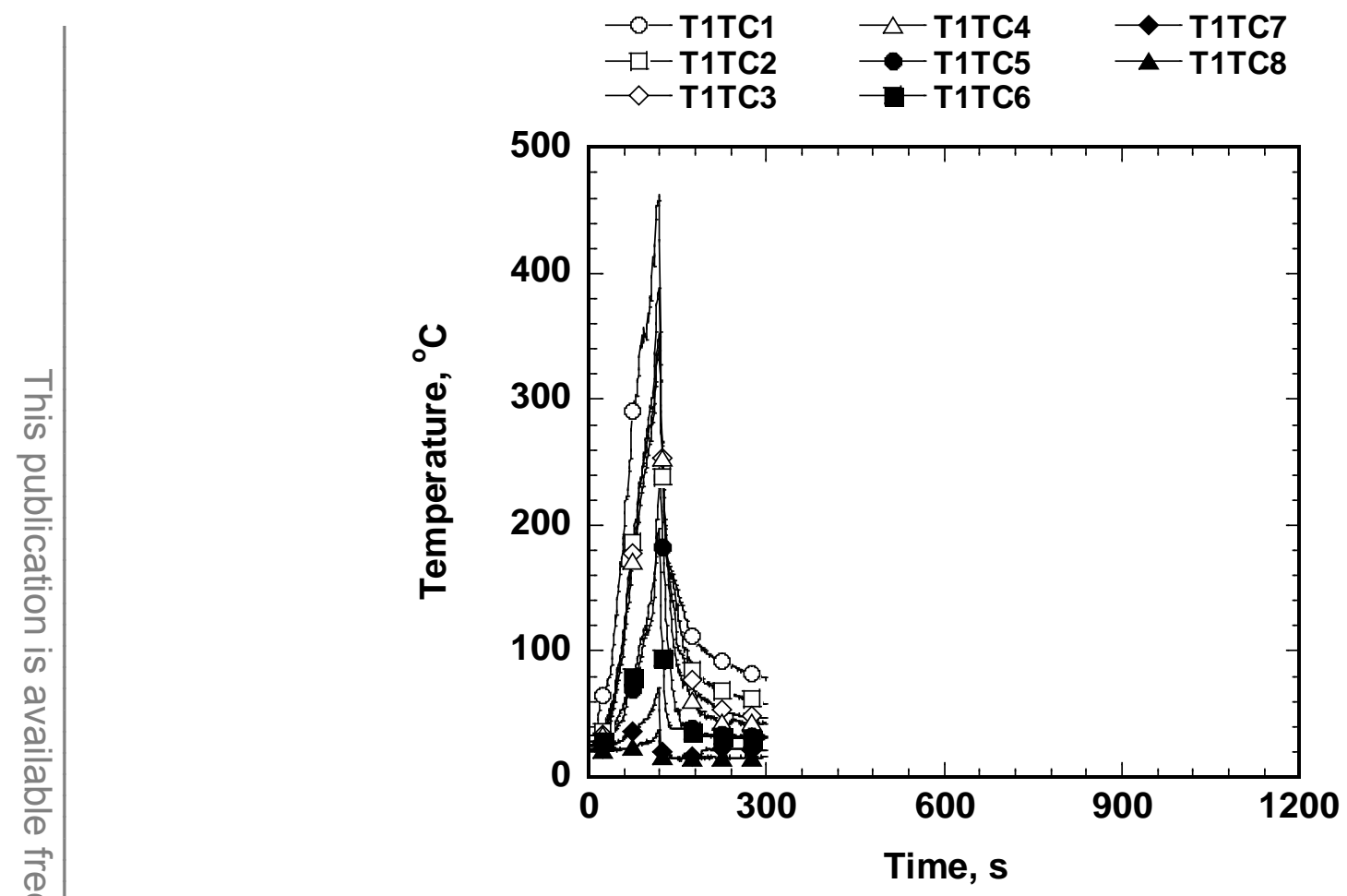

Figure 28. Temperatures at Thermocouple Array 1 (T1) for Living Room Experiment \#2.

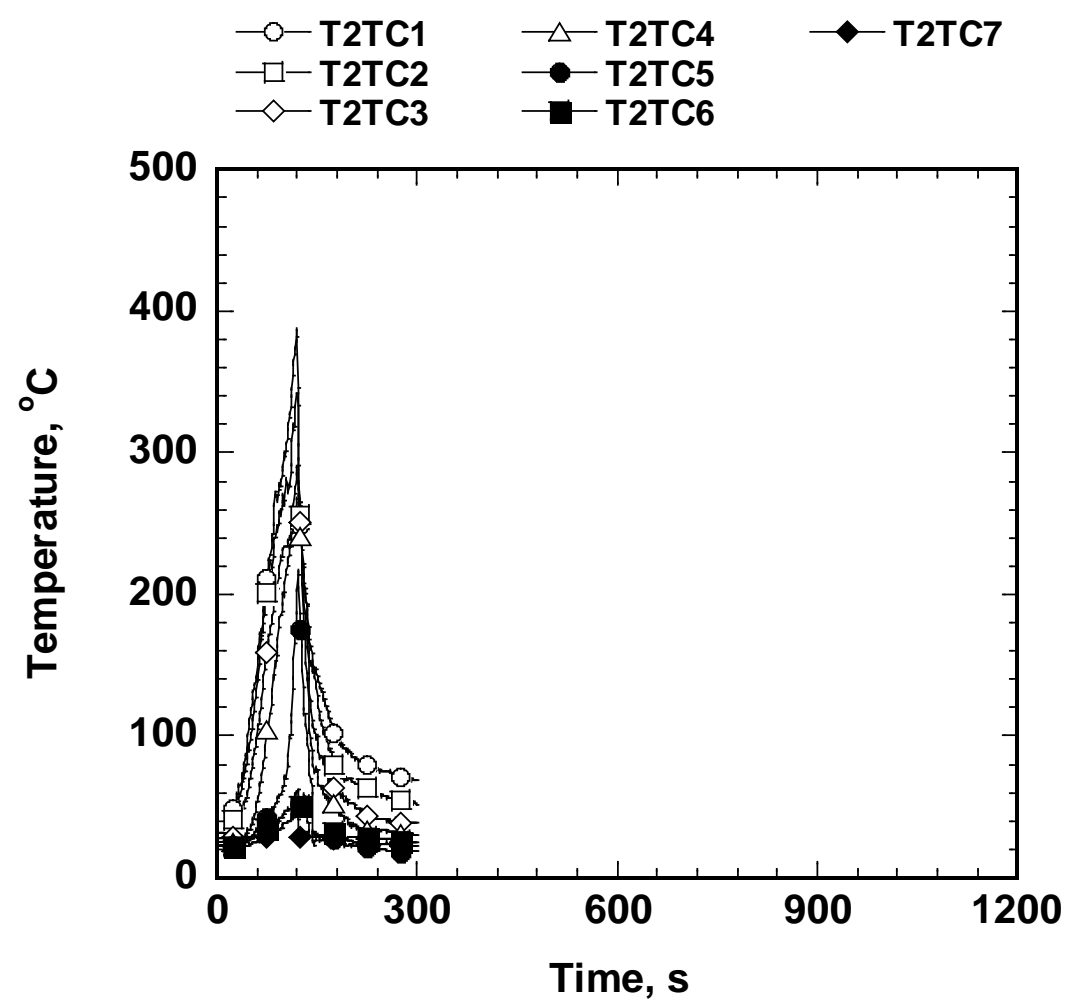

Figure 29. Temperatures at Thermocouple Array 2 (T2) for Living Room Experiment \#2. 


\subsection{Heat Flux Profile at Three Mask Locations}

Voltage signal (V) outputs from each heat flux gauge were converted into heat flux values $\left(\mathrm{kW} / \mathrm{m}^{2}\right)$ using calibration graphs for each gauge. The heat flux values for the three masks in each experiment are displayed in the graphs that follow (Figures 30 -35).

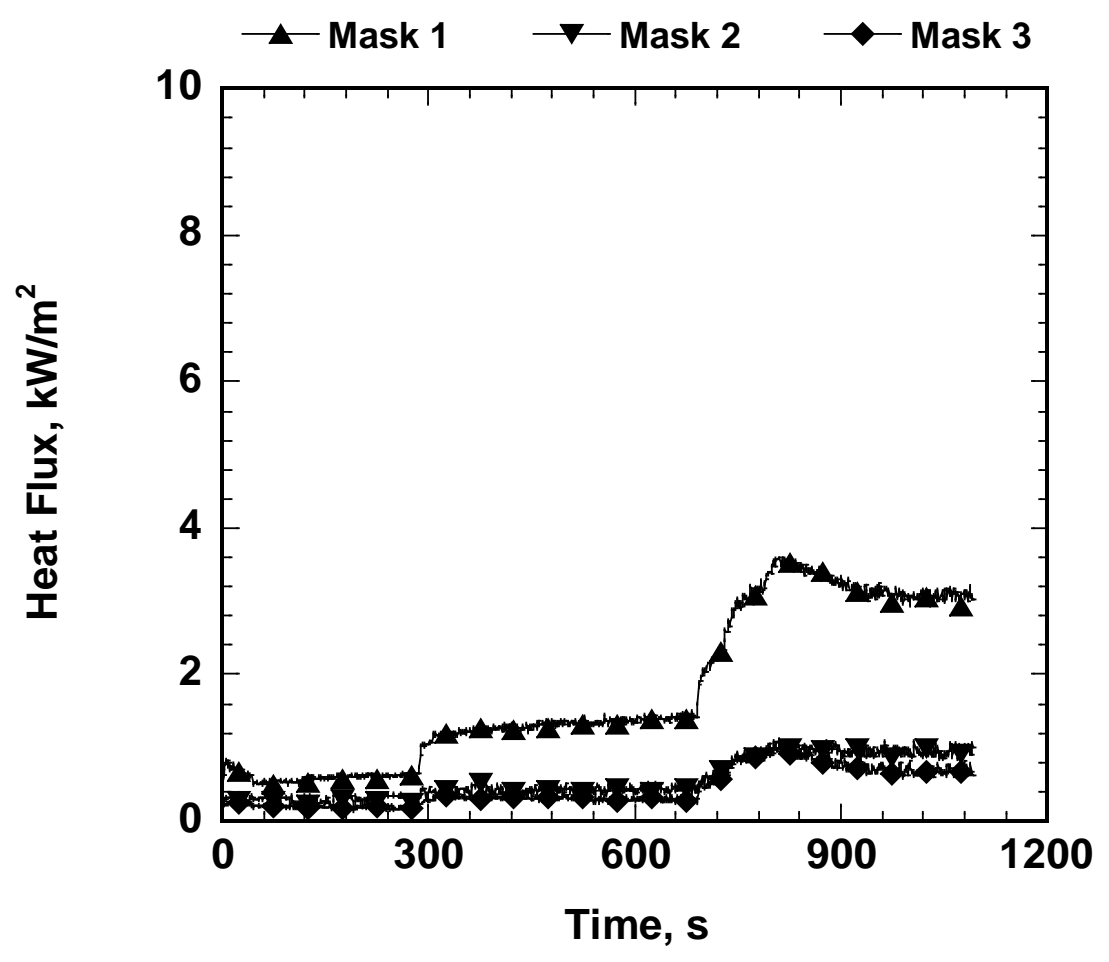

Figure 30. Heat Flux profile at three masks for Natural Gas Experiment \#1. 


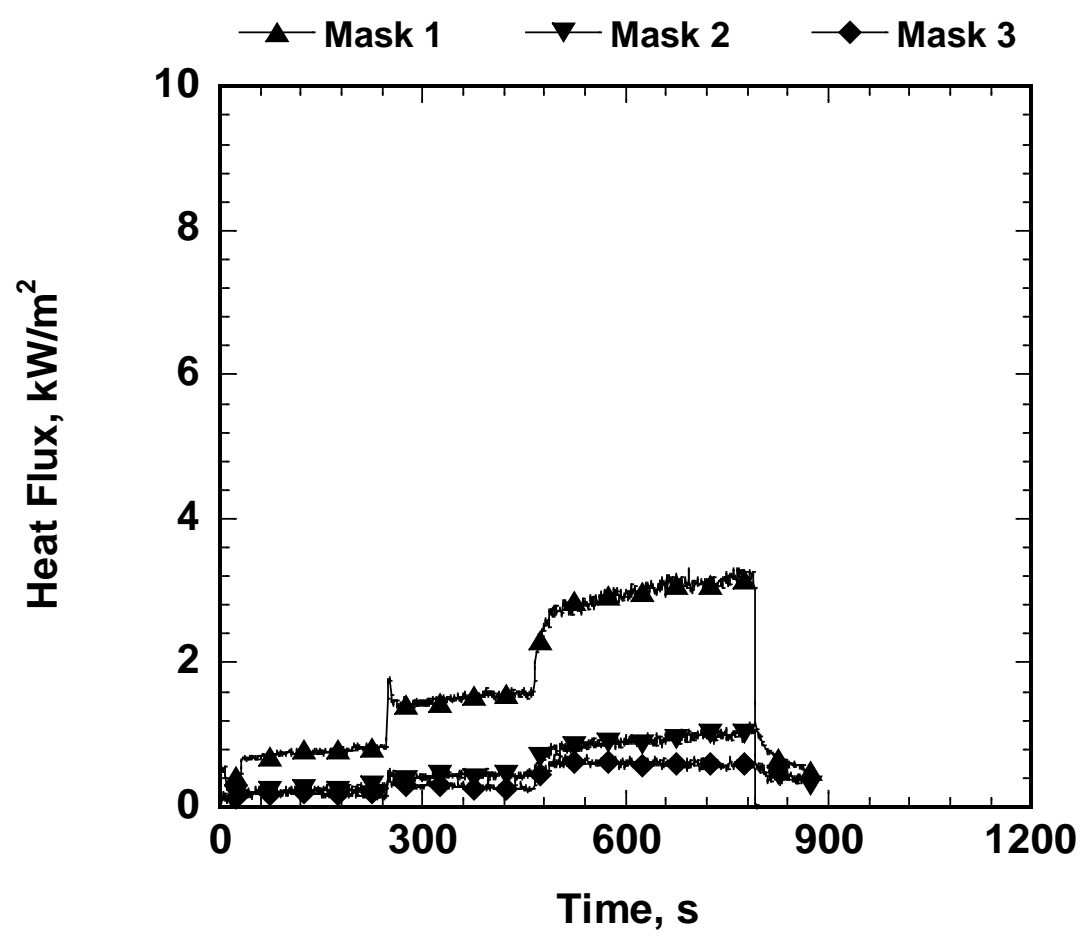

Figure 31. Heat Flux profile at three masks for Natural Gas Experiment \#2.

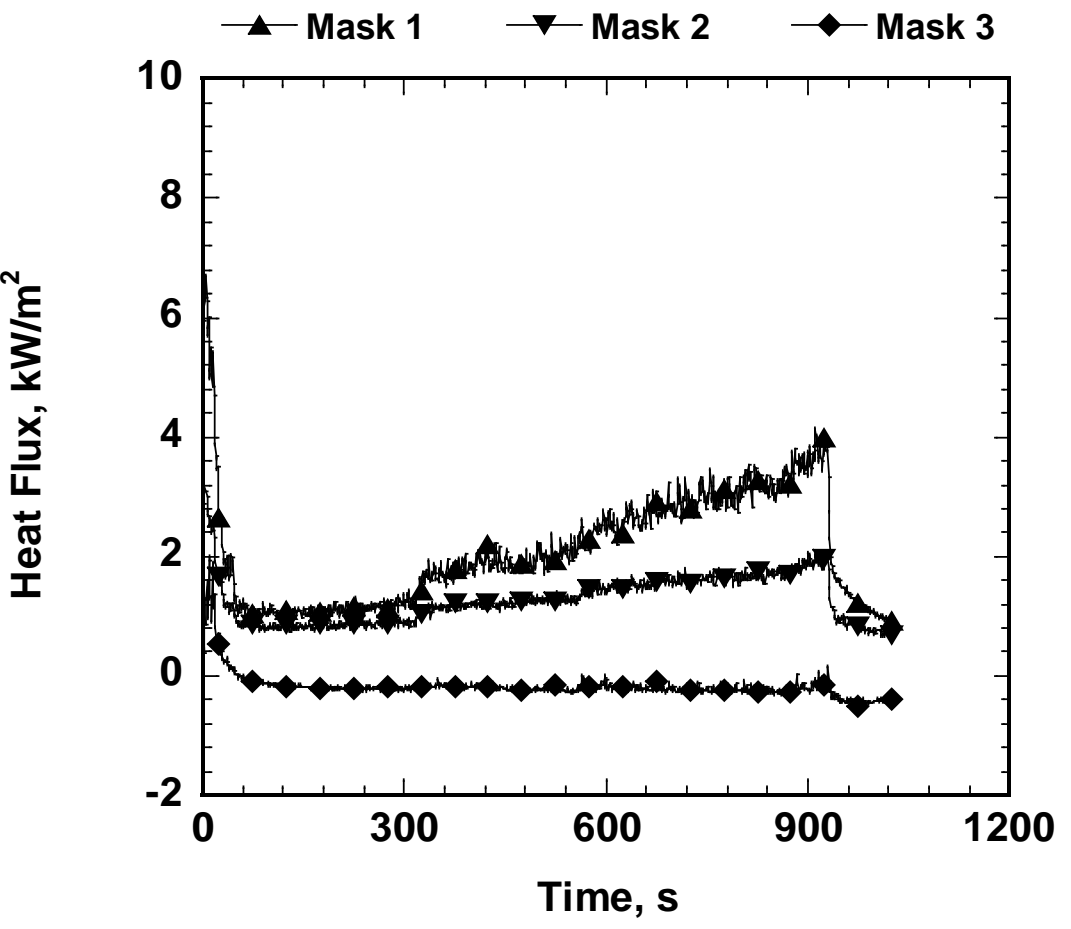

Figure 32. Heat Flux profile at three masks for Heptane Experiment \#1. 


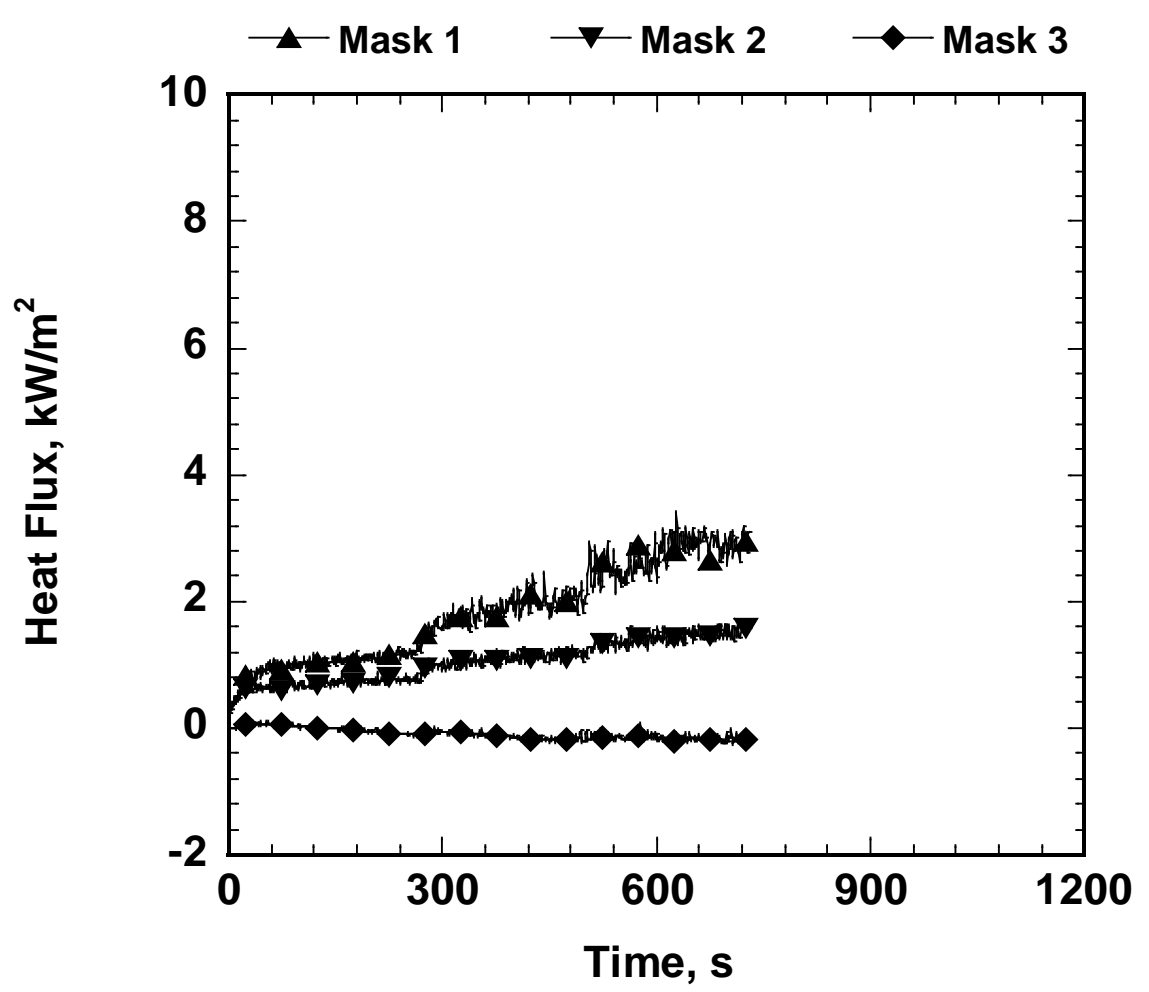

Figure 33. Heat Flux profile at three masks for Heptane Experiment \#2

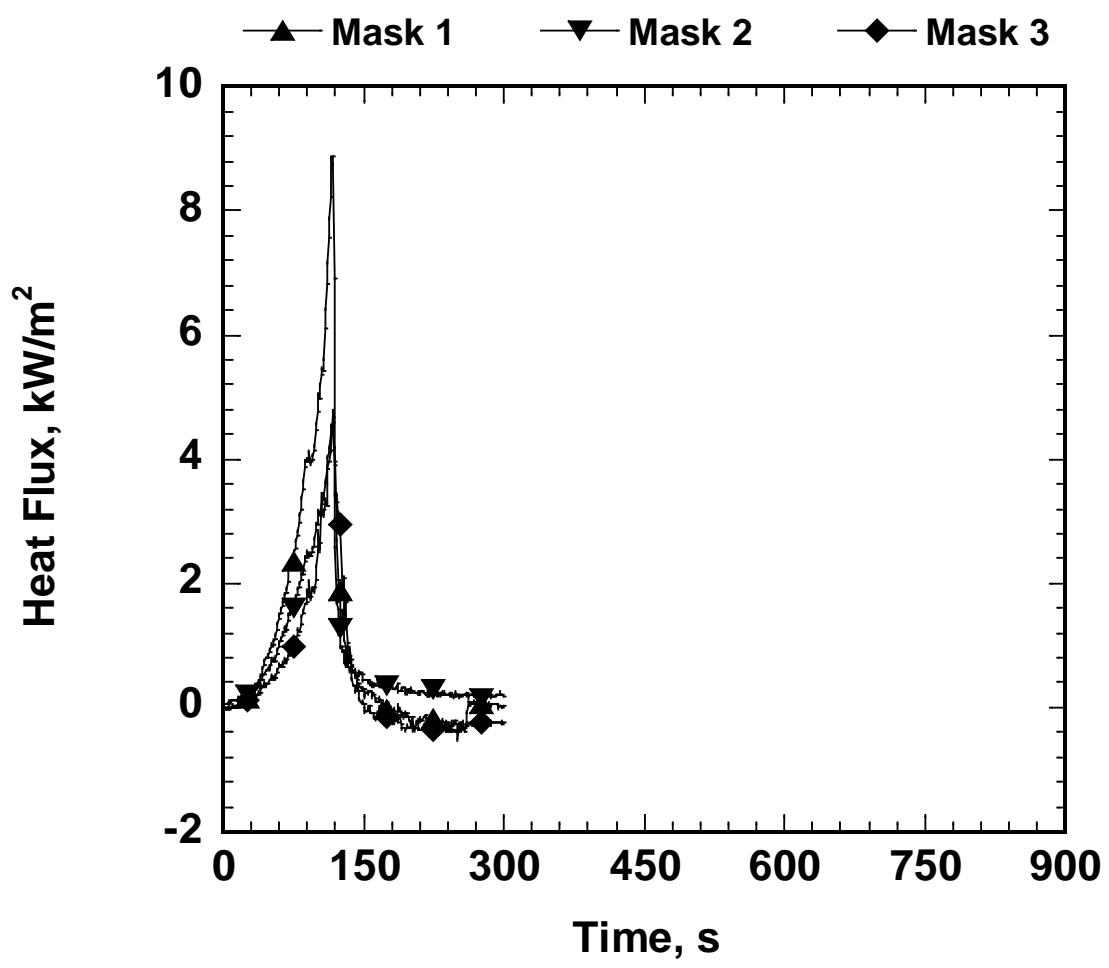

Figure 34. Heat Flux profile at three masks for Living Room Experiment \#1. 


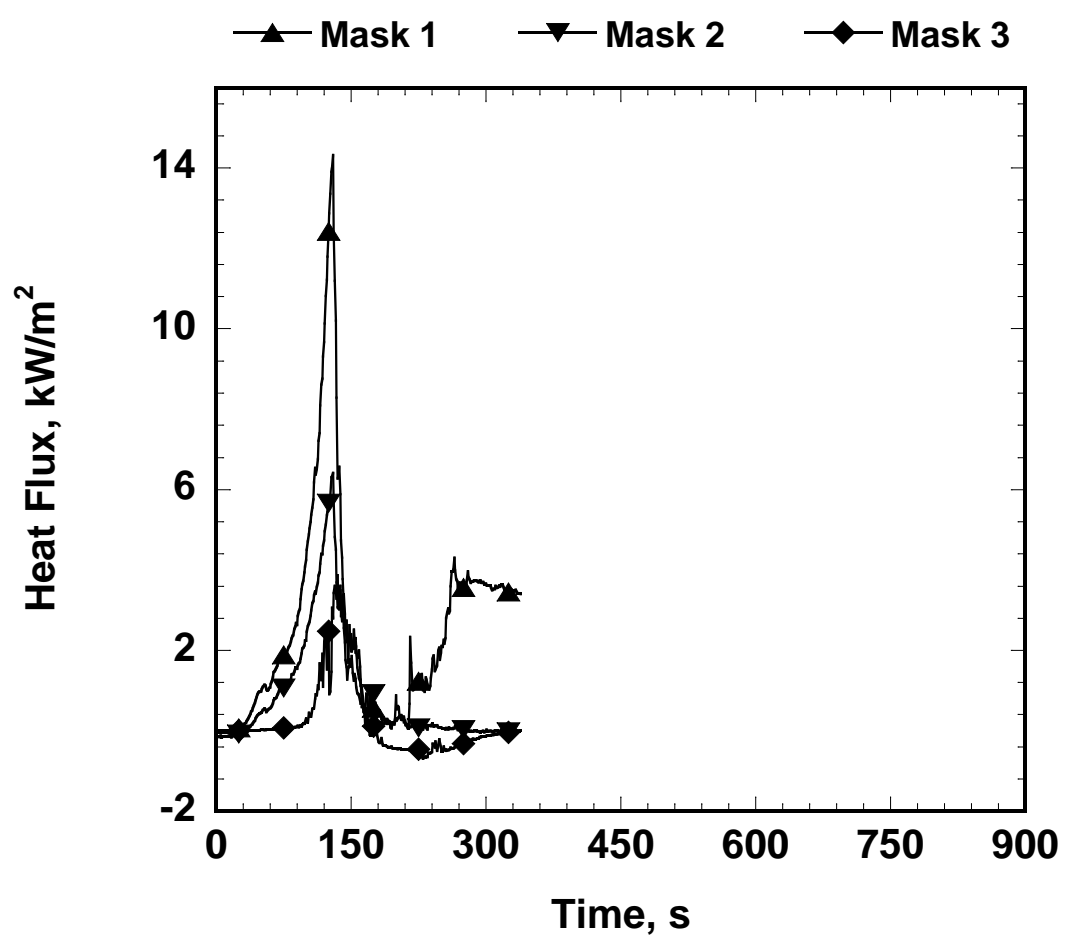

Figure 35. Heat Flux profile at three masks for Living Room Experiment \#2.

\subsection{Results of the Natural Gas Experiments}

The Natural Gas Experiment flame height from the surface of the burner was between

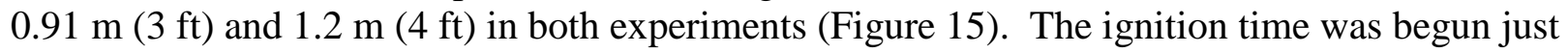
after the experiment start time as the experiment was begun after initiating the bullet cameras as well as the data acquisition system and HRR computers. There was also a brief lag time between the fuel flow rate and actual HRR recorded at the burner. Table 4 shows separate rows for the begin time and ignition time for the Natural Gas Experiment \#1. Table 5 shows the specific temperatures at TC1 and TC3 for specific thermal sensing units, when the warning indicators changed their blinking status during the experiment.

Table 4. Timeline and details for Natural Gas Experiment \#1.

\begin{tabular}{|c|c|c|c|}
\hline $\begin{array}{c}\text { Natural Gas } \\
\text { Experiment 1 }\end{array}$ & Mask 1 & Mask 2 & Mask 3 \\
\hline Experiment begin time & $0: 00$ & $0: 00$ & $0: 00$ \\
\hline Time at ignition & $0: 10$ & $0: 10$ & $0: 10$ \\
\hline Blinking Green & $8: 34$ & $10: 25$ & $18: 30$ \\
\hline Solid Green & $15: 21$ & $16: 57$ & No change \\
\hline Solid Red & $16: 48$ & $18: 45$ & No change \\
\hline Blinking Red & $17: 33$ & $19: 42$ & No change \\
\hline Experiment end time & $23: 12$ & $23: 12$ & $23: 12$ \\
\hline
\end{tabular}


Table 5. Performance of the three thermal sensing units in Natural Gas Experiment \# 1.

\begin{tabular}{|c|c|c|c|c|c|c|}
\hline $\begin{array}{c}\text { Natural Gas } \\
\text { Experiment 1 }\end{array}$ & \multicolumn{2}{l|}{ Mask 1 (TSU\#5) } & \multicolumn{2}{l|}{ Mask 2 (TSU\#3) } & \multicolumn{2}{l|}{ Mask 3 (TSU\#2) } \\
\hline Temperature $\left({ }^{\circ} \mathrm{C}\right)$ & M1TC1 & M1TC3 & M2TC1 & M2TC3 & M3TC1 & M2TC3 \\
\hline Blinking Green $\left({ }^{\circ} \mathrm{C}\right)$ & 62.4 & 65.2 & 66.3 & 59.3 & 54.0 & 59.3 \\
\hline Solid Green $\left({ }^{\circ} \mathrm{C}\right)$ & 108.3 & 115.6 & 110.5 & 100.8 & No change & No change \\
\hline Solid Red $\left({ }^{\circ} \mathrm{C}\right)$ & 114.6 & 121.1 & 116.3 & 107.4 & No change & No change \\
\hline Blinking Red $\left({ }^{\circ} \mathrm{C}\right)$ & 115.6 & 122.4 & 120.0 & 110.6 & No change & No change \\
\hline
\end{tabular}

The graph in Figure 36 shows the temperatures for the three thermocouples at the location of Mask 1. TC1 and TC3 are attached to the front surface of the TSU device and the facepiece, whereas TC5 is the ambient temperature sensing thermocouple. The graph in Figure 37 shows the temperatures for the three thermocouples at the location of Mask 2, whereas the graph in Figure 38 shows the temperatures for the three thermocouples at the location of Mask 3. The graphs signify the difference in the temperatures at the surface of the TSU devices as well as the facepiece based on their location from the source of fire and their height from the floor. The timeline and the experiment details for Natural Gas Experiment \#2 are shown in Tables 6 and 7. Temperatures for Masks 1, 2, and 3 for Natural Gas Experiment \#2 are graphed in Figures $39-41$.

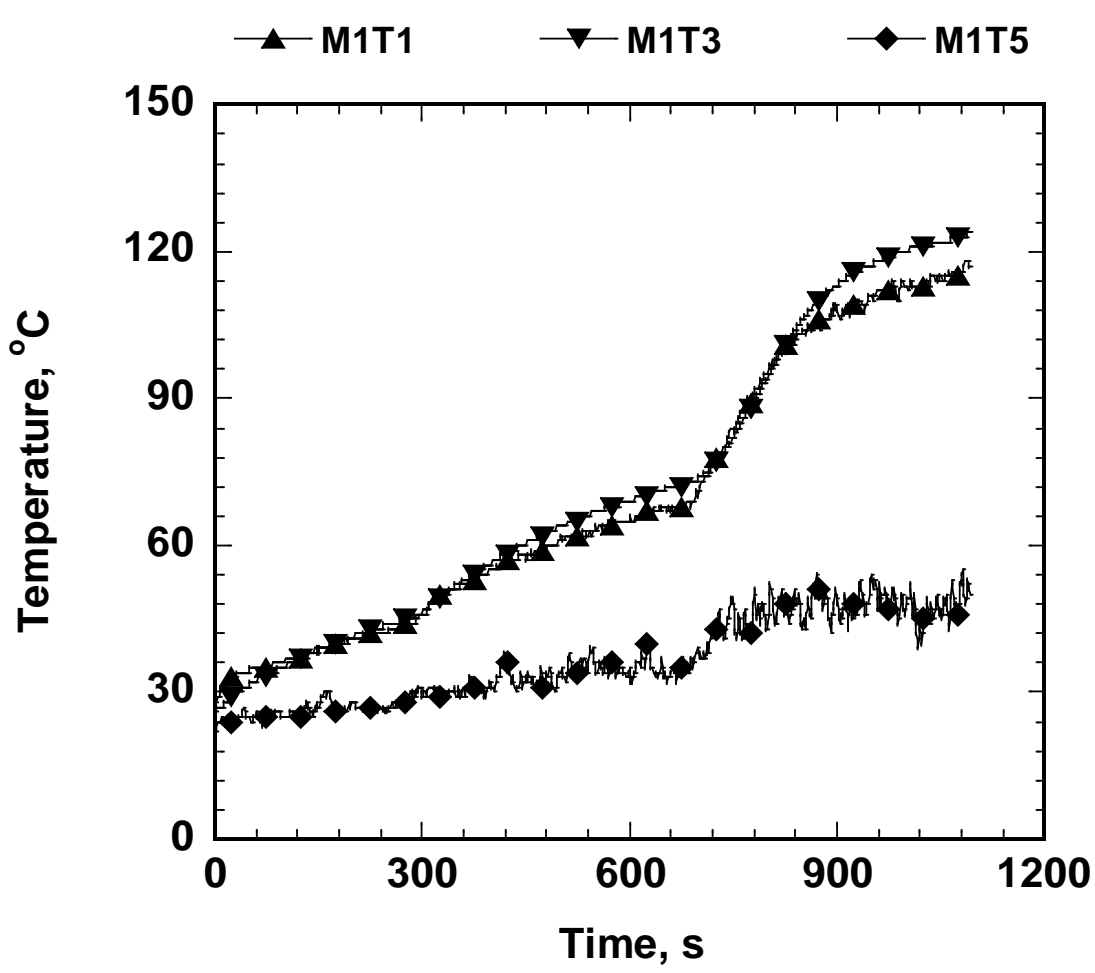

Figure 36. Temperatures at Mask 1 for Natural Gas Experiment \#1. 


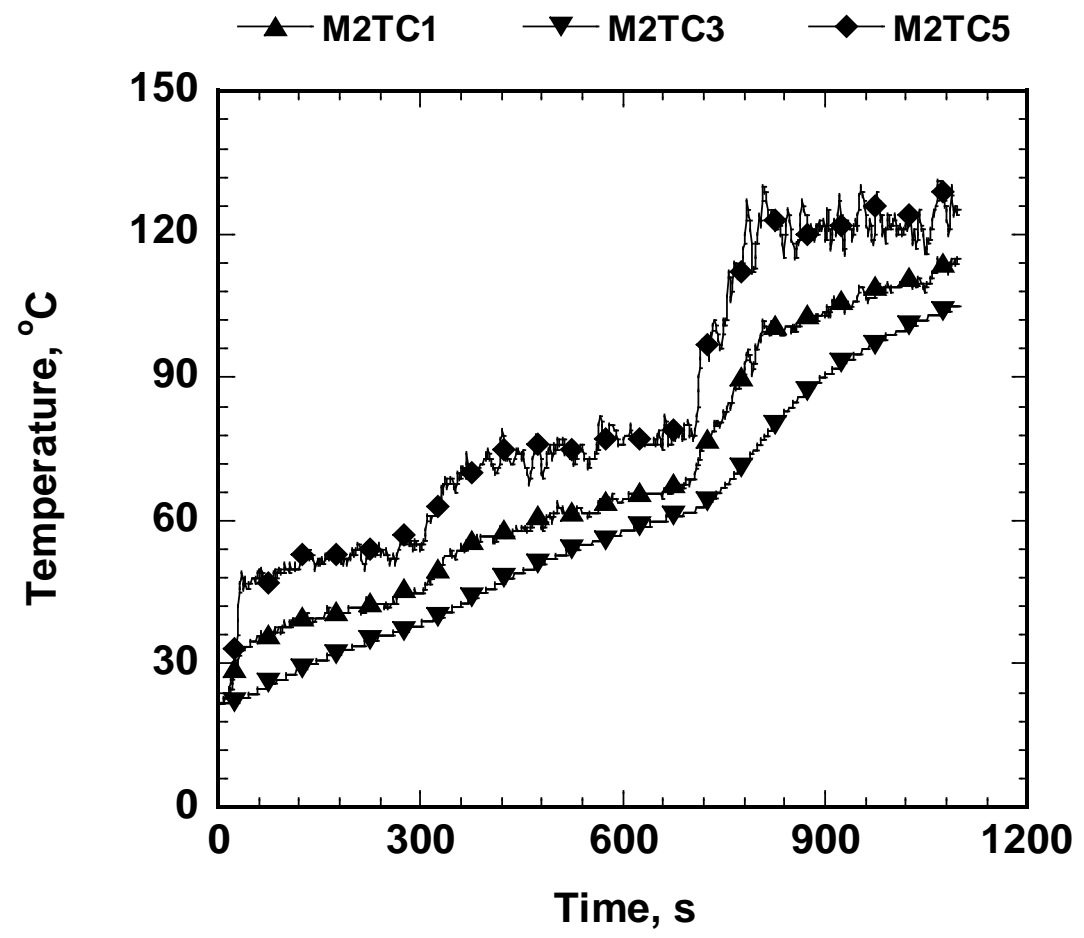

Figure 37. Temperatures at Mask 2 for Natural Gas Experiment \#1.

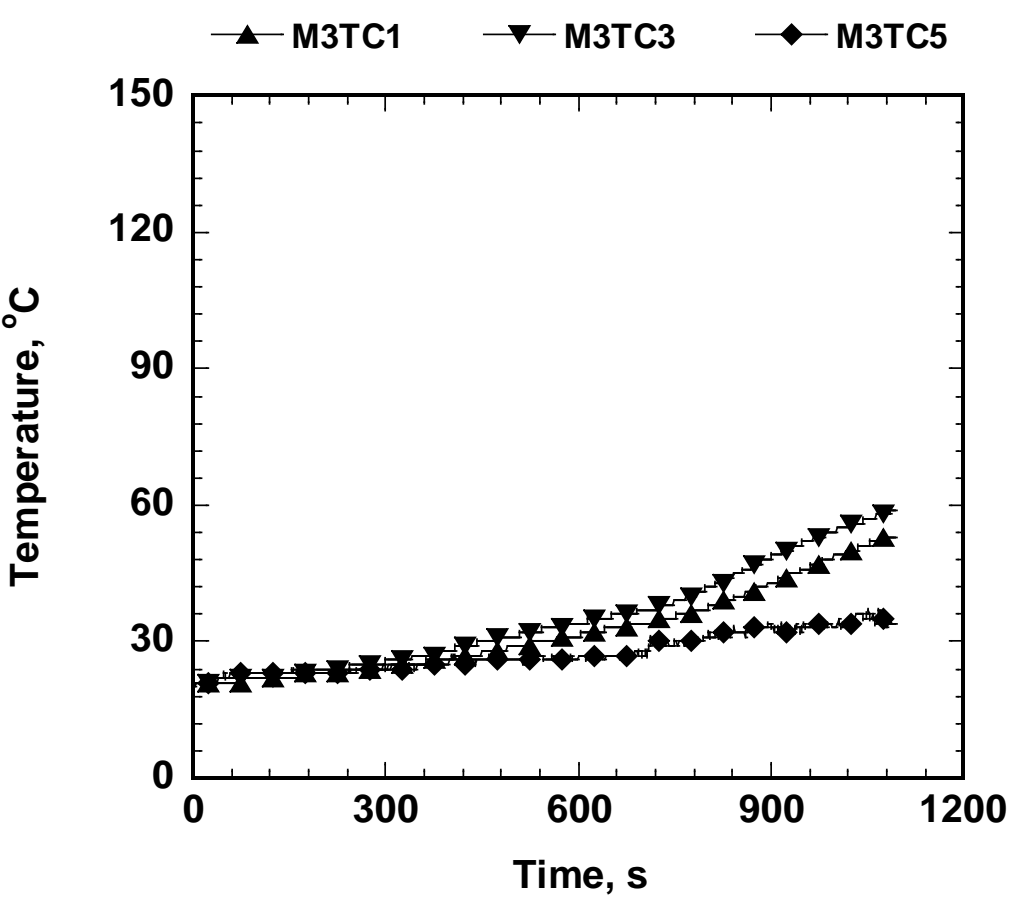

Figure 38. Temperatures at Mask 3 for Natural Gas Experiment \#1. 
Table 6. Timeline and details for Natural Gas Experiment \#2.

\begin{tabular}{|c|c|c|c|}
\hline $\begin{array}{c}\text { Natural Gas } \\
\text { Experiment 2 }\end{array}$ & Mask 1 & Mask 2 & Mask 3 \\
\hline Experiment begin time & $0: 00$ & $0: 00$ & $0: 00$ \\
\hline Time at ignition & $0: 10$ & $0: 10$ & $0: 10$ \\
\hline Blinking Green & $6: 24$ & $7: 18$ & $12: 04$ \\
\hline Solid Green & $11: 58$ & $13: 02$ & No change \\
\hline Solid Red & $13: 30$ & No change & No change \\
\hline Blinking Red & $14: 30$ & No change & No change \\
\hline Experiment end time & $14: 40$ & $14: 40$ & $14: 40$ \\
\hline
\end{tabular}

Table 7. Performance of the three thermal sensing units in natural gas Experiment \# 2.

\begin{tabular}{|l|c|c|c|c|c|c|}
\hline $\begin{array}{l}\text { Natural Gas } \\
\text { Experiment2 }\end{array}$ & \multicolumn{2}{|l|}{ Mask1 (TSU\#5) } & \multicolumn{2}{c|}{ Mask2 (TSU\#4) } & \multicolumn{2}{l|}{ Mask3 (TSU\#6) } \\
\hline Temperature $\left({ }^{\circ} \mathrm{C}\right)$ & M1TC1 & M1TC3 & M2TC1 & M2TC3 & M3TC1 & M2TC3 \\
\hline Blinking Green $\left({ }^{\circ} \mathrm{C}\right)$ & 64.9 & 68.1 & 66.2 & 68.1 & 57.2 & 53.2 \\
\hline Solid Green $\left({ }^{\circ} \mathrm{C}\right)$ & 105.8 & 114.1 & 111.2 & 103.4 & No change & No change \\
\hline Solid Red $\left({ }^{\circ} \mathrm{C}\right)$ & 101.4 & 117.2 & No change & No change & No change & No change \\
\hline Blinking Red $\left({ }^{\circ} \mathrm{C}\right)$ & 87.0 & 102.0 & No change & No change & No change & No change \\
\hline
\end{tabular}

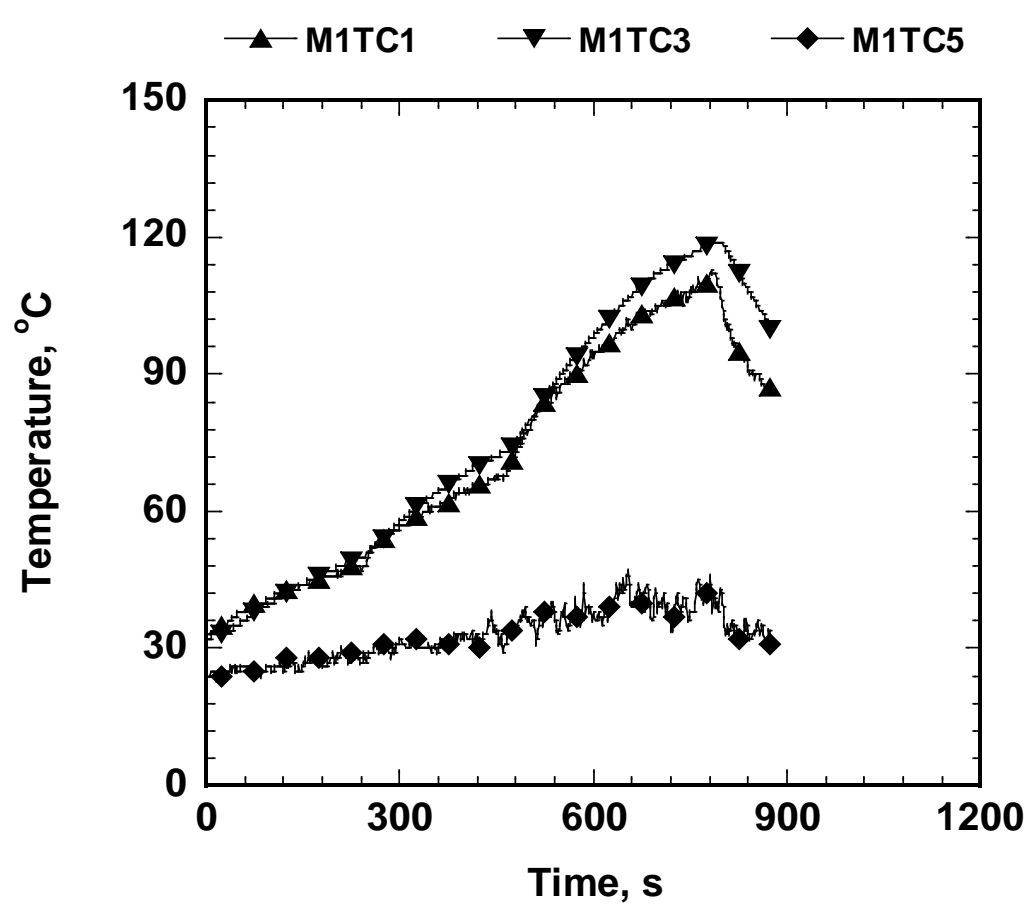

Figure 39. Temperatures at Mask 1 for Natural Gas Experiment \#2. 


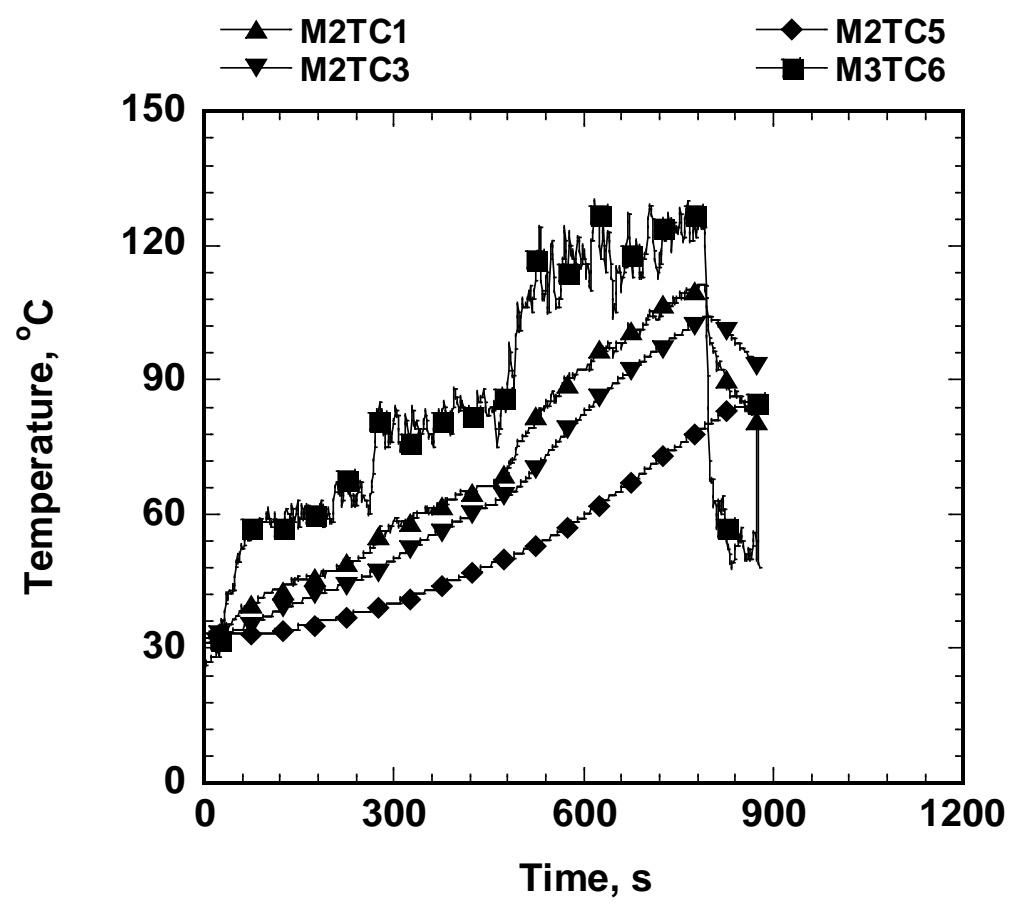

Figure 40. Temperatures at Mask 2 for Natural Gas Experiment \#2.

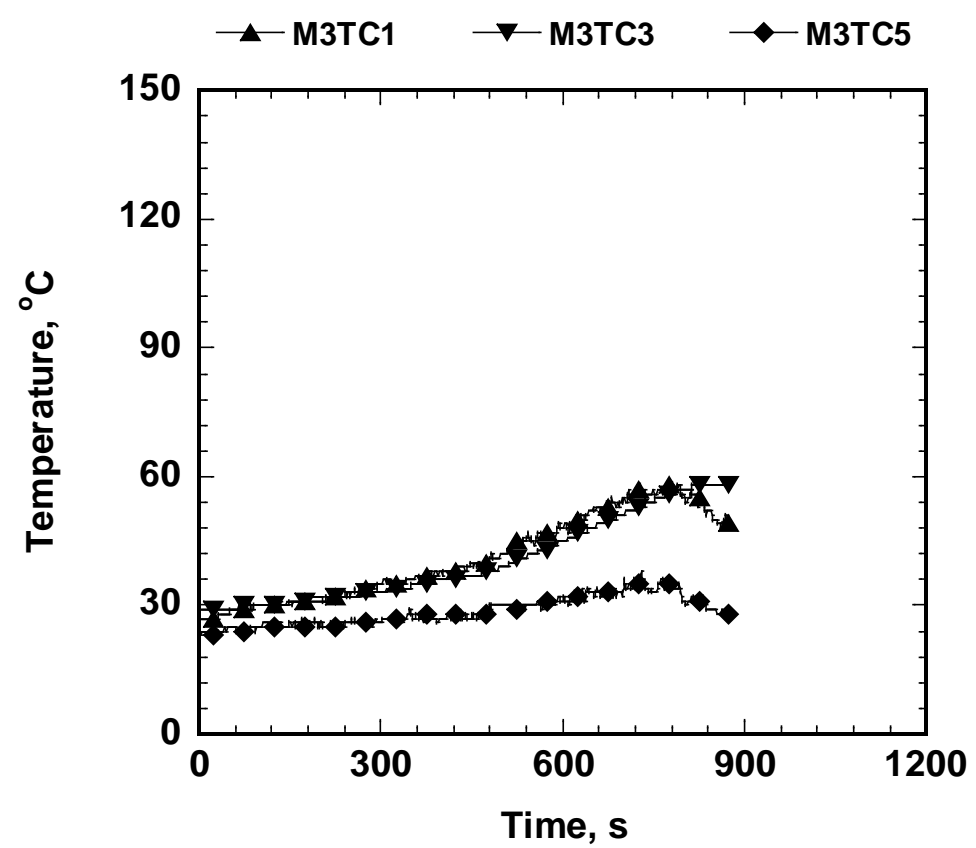

Figure 41. Temperatures at Mask 3 for Natural Gas Experiment \#2. 


\subsection{Results of the Heptane Experiments}

The heptane experiment flame height from the surface of the burner was between $0.91 \mathrm{~m}$ ( $3 \mathrm{ft}$ )

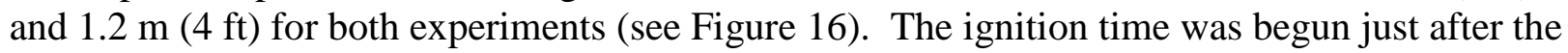
experiment begin time as there was a time lag between the fuel flow rate and the actual HRR recorded at the burner. The timeline and the experiment details for Heptane Experiment \#1 are shown in Table 8. The temperatures at the thermal sensing units attached to each mask for Heptane Experiment \#1 are graphed in Figures 42 - 44. Table 9 shows the specific temperatures at TC1 and TC3 for specific thermal sensing units, when the warning indicators changed their blinking status during the experiment. The timeline and the experiment details for Heptane Experiment \#2 are shown in Tables 10 and 11. Temperatures for Masks 1, 2, and 3 for Heptane Experiment \#2 are graphed in Figures 45 - 47.

Table 8. Timeline and details for Heptane Experiment \#1.

\begin{tabular}{|c|c|c|c|}
\hline $\begin{array}{c}\text { Heptane Experiment } \\
\text { 1 }\end{array}$ & Mask 1 & Mask 2 & Mask 3 \\
\hline Experiment begin time & $0: 00$ & $0: 00$ & $0: 00$ \\
\hline Time at ignition & $1: 25$ & $1: 25$ & $1: 25$ \\
\hline Blinking Green & $2: 35$ & $2: 30$ & $8: 35$ \\
\hline Solid Green & $12: 09$ & $9: 55$ & No change \\
\hline Solid Red & $13: 20$ & $12: 12$ & No change \\
\hline Blinking Red & $14: 37$ & $13: 15$ & No change \\
\hline Experiment end time & $17: 05$ & $17: 05$ & $17: 05$ \\
\hline
\end{tabular}

Table 9. Performance of the three thermal sensing units in Heptane Experiment \# 1.

\begin{tabular}{|c|c|c|c|c|c|c|}
\hline $\begin{array}{c}\text { Heptane } \\
\text { Experiment 1 }\end{array}$ & \multicolumn{2}{|c|}{ Mask 1 (TSU\#5) } & \multicolumn{2}{c|}{ Mask 2 (TSU\#4) } & \multicolumn{2}{c|}{ Mask 3 (TSU\#6) } \\
\hline Temperature $\left({ }^{\circ} \mathrm{C}\right)$ & M1TC1 & M1TC3 & M2TC1 & M2TC3 & M3TC1 & M2TC3 \\
\hline Blinking Green $\left({ }^{\circ} \mathrm{C}\right)$ & 61.4 & 70.0 & 73.2 & 67.1 & 30.9 & 53.3 \\
\hline Solid Green $\left({ }^{\circ} \mathrm{C}\right)$ & 117 & 119.8 & 124.7 & 107.6 & No change & No change \\
\hline Solid Red $\left({ }^{\circ} \mathrm{C}\right)$ & 112.5 & 121.8 & 43.0 & 123.9 & No change & No change \\
\hline Blinking Red $\left({ }^{\circ} \mathrm{C}\right)$ & 104.5 & 109.5 & 149.6 & 130.0 & No change & No change \\
\hline
\end{tabular}




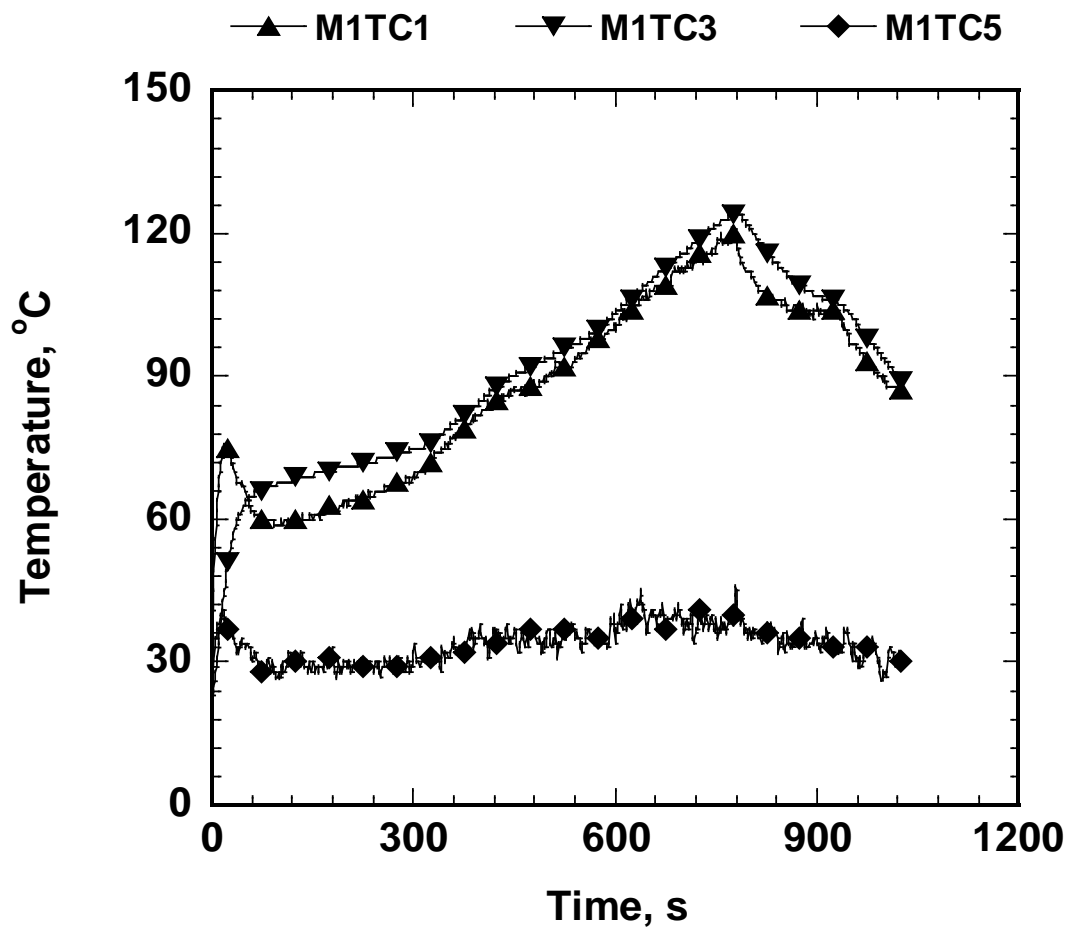

Figure 42. Temperatures at Mask 1 for Heptane Experiment \#1.

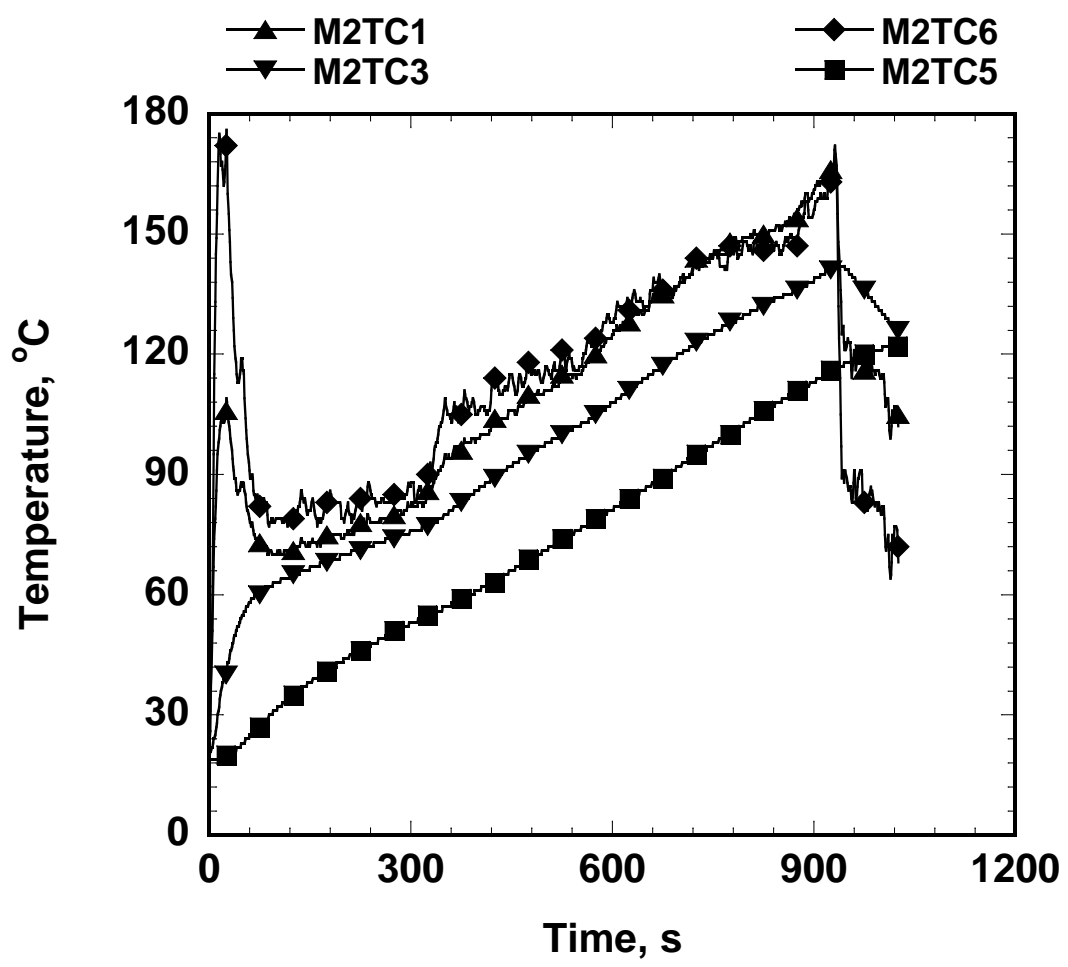

Figure 43. Temperatures at Mask 2 for Heptane Experiment \#1. 


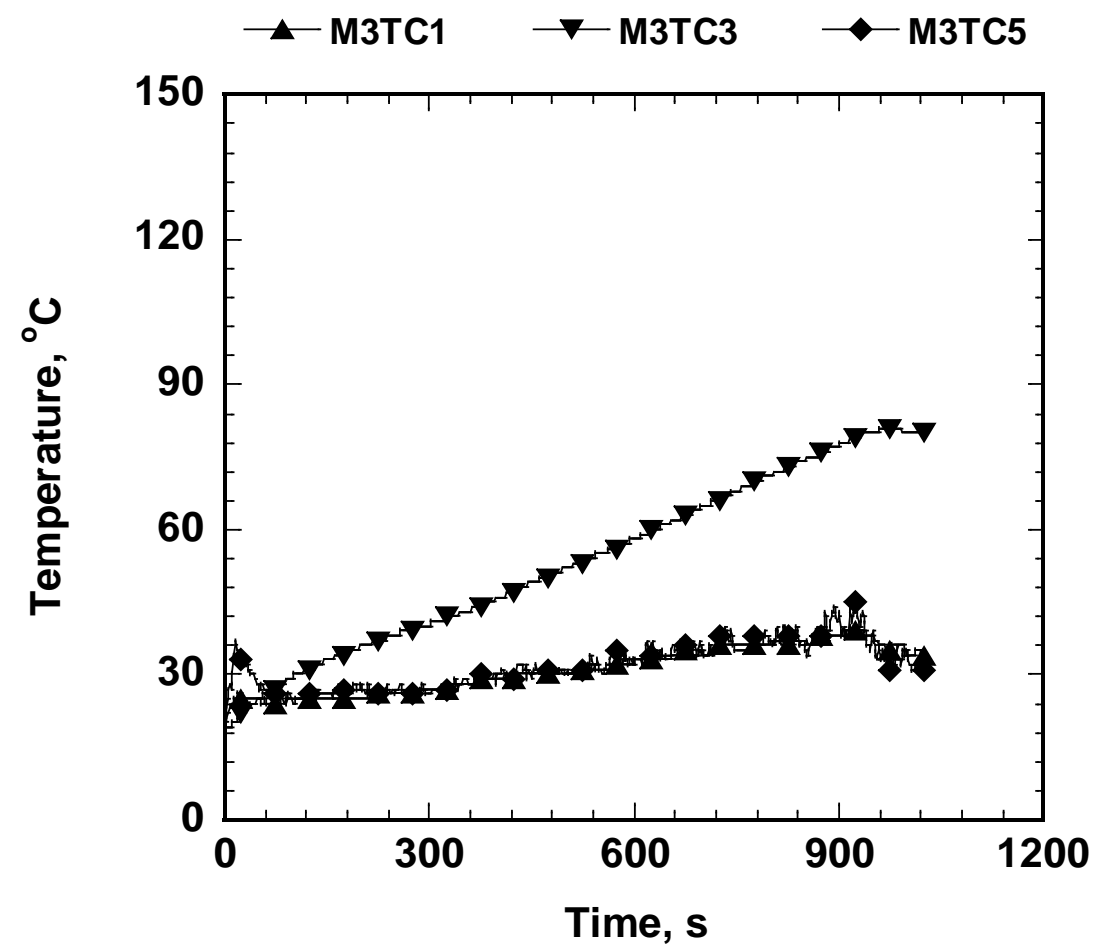

Figure 44. Temperatures at Mask 3 for Heptane Experiment \#1.

Table 10. Timeline and details for Heptane Experiment \#2.

\begin{tabular}{|c|c|c|c|}
\hline $\begin{array}{c}\text { Heptane Experiment } \\
\text { 2 }\end{array}$ & Mask 1 & Mask 2 & Mask 3 \\
\hline Experiment begin time & $0: 00$ & $0: 00$ & $0: 00$ \\
\hline Time at ignition & 0.00 & 0.00 & 0.00 \\
\hline Blinking Green & $3: 40$ & No response & $7: 15$ \\
\hline Solid Green & $10: 20$ & No response & No change \\
\hline Solid Red & $11: 10$ & No response & No change \\
\hline Blinking Red & No change & No response & No change \\
\hline Experiment end time & $12: 00$ & $12: 00$ & No change \\
\hline
\end{tabular}

Table 11. Performance of the three thermal sensing units in Heptane Experiment \# 2

\begin{tabular}{|c|c|c|c|c|c|c|}
\hline $\begin{array}{l}\text { Heptane } \\
\text { Experiment 2 }\end{array}$ & \multicolumn{2}{|l|}{ Mask1 (TSU\#5) } & \multicolumn{2}{c|}{ Mask2 (TSU\#3) } & \multicolumn{2}{c|}{ Mask3 (TSU\#2) } \\
\hline Temperature $\left({ }^{\circ} \mathrm{C}\right)$ & M1TC1 & M1TC3 & M2TC1 & M2TC3 & M3TC1 & M2TC3 \\
\hline Blinking Green $\left({ }^{\circ} \mathrm{C}\right)$ & 60.1 & 62.7 & No response & No response & 27.4 & 48.9 \\
\hline Solid Green $\left({ }^{\circ} \mathrm{C}\right)$ & 106.2 & 111.0 & No response & No response & No change & No change \\
\hline Solid Red $\left({ }^{\circ} \mathrm{C}\right)$ & 111.9 & 117.3 & No response & No response & No change & No change \\
\hline Blinking Red $\left({ }^{\circ} \mathrm{C}\right)$ & $\begin{array}{c}\text { No } \\
\text { change }\end{array}$ & $\begin{array}{c}\text { No } \\
\text { change }\end{array}$ & No response & No response & No change & No change \\
\hline
\end{tabular}




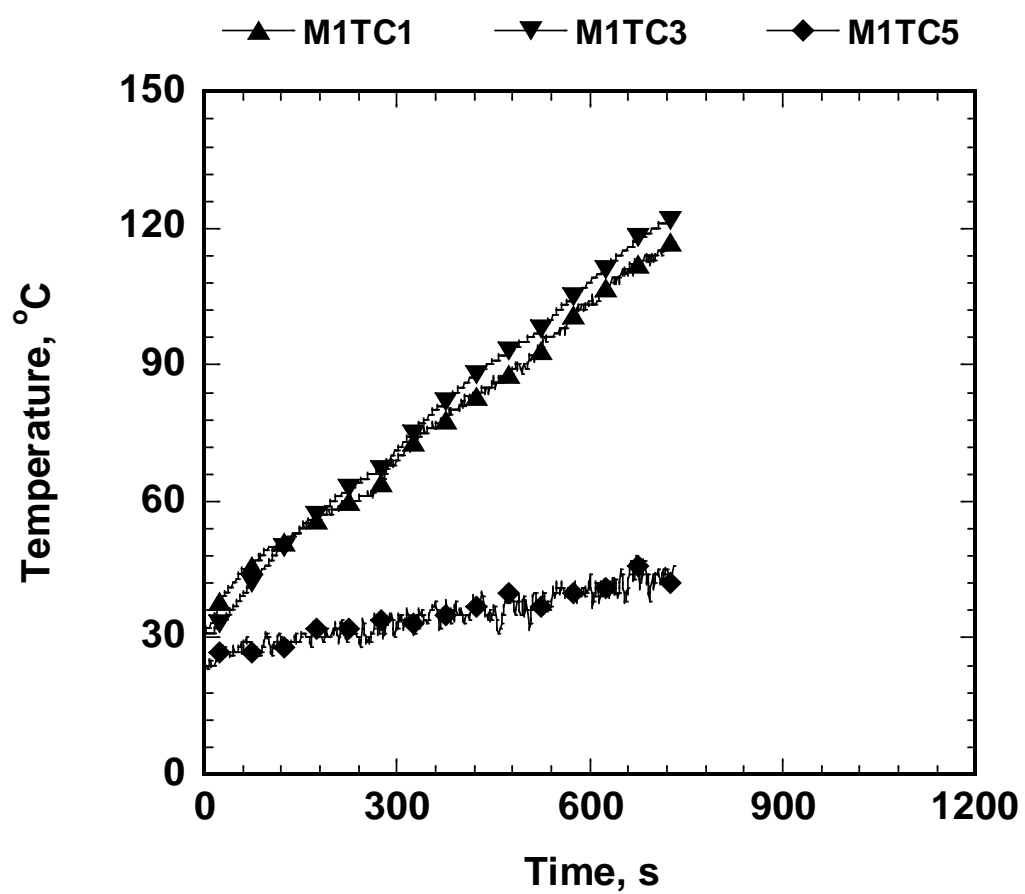

Figure 45. Temperatures at Mask 1 for Heptane Experiment \#2.

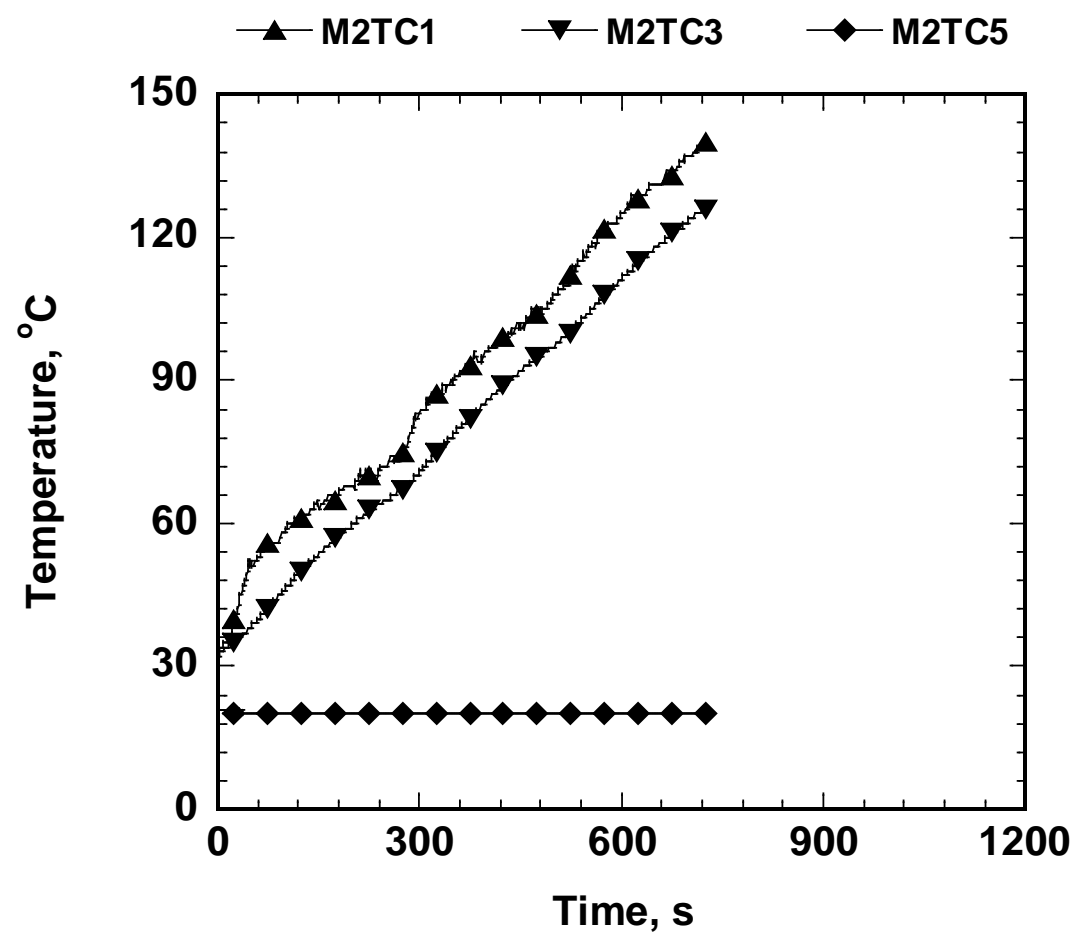

Figure 46. Temperatures at Mask 2 for Heptane Experiment \#2. 


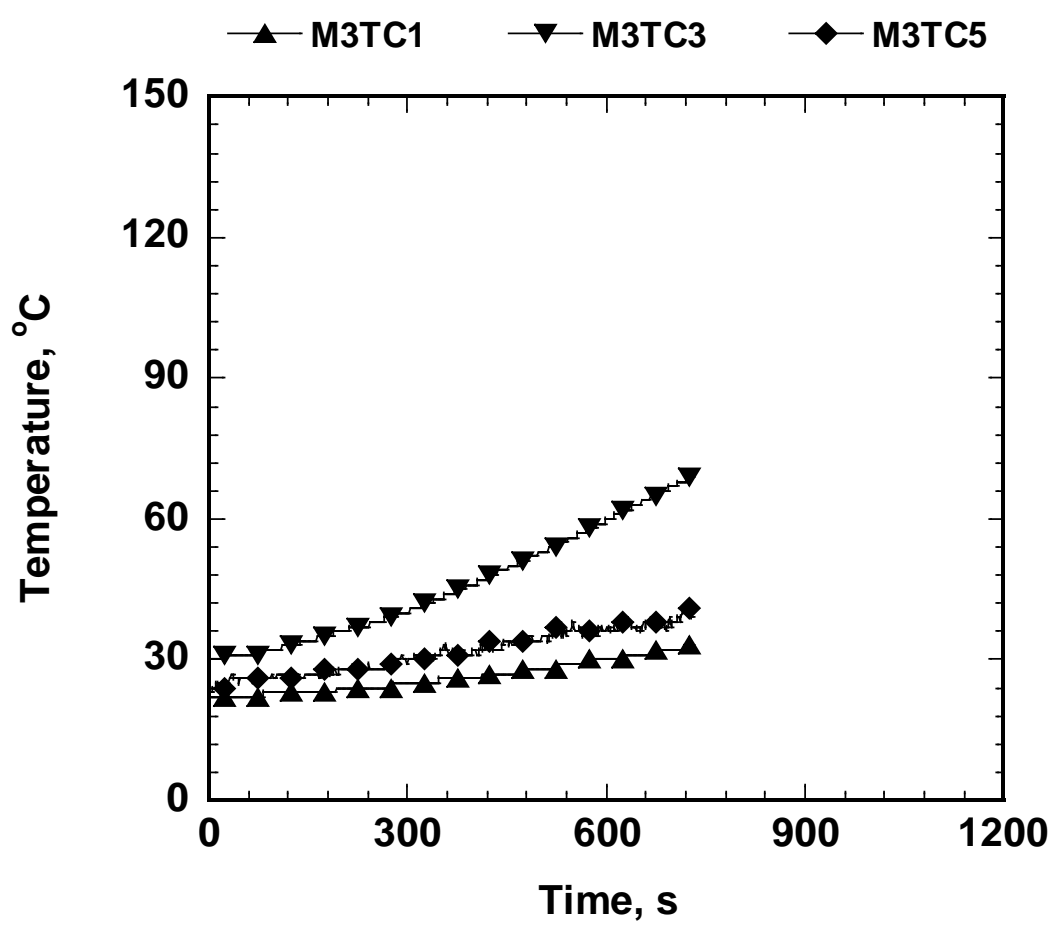

Figure 47. Temperatures at Mask 3 for Heptane Experiment \#2.

\subsection{Results of the Living Room Fire Experiments}

The living room fire experiments were the shortest experiment experiments conducted in the ISO room, with durations of $180 \mathrm{~s}$ and $140 \mathrm{~s}$. As explained earlier, these experiments were short in an effort to avoid the flashover temperatures that could have damaged the infrastructure of the ISO room as well as the masks and thermal sensing units. Even though care was taken to avoid flashover temperatures, the temperatures in the upper layer of the room were measured to reach above $600^{\circ} \mathrm{C}$. The flame height from the couch was measured to be in the range of $1.2 \mathrm{~m} \mathrm{(4 \textrm {ft } )}$ to $1.5 \mathrm{~m}$ (5 ft) from the floor. The timeline and the experiment details for Living Room Experiment \#1 are shown in Table 12. Table 13 shows the specific temperatures at TC1 and TC3 for specific thermal sensing units, when the warning indicators changed their blinking status during the experiment. The temperatures at the thermal sensing units attached to each mask for Living Room Experiment \#1 are graphed in Figures 48 - 50. The timeline and the experiment details for Living Room Experiment \#2 are shown in Tables 14 and 15. Temperatures for Masks 1, 2, and 3 for Heptane Experiment \#2 are graphed in Figures 51 - 53. 


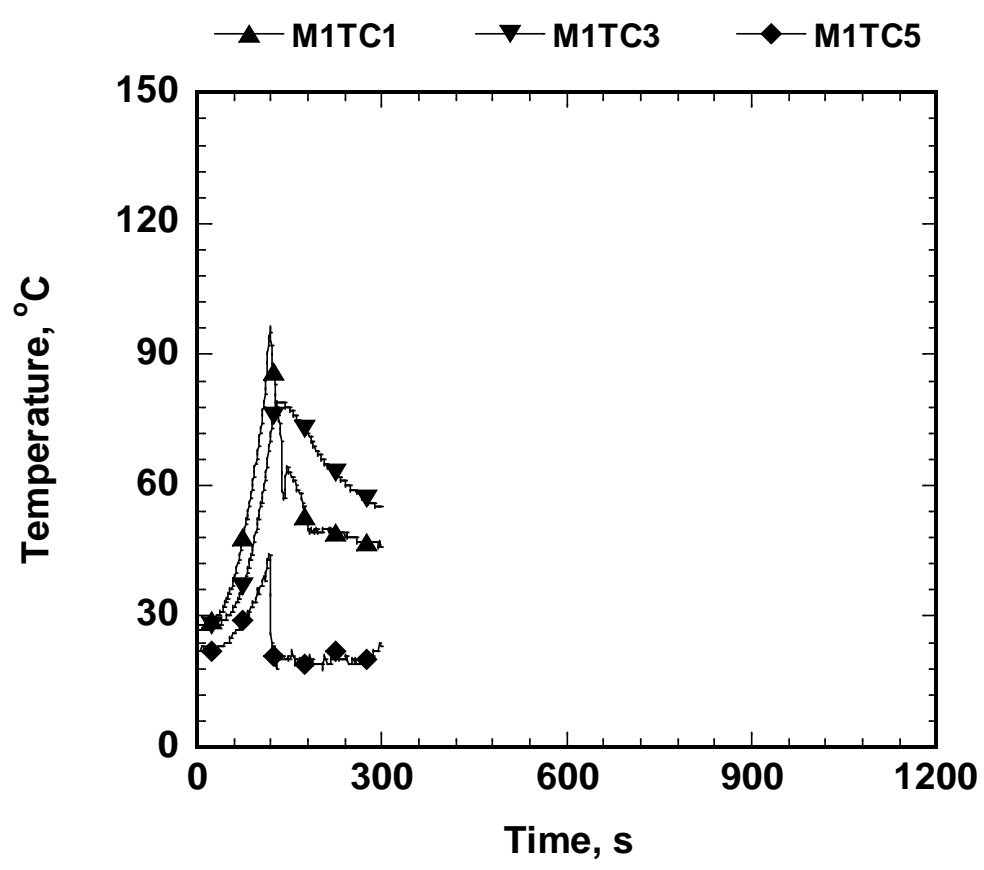

Table 12. Timeline and details of Living Room Experiment \#1.

\begin{tabular}{|c|c|c|c|}
\hline $\begin{array}{c}\text { Living Room } \\
\text { Experiment 1 }\end{array}$ & Mask 1 & Mask 2 & Mask 3 \\
\hline Experiment begin time & $0: 00$ & $0: 00$ & $0: 00$ \\
\hline Time at ignition & $0: 40$ & $0: 40$ & $0: 40$ \\
\hline Blinking Green & $2: 33$ & $2: 23$ & $3: 20$ \\
\hline Solid Green & Skipped & Skipped & No change \\
\hline Solid Red & $2: 45$ & $2: 25$ & No change \\
\hline Blinking Red & No change & No change & No change \\
\hline Experiment end time & $3: 00$ & $3: 00$ & $3: 00$ \\
\hline
\end{tabular}

Table 13. Performance of the three thermal sensing units in Living Room Experiment \# 1.

\begin{tabular}{|c|c|c|c|c|c|c|}
\hline $\begin{array}{c}\text { Living Room } \\
\text { Experiment 1 }\end{array}$ & \multicolumn{2}{|l|}{ Mask 1 (TSU\#5) } & \multicolumn{2}{l|}{ Mask 2 (TSU \#4) } & \multicolumn{2}{l|}{ Mask 3 (TSU\#2) } \\
\hline Temperature $\left({ }^{\circ} \mathrm{C}\right)$ & M1TC1 & M1TC3 & M2TC1 & M2TC3 & M3TC1 & M2TC3 \\
\hline Blinking Green $\left({ }^{\circ} \mathrm{C}\right)$ & 63.2 & 77.7 & 102.7 & 92.1 & 43.1 & 49.5 \\
\hline Solid Green $\left({ }^{\circ} \mathrm{C}\right)$ & $\begin{array}{c}\text { No } \\
\text { change }\end{array}$ & $\begin{array}{c}\text { No } \\
\text { change }\end{array}$ & $\begin{array}{c}\text { No } \\
\text { change }\end{array}$ & $\begin{array}{c}\text { No } \\
\text { change }\end{array}$ & $\begin{array}{c}\text { No } \\
\text { change }\end{array}$ & $\begin{array}{c}\text { No } \\
\text { change }\end{array}$ \\
\hline Solid Red $\left({ }^{\circ} \mathrm{C}\right)$ & 59.3 & 75.4 & 95.0 & 92.6 & $\begin{array}{c}\text { No } \\
\text { change }\end{array}$ & $\begin{array}{c}\text { No } \\
\text { change }\end{array}$ \\
\hline Blinking Red $\left({ }^{\circ} \mathrm{C}\right)$ & $\begin{array}{c}\text { No } \\
\text { change }\end{array}$ & $\begin{array}{c}\text { No } \\
\text { change }\end{array}$ & $\begin{array}{c}\text { No } \\
\text { change }\end{array}$ & $\begin{array}{c}\text { No } \\
\text { change }\end{array}$ & $\begin{array}{c}\text { No } \\
\text { change }\end{array}$ & $\begin{array}{c}\text { No } \\
\text { change }\end{array}$ \\
\hline
\end{tabular}

Figure 48. Temperatures at Mask 1 for Living Room Experiment \#1. 


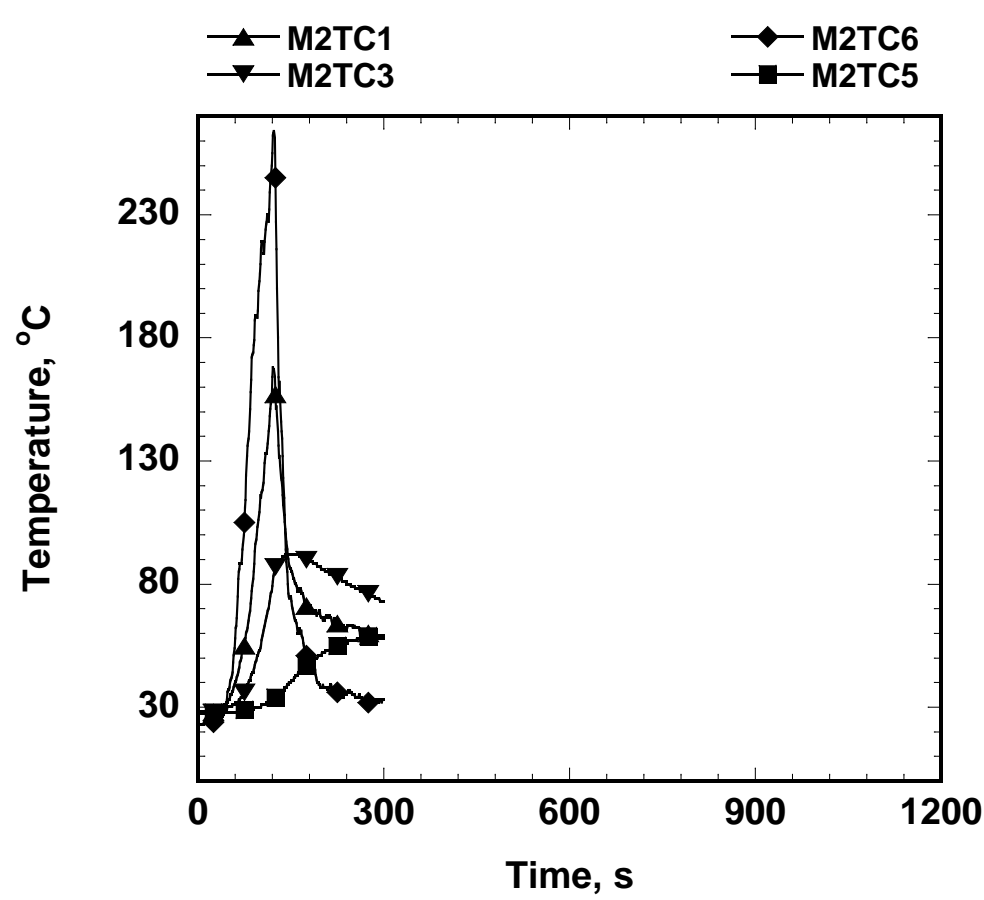

Figure 49. Temperatures at Mask 2 for Living Room Experiment \#1.

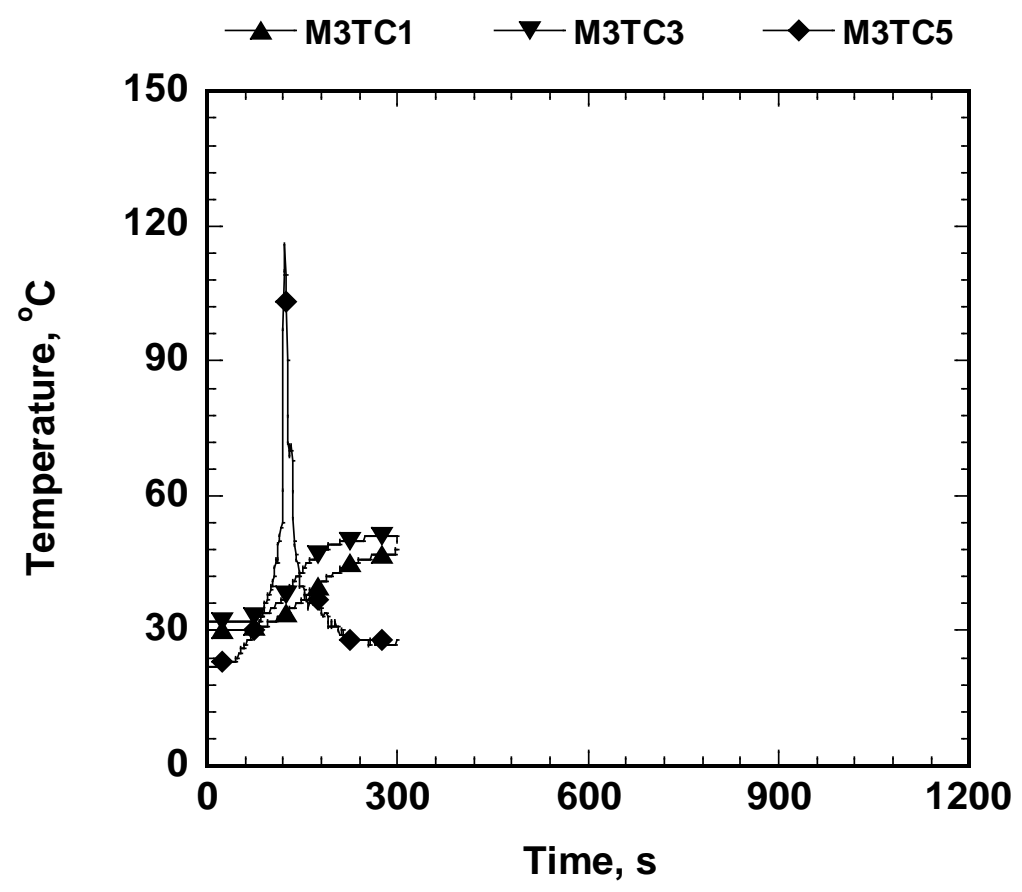

Figure 50. Temperatures at Mask 3 for Living Room Experiment \#1. 
Table 14. Timeline and details for Living Room Experiment \#2.

\begin{tabular}{|c|c|c|c|}
\hline $\begin{array}{c}\text { Living Room } \\
\text { Experiment 2 }\end{array}$ & Mask 1 & Mask 2 & Mask 3 \\
\hline Experiment begin time & $0: 00$ & $0: 00$ & $0: 00$ \\
\hline Time at ignition & $1: 00$ & $1: 00$ & $1: 00$ \\
\hline Blinking Green & $3: 00$ & $2: 58$ & $3: 12$ \\
\hline Solid Green & Skipped & Skipped & Skipped \\
\hline Solid Red & $3: 11$ & $3: 09$ & $3: 25$ \\
\hline Blinking Red & No change & No change & No change \\
\hline Experiment end time & $3: 35$ & $3: 45$ & $3: 45$ \\
\hline
\end{tabular}

Table 15. Performance of the three thermal sensing units in Living Room Experiment \#2.

\begin{tabular}{|c|c|c|c|c|c|c|}
\hline $\begin{array}{l}\text { Living Room } \\
\text { Experiment 2 }\end{array}$ & \multicolumn{2}{|l|}{ Mask 1 (TSU\#5) } & \multicolumn{2}{l|}{ Mask 2 (TSU\#4) } & \multicolumn{2}{l|}{ Mask 3 (TSU\#6) } \\
\hline Temperature $\left({ }^{\circ} \mathrm{C}\right)$ & M1TC1 & M1TC3 & M2TC1 & M2TC3 & M3TC1 & M2TC3 \\
\hline Blinking Green $\left({ }^{\circ} \mathrm{C}\right)$ & 51.9 & 89.2 & 115.6 & 138.5 & 40.6 & 53.9 \\
\hline Solid Green $\left({ }^{\circ} \mathrm{C}\right)$ & $\begin{array}{c}\text { No } \\
\text { change }\end{array}$ & $\begin{array}{c}\text { No } \\
\text { change }\end{array}$ & $\begin{array}{c}\text { No } \\
\text { change }\end{array}$ & $\begin{array}{c}\text { No } \\
\text { change }\end{array}$ & $\begin{array}{c}\text { No } \\
\text { change }\end{array}$ & $\begin{array}{c}\text { No } \\
\text { change }\end{array}$ \\
\hline Solid Red $\left({ }^{\circ} \mathrm{C}\right)$ & 55.5 & 80.9 & 106.8 & 136.5 & 43.3 & 55.7 \\
\hline Blinking Red $\left({ }^{\circ} \mathrm{C}\right)$ & $\begin{array}{c}\text { No } \\
\text { change }\end{array}$ & $\begin{array}{c}\text { No } \\
\text { change }\end{array}$ & $\begin{array}{c}\text { No } \\
\text { change }\end{array}$ & $\begin{array}{c}\text { No } \\
\text { change }\end{array}$ & $\begin{array}{c}\text { No } \\
\text { change }\end{array}$ & $\begin{array}{c}\text { No } \\
\text { change }\end{array}$ \\
\hline
\end{tabular}

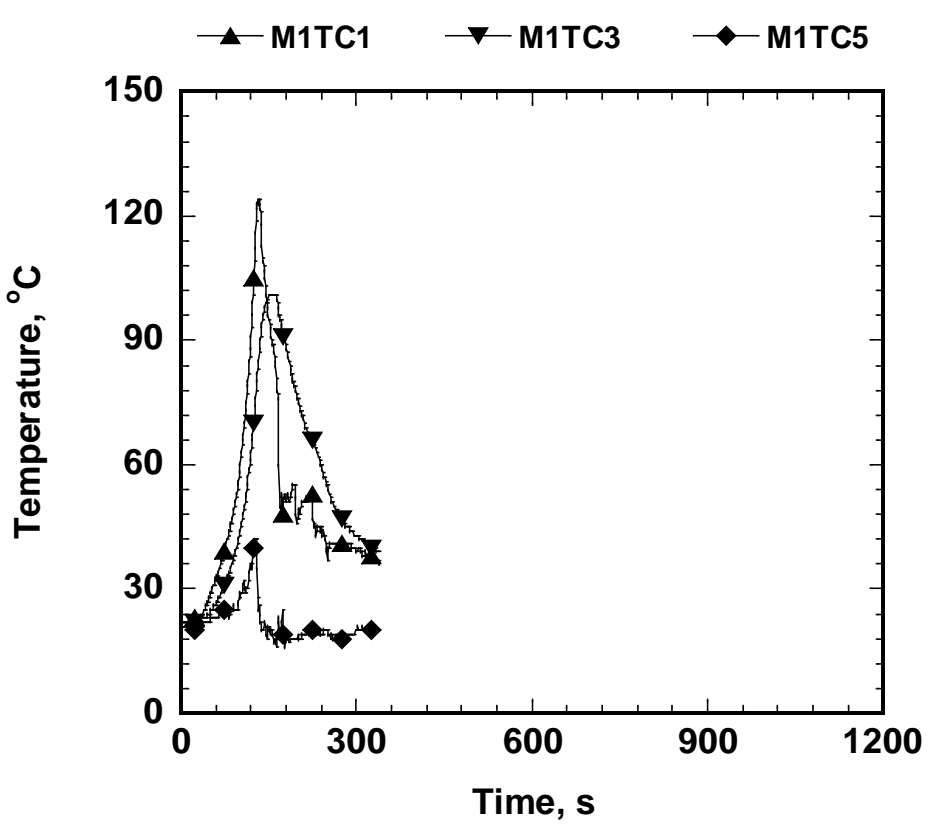

Figure 51. Temperatures at Mask 1 for Living Room Experiment \#2. 


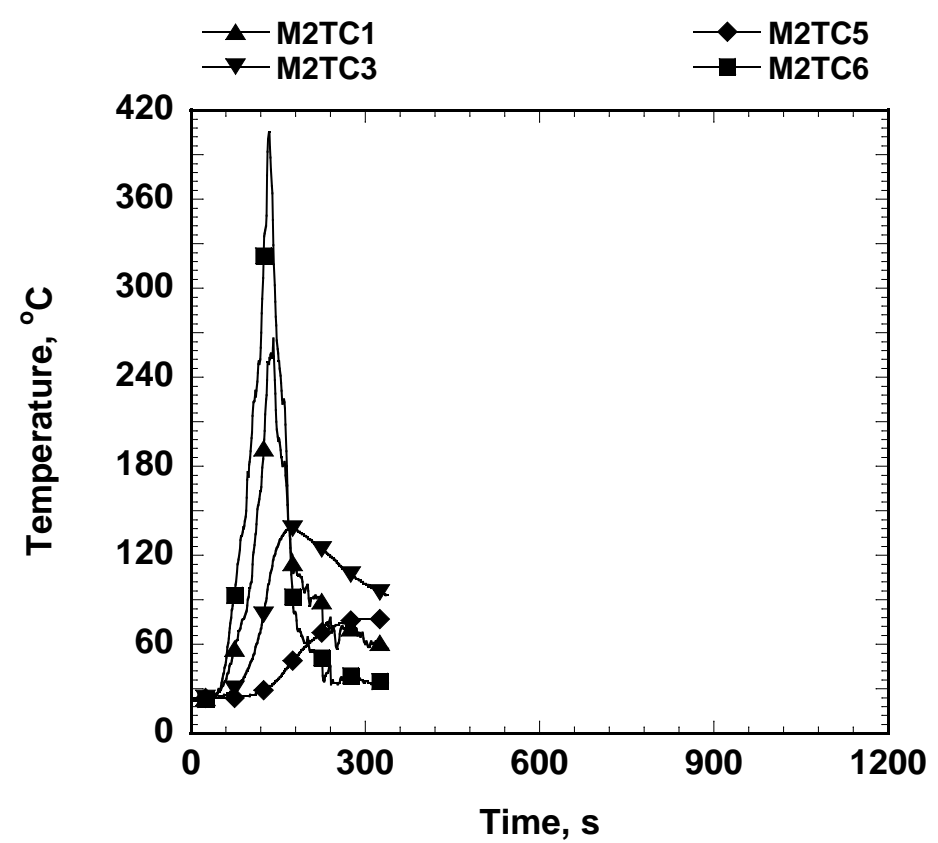

Figure 52. Temperatures at Mask 2 for Living Room Experiment \#2.

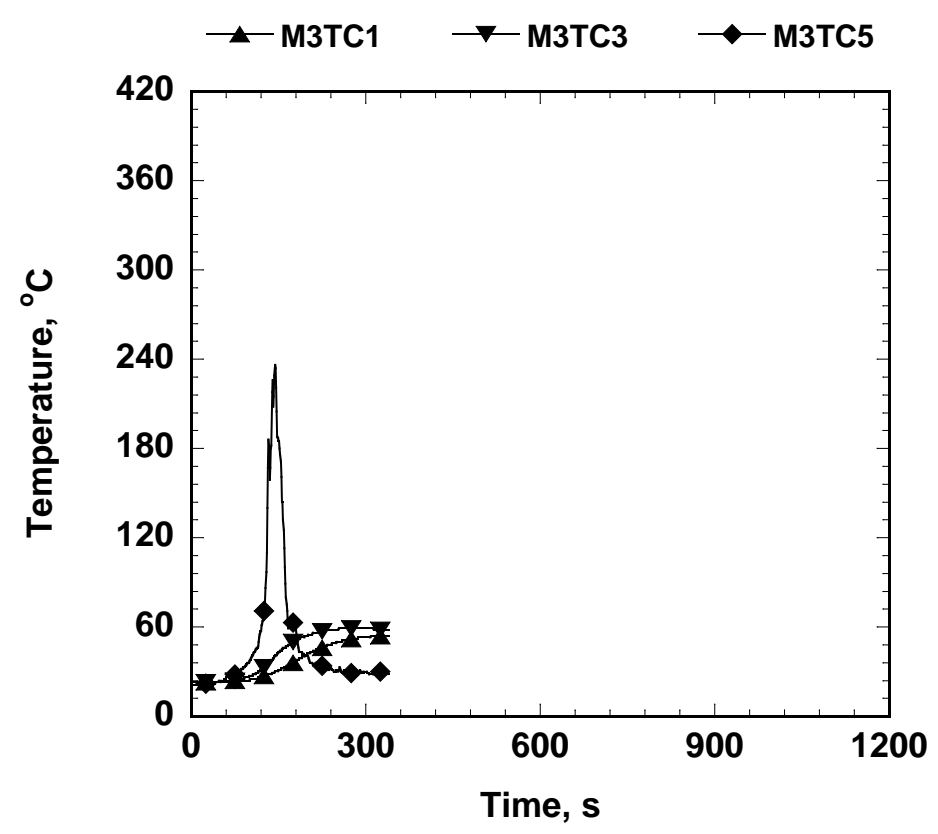

Figure 53. Temperatures at Mask 3 for Living Room Experiment \#2. 


\subsection{Experimental Uncertainty}

There are different components of uncertainty in the positioning, temperature, thermal flux, and time data reported here. Uncertainties are grouped into two categories according to the method used to estimate them. Type A uncertainties are those which are evaluated by statistical methods, and Type B are those which are evaluated by other means [Taylor 1994]. Type B analysis of systematic uncertainties involves estimating the upper $(+a)$ and lower $(-a)$ limits for the quantity in question such that the probability that the value would be in the interval $( \pm a)$ is essentially $100 \%$. After estimating uncertainties by either Type A or B analysis, the uncertainties are combined in quadrature to yield the combined standard uncertainty. Multiplying the combined standard uncertainty by a coverage factor of two results in the expanded uncertainty which corresponds to a $95 \%$ confidence interval $(2 \sigma)$.

Components of uncertainty are tabulated in Table 16. Some of these components, such as the zero and calibration elements, are derived from instrument specifications. Other components, such as radiative cooling/heating include past experience with thermocouples in high temperature environments.

The uncertainty in the gas temperature measurements includes radiative cooling in each of the experiments series, but also includes radiative heating for thermocouple located inside the facepiece. Gas temperature measurements were monitored up $140{ }^{\circ} \mathrm{C}$. There were no temperature fluctuations of large magnitude and typically the temperature changed slowly. Thermocouples were located in hot and cool locations. When positioned in hot gases, the thermocouple beads would have radiated some energy to the cooler objects such as the facepiece or headform and this radiative cooling could have caused the recorded temperature to be lower than the actual gas temperature. On the other hand, a thermocouple positioned inside the facepiece would have been in a cooler environment, but radiation from the hotter gases could have radiated some energy to the thermocouple bead causing radiative heating of the bead. This could have caused the recorded temperature to be greater than the temperature inside the facepiece. Calibration data was obtained from the thermocouple manufacturer and the measurements were very repeatable. This resulted in an estimate of $-32 \%$ to $+15 \%$ total expanded relative uncertainty for the temperature measurements.

Calibration of heat flux gauges was completed at lower fluxes and then extrapolated to higher values and this resulted in a higher uncertainty in the flux measurement. Combining all of component uncertainties for total heat flux resulted in a total expanded uncertainty of - $23 \%$ to $+23 \%$ for the flux measurements. Estimating the uncertainty in the thermal sensing unit response or activation temperature for the static oven and flow loop experiments required the uncertainties in air temperature, alarm activation, and repeatability to generate a total expanded uncertainty range of $-27 \%$ to $+29 \%$. In all the experimental experiment series, uncertainty in the physical position of the instrumentation such as thermocouples or heat flux gauges was estimated to have the lowest total expanded uncertainty of $\pm 11 \%$. 
Table 16: Uncertainty in full-scale experimental data.

\begin{tabular}{|c|c|c|c|}
\hline & $\begin{array}{l}\text { Component } \\
\text { Standard } \\
\text { Uncertainty }\end{array}$ & $\begin{array}{l}\text { Combined } \\
\text { Standard } \\
\text { Uncertainty }\end{array}$ & $\begin{array}{c}\text { Total } \\
\text { Expanded } \\
\text { Uncertainty }\end{array}$ \\
\hline \begin{tabular}{|} 
GasTemperature \\
Calibration \\
Radiative Cooling \\
Radiative Heating \\
Repeatability $^{1}$ \\
Random $^{1}$
\end{tabular} & $\begin{array}{c} \pm 1 \% \\
-15 \% \text { to }+0 \% \\
-0 \% \text { to }+5 \% \\
\pm 5 \% \\
\pm 3 \%\end{array}$ & $-16 \%$ to $+8 \%$ & $-32 \%$ to $+15 \%$ \\
\hline \begin{tabular}{|l} 
Total Heat Flux \\
$\quad$ Calibration \\
Zero \\
Repeatability $^{1}$ \\
Random $^{1}$
\end{tabular} & $\begin{array}{c} \pm 10 \% \\
-2 \% \text { to }+2 \% \\
\pm 5 \% \\
\pm 3 \%\end{array}$ & $-12 \%$ to $+12 \%$ & $-23 \%$ to $+23 \%$ \\
\hline $\begin{array}{l}\text { Activation } \\
\text { Temperature } \\
\text { Zero } \\
\text { Temperature } \\
\text { Alarm/Light } \\
\text { Activation }^{1} \\
\text { Repeatability }^{1} \\
\text { Random }^{1}\end{array}$ & $\begin{array}{c} \pm 2 \% \\
\pm 12 \% \\
-0 \% \quad \text { to }+5 \% \\
\pm 5 \% \\
\pm 3 \%\end{array}$ & $-13 \%$ to $+14 \%$ & $-27 \%$ to $+29 \%$ \\
\hline $\begin{array}{l}\text { Instrument Location } \\
\text { Zero } \\
\text { Repeatability }^{1} \\
\text { Random }^{1}\end{array}$ & $\begin{array}{l} \pm 1 \% \\
\pm 5 \% \\
\pm 2 \%\end{array}$ & $\pm 5 \%$ & $\pm 11 \%$ \\
\hline
\end{tabular}




\subsection{DISCUSSION}

The response of the thermal sensing units across the three experiments was different, depending upon the intensity and the rate of increase of heat in a particular experiment. None of the thermal sensing units deformed or melted in any of the Full-scale fire experiments.

However, some surface marks and scratches were noticed on thermal sensing units \#5 and \#4 at the conclusion of the living room fire experiments. This was likely due to the fact that the temperatures for those experiments increased drastically within several seconds, perhaps demonstrating one of the most hazardous conditions for firefighters and their protective gear. Thermal sensing unit \#5 (located at Mask 1, see Figure 14 for location) survived the complete experiment regimen. Thermal sensing units \#2, \#4, \#5, and \#6 were noted to indicate 'sudden hot conditions through actuation of their solid red indicator immediately after the green blink indicator, when the temperatures increased to more than $200^{\circ} \mathrm{C}$ within a few seconds during the living room fire experiments.

As stated earlier, Mask 1 represented the position of thermal sensing unit when exposed to intense radiation. Thermal sensing unit \#5 was tested for reproducible performance at Mask 1 in all three of the experiments. That device consistently indicated 'blinking green' for both of the natural gas experiments between the temperatures of $60^{\circ} \mathrm{C}$ to $65^{\circ} \mathrm{C}$. Thermal sensing unit \#5 also produced a 'blinking green' indicator between the temperatures of $68^{\circ} \mathrm{C}$ to $73^{\circ} \mathrm{C}$ for both of the heptane experiments, whereas the same device produced a 'blinking green' indicator between the temperatures $68^{\circ} \mathrm{C}$ to $73^{\circ} \mathrm{C}$ momentarily in the living room fire experiment.

The thermal sensing unit \#5 at Mask 1 responded first in both of the natural gas experiments, followed by the devices at Mask 2 and Mask 3. The thermal sensing units \#3 and \#4 at Mask 2 responded first in the first heptane experiment and the two living room fire experiments, followed by the thermal sensing unit \#5 at Mask 1 and thermal sensing unit \#2 and \#6 at Mask 3. The response of Mask 1 in the natural gas experiment is consistent with the intense radiant heat that was incident upon the mask was due to the height of the burner and the mask being the same, exposing it to increased radiative heat when compared to Mask 2 and Mask 3.

The thermal sensing unit at Mask 2 responded earlier than the thermal sensing unit at Mask 1 in the Heptane Experiment \# 1 due to a hot upper layer of gases formed in the ISO room after ignition. The heptane burns produced large amounts of soot that led to the formation of a heated gas layer in the upper volume of the room. The hot soot layer was seen up to $1.2 \mathrm{~m}(4 \mathrm{ft})$

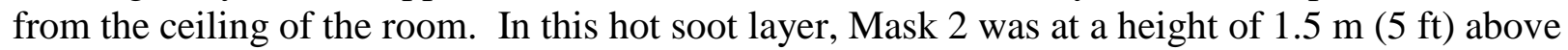
the floor, just at the height of the soot layer. These hot layers of gases resulted in a convective heat transfer to Mask 2, which led to it being heated and its attached thermal sensing unit indicators actuating earlier than for Mask 1 or Mask 3. Mask 1 was located at a distance of a 0.3 $\mathrm{m}$ (1ft) above the floor, so it was lower in elevation than the heptane burner height by $0.15 \mathrm{~m}$ (6 in). This would have been consistent as to why Mask 1 did not experience radiation as intense as in the natural gas experiments. The thermal sensing unit at Mask 3 responded later in the heptane experiments as well.

The thermal sensing unit at Mask 2 responded earlier than the device at Mask 1 in the living room fire experiments as well, but the difference in the response time of the two devices was between $5 \mathrm{~s}$ to $10 \mathrm{~s}$. The couch was ignited at the rear leftmost point in the room, leading to large amounts of soot production from the left corner to the nearest 'cooler region,' which was located in the upper volume of the ISO room. The hot layer of sooty gases in the living room 


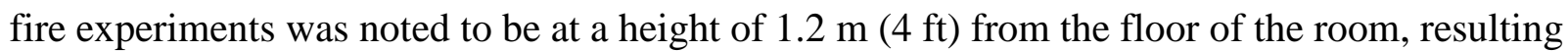
in the condition that half of the room was filled with hot gases. This hot layer resulted in increased convective heat transfer to Mask 2, leading to display of the 'blinking green' indicator. Interestingly, Mask 1 and Mask 2 did not display the 'solid green' indicators and instead went straight to the 'solid red' indicators within $10 \mathrm{~s}$, suggesting the development of hazardous conditions within $120 \mathrm{~s}$ after the experiment ignition.

The thermal sensing unit at Mask 3 also responded quickly in the two living room fire experiments when compared to the natural gas or heptane experiments, likely due to the intense heat and smoke that was generated within a 120 s time period, and was noted to actuate the 'solid red' indicator within $10 \mathrm{~s}$ of actuating the 'blinking green' indicator, providing a 'validation' of sorts regarding the hazardous scenario that was existing in the ISO room at that time. Further, the thermal sensing unit at Mask 3 was noted to actuate only the 'blinking green' indicator in the natural gas and heptane experiments due to the (comparatively) limited conductive heat transfer characteristic of those experiments. As such, the 'slowest' indicator response was from the thermal sensing unit at Mask 3 in 4 of the 6 experiments conducted in the ISO room, whereas the devices at Mask 1 and Mask 2 responded quickly depending upon the intensity, the rate of increase of temperature, and the hot upper layer of gases created in the ISO room. Figure 54 shows the post-experiment condition after Living Room fire Experiment \#2. Thermal sensing unit \#3 failed to indicate any warning indicators in Heptane experiment \#2 at the location of Mask 2. The cause of this apparent malfunction was unknown. The recorded gas temperatures in Heptane experiment \#1 were higher than in Heptane experiment \#2. The impact of repeated or cyclical exposures of a sensing unit to thermal conditions was not examined during this limited set of full-scale experiments.

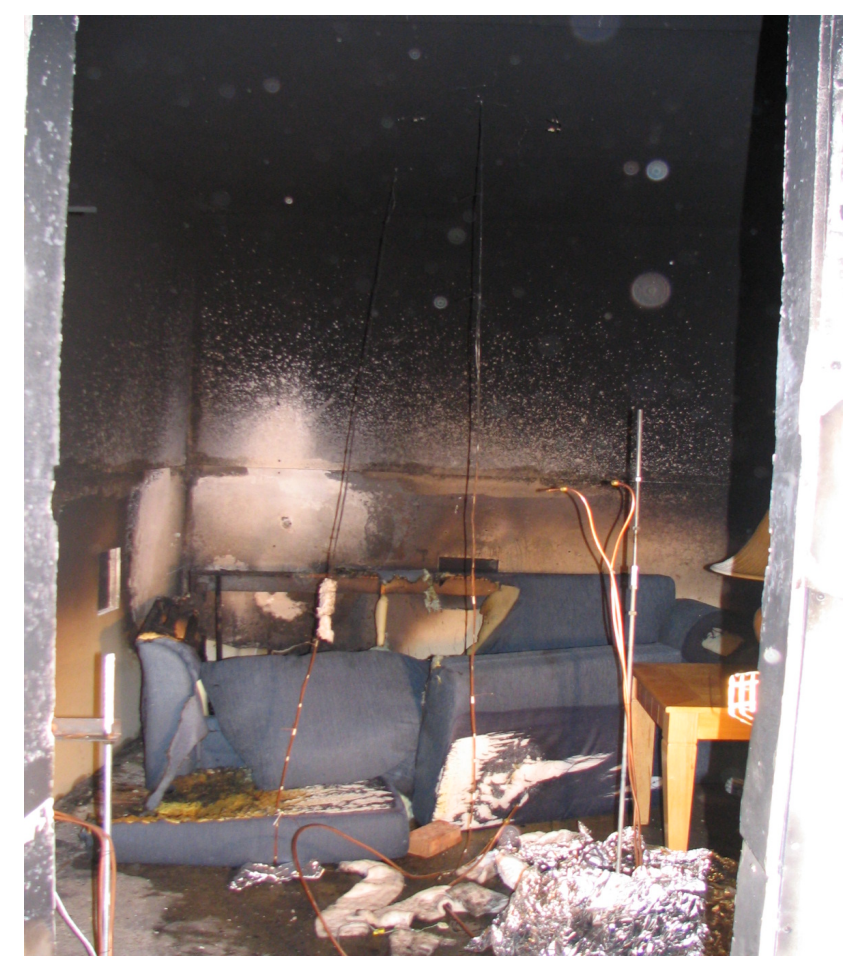

Figure 54. Post-experiment condition of the ISO experiment room for the living room fire experiment. 
Figure 55 displays the post-experiment condition of the three masks exposed to the fire during living room fire experiment \#2, one of the most intense experiments conducted in the ISO room. Mask 2 on the left of the image was the most damaged; it was located $1.5 \mathrm{~m}$ (5 ft) from the floor, and its damage was due to convective heat transfer in the upper layer. The damage included deformation of the polycarbonate lens and thermal decomposition of the plastic heads of the mounting screws for the lens. No crazing (formation of fine lines or surface cracking) or bubbling of the lens was observed. Soot was also deposited onto exposed surfaces of the mask and lens. Mask 3 on the right side of Figure 55 was the least damaged mask, and its placement further away from the fire and in the lower layer primarily represented the conditions of conductive heat transfer. Mask 1 in the middle exhibited less damage than Mask 2 that was exposed in the upper layer. Some deformation, but no crazing or bubbling, of the lens was observed.

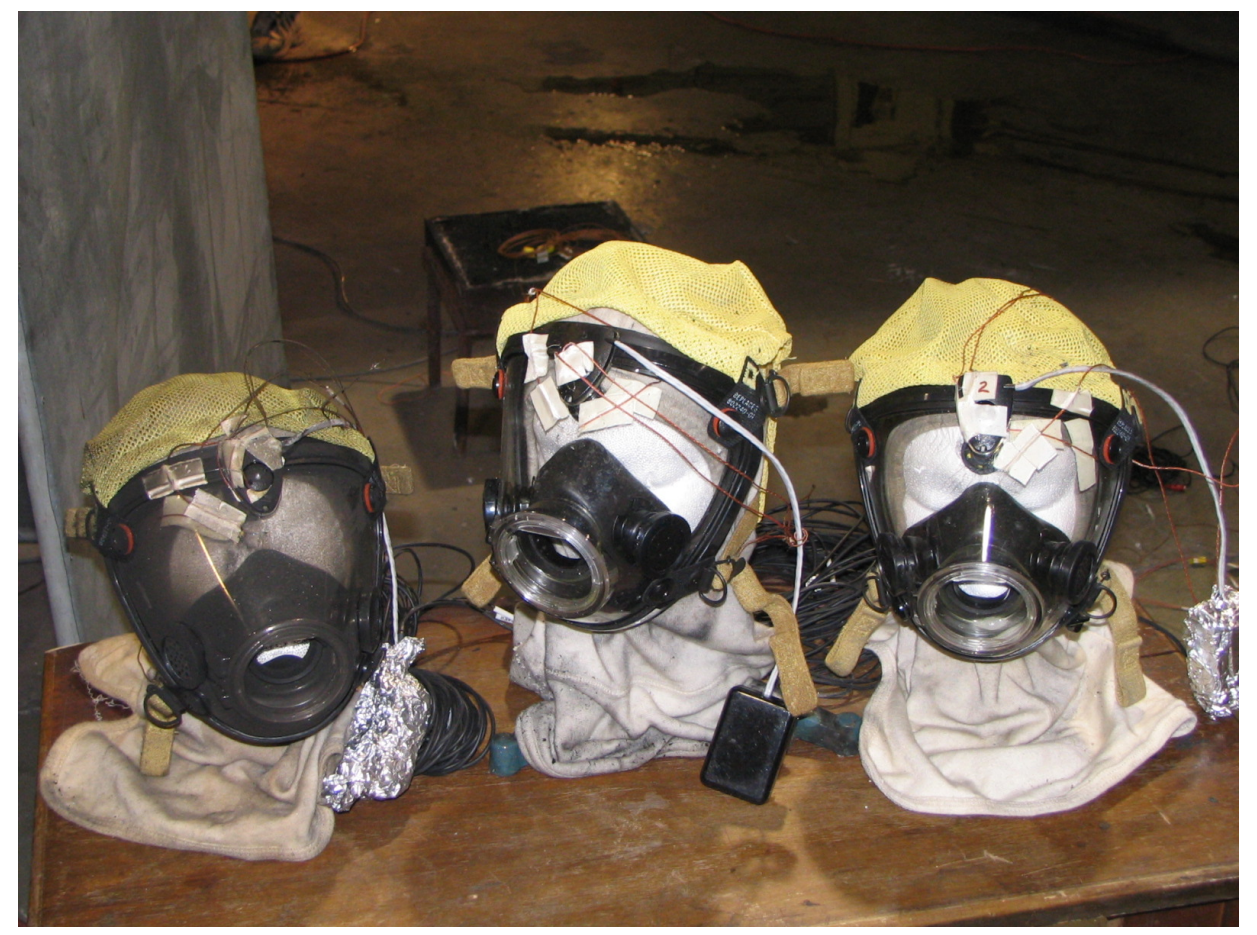

Figure 55. The post-experiment condition of the three masks after Living Room Experiment \#2.

Figure 56 shows thermal sensing unit \#4 mounted on Mask 2 at a height of $1.5 \mathrm{~m} \mathrm{(5 \textrm {ft } )}$ from the floor (this was the most damaged mask after the living room fire experiment). Figure

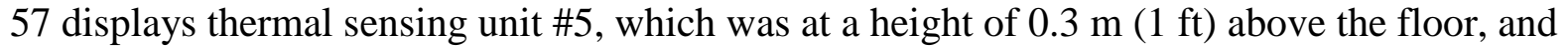
closest to the source of the fire (this device was exposed to the most heat from the source that due to radiation heat-transfer). Thermal sensing unit \#5 was deformed, but was not as heavily

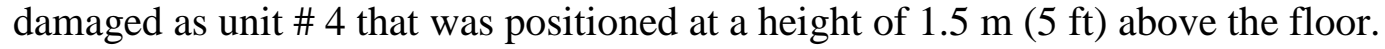




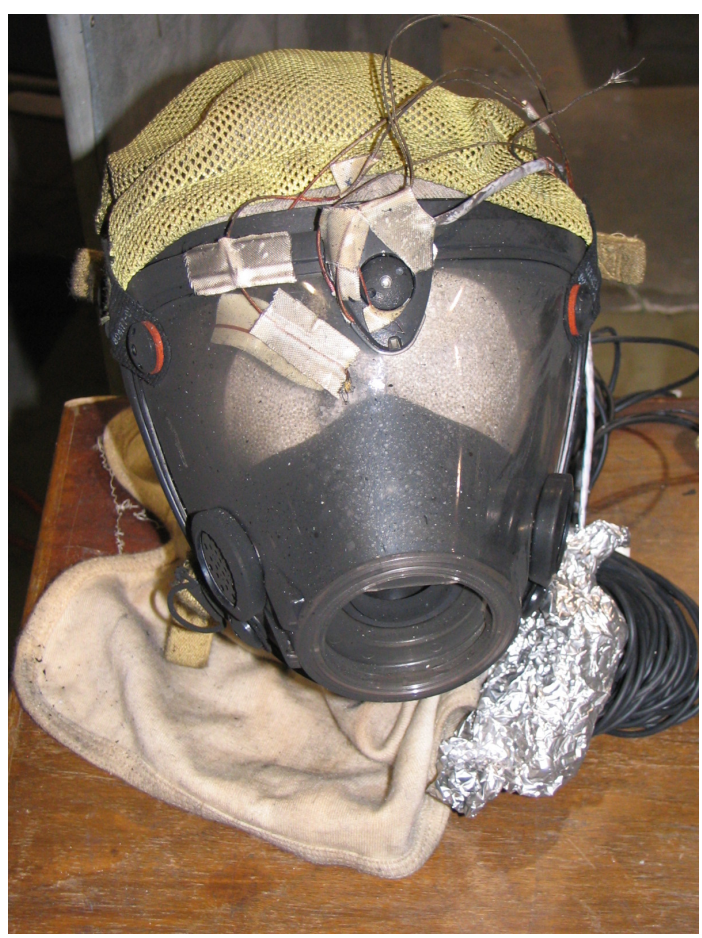

Figure 56. Mask \#2 resulting from convective heat-transfer, and which was positioned at a distance of $1.5 \mathrm{~m}(5 \mathrm{ft})$ above the floor.

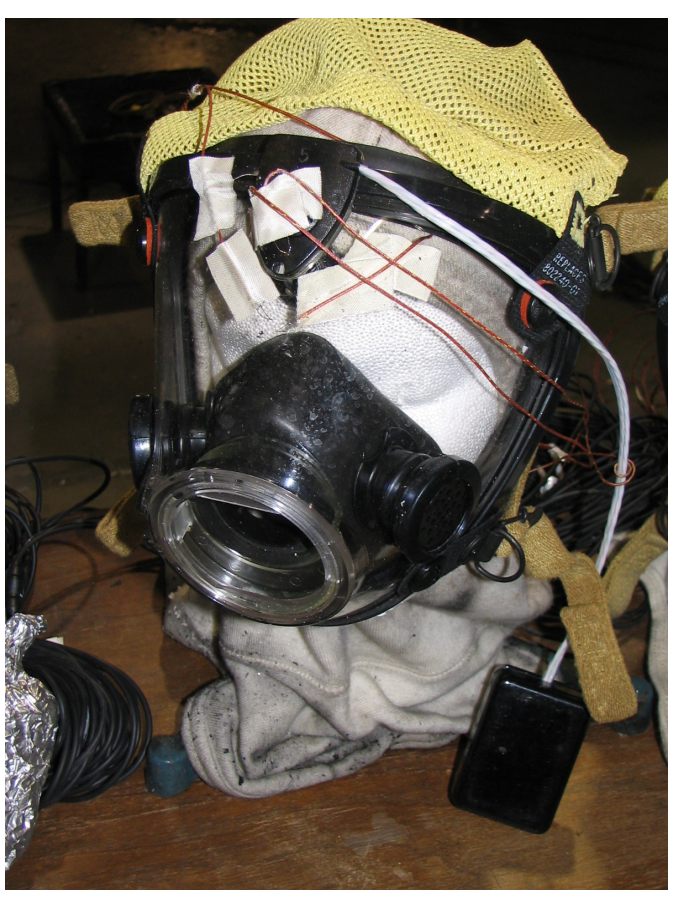

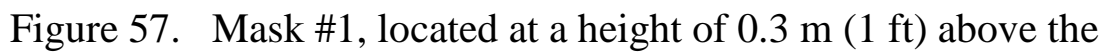
floor, and closest to the source of the fire. 


\subsection{COMPARISON OF THERMAL SENSING UNITS IN FIRE USING DIFFERENT FUELS}

The thermal sensing units performed consistently for all three types of fuels used in the full-scale fire experiments. The performance of the devices was based on the heat generated in each type of experiment rather than the type of fuel because of the nature of the heat sensors (i.e., they detect heat, no matter what is the source). Figures 20 through 29 show the temperature profile in the ISO room at the two thermocouple arrays. The data indicate that the temperatures at higher elevations in the room reached a level of $400^{\circ} \mathrm{C}$ to $450^{\circ} \mathrm{C}$ during the living room experiments, whereas these temperatures were lowest in the natural gas experiments (i.e., $200{ }^{\circ} \mathrm{C}$ to $250^{\circ} \mathrm{C}$ ), and the heptane experiments were in between these two ranges. The heat flux that was generated in the six experiments was in the range of $1 \mathrm{~kW} / \mathrm{m}^{2}$ to $14 \mathrm{~kW} / \mathrm{m}^{2}$, as shown in Figures 30 through 35 . A heat flux of $6.4 \mathrm{~kW} / \mathrm{m}^{2}$ causes the human skin to experience pain with a $1 \mathrm{~s}$ exposure and blisters the skin in $18 \mathrm{~s}$ with second-degree burn injury (NFPA, 1971). A heat flux of $10.4 \mathrm{~kW} / \mathrm{m}^{2}$, however, causes the human skin to experience pain with a 3 second exposure and blisters the skin in 9 seconds with a second-degree burn injury. A heat flux of 12.5 $\mathrm{kW} / \mathrm{m}^{2}$ causes wood volatiles to ignite with extended exposure and piloted ignition (NFPA, 1971). The earlier specified values of heat flux renders comparison of the heat flux values attained in the full-scale fire experiments relatively easy.

In the two full-scale living room experiments, the couch and the side table did not burn in the same manner. In the first living room experiment, the experiment-terminating criteria was exercised stringently, whereas the second living room experiment was allowed to continue further in order to assess the performance of the devices in extremely hot conditions, when the risk of the mask and the thermal sensing unit being destroyed was greater.

\subsection{CONCLUSIONS}

A limited series of thermal exposure experiments in a full-scale room provide performance data for thermal sensing technology. Full-scale exposures such as those described in this report provide insight as to how energy or heat transferred via conduction, convection, and radiation can impact the performance of thermal sensing units. During these thermal exposures, masks with thermal sensing units were positioned in locations that were designed to expose the devices to high thermal radiative flux (Mask 1), high convective heat flux (Mask 2), and low thermal radiative and convective flux (Mask 3). Fuels were varied from natural gas, to liquid heptane, to typical furniture. During each experiment and at each location, the thermal sensing units typically survived the thermal conditions, tracked the gas temperatures, and provided a visual display linked to the thermal conditions. The display of solid or blinking green and red LEDs would provide the fire fighter with real time update as to the changing thermal conditions.

During thermal exposures, gas temperatures and heat fluxes were monitored as well as sensing unit temperatures to characterize how the thermal sensing unit responded to changing thermal conditions. As one would expect, the gas temperatures demonstrate significant 
differences in thermal conditions at each mask location. The mask nearest the fire experienced the highest radiative thermal flux while the mask most distant from the fire experienced significantly less radiative and conductive fluxes. The heat flux that was generated in the six experiments was in the range of $1 \mathrm{~kW} / \mathrm{m}^{2}$ to $14 \mathrm{~kW} / \mathrm{m}^{2}$.

Thermal sensing units melted or deformed in the full-scale experiments, wherein the heat flux reached a maximum level of $14 \mathrm{~kW} / \mathrm{m}^{2}$ for a few seconds. A thermal sensing unit did fail during a heptane fire experiment. It was not clear why the sensing unit failed. The devices also did successfully function in the different kinds of environments generated by burning three different types of fuels. The results from the full-scale testing suggest that the thermal sensing unit can withstand flame-resistant experiments and can perform in highly convective and radiative heat environments, but the temperatures at which the warning indicators are triggered also vary considerably according to the characteristics of the environment in which they are tested. Similarly, there are some inconsistencies in the warning indicators subject to the exposure in similar environments. It was observed that the repeatability and reproducibility of the thermal sensing unit were less consistent from experiment to experiment in the full-scale testing as compared to the laboratory-scale experiments (Deshmukh et al. 2013), likely due to the difference between the controlled and uncontrolled environments.

Combining the results of these full-scale experiments with the previous lab-scale experiments suggests that thermal sensing technology could provide the fire fighter with information about the thermal conditions whether the fire fighter was standing still, moving through smoke, or exposed to flaming conditions. The differences observed in the gas temperatures also demonstrate the need to examine the performance of all situation awareness technology in each of the scenarios. The impact of repeated thermal exposures on the sensing unit also needs to be characterized better. Standard testing protocols need to include conduction-, convection-, and radiation-dominated thermal conditions because fire fighters are exposed to all three scenarios.

Thermal sensing units can provide a fire fighter or emergency responder with information about their environment, but currently technology can only provide a snapshot of current conditions. The technology may include some past exposure as it displays information, but the technology can't predict future conditions. In this work, a thermal sensing unit can detect the change from previous thermal conditions, but it can not predict whether a fire is decreasing or increasing in heat release rate. This implementation of thermal sensing technology displays a change in conditions, but does not provide information about how long the fire fighter has been exposed to these conditions or whether the fire fighter should evacuate. Even if this technology provided the fire fighter with a signal to evacuate, would a series of green and red LEDs be sufficient to cause a fire fighter to retreat? Obviously, thermal sensing units can only help the fire fighter be aware of their environment and their response or action to that information rests on their training and their ability to use the information.

Situational awareness technology can provide the fire service with more information that can be utilized by the fire fighter to understand the thermal conditions in which they are operating. With training, the fire fighter will be better able to use this data or understanding to work more safely and more effectively. It will be important that all situational awareness technology be able to survive and function in multiple exposures to the wide range of conditions that fire fighters experience. Representative performance metrics and standard testing protocols would allow the fire service to better understand the performance characteristics of the thermal 
sensors. In addition, a standardized testing protocol would allow the manufacturers to match the performance of their devices with the requirements of the fire service. 


\subsection{REFERENCES}

International Organization for Standardization, (2003) Full-Scale Room Test for Surface Products, ISO 9705-2003, Geneva, Switzerland.

American Society for Testing and Materials, (1997). E162 - Standard Test Method for Surface Flammability of Materials Using a Radiant Heat Source, Annual Book of ASTM Standards, Vol. 04.07, West Conshohocken, PA.

American Society for Testing and Materials,(1997). E 1321 - Standard Test Method for Determining Materials Ignition and Flame Spread Properties, Annual Book of ASTM Standards, Vol. 04.07. West Conshohocken, PA: American Society for Testing and Materials.

Bretschneider, N., Brattke, S. \& Rein, K. (2006). Head mounted displays for fire fighters. Proceedings of the $3^{\text {rd }}$ International Forum on Applied Wearable Computing, Bremen Germany.

Babrauskas V., (2002). Heat Release Rates, The SFPE Handbook of Fire Protection Engineering, $3^{\text {rd }}$ Edition (Section 3, Chapter 1), National Fire Protection Association and The Society of Fire Protection Engineers, Quincy, MA, P.J. DiNenno, D.Drysdale, C.L. Beyler, and W.D. Walton, eds., pp.1-37.

Bryant, R.A., Ohlemiller, T.J., Johnsson, E.L., Hamins, A., Grove, B. S., Guthrie, W.F., Maranghides, A., Mulholland, G.W. (2004). The NIST 3 Megawatt Quantitative Heat Release Rate Facility - Description and Procedures NISTIR 7052, Gaithersburg, MD: National Institute of Standards and Technology.

Campbell Scientific, Inc., (1989). CR 23X Datalogger Operator’s Manual, Logan Utah: Campbell Scientific.

Deshmukh, A., Casali, J. G., Lancaster, J.A., Bryner, N.P., McLane, R.A. (2013). Thermal Exposure Sensor for Fire Fighters-Laboratory-Scale Performance Experiments, NIST Technical Note XXXX, Gaithersburg, MD: National Institute of Standards and Technology.

Donnelly, M.K., Davis, W.D., Lawson, J.R., Selepak, M.J. (2006). Thermal Environment for Electronic Equipment used by First Responders, NIST Internal Report, Gaithersburg, MD: National Institute of Standards and Technology.

Dillon, S. E. (1998). Analysis of the ISO 9705 Room /Corner Test: Simulations, Correlations and Heat Flux Measurements, NIST-GCR-98-756, Gaithersburg, MD: National Institute of Standards and Technology. 
International Organization for Standardization, (2003) Full-Scale Room Test for Surface Products, ISO 9705-2003, Geneva, Switzerland.

Lawson, J. Randall. and Twilley, W. H. (1999). Development of an Apparatus for Measuring the Thermal Performance of Fire Fighters’ Protective Clothing, NISTIR 6400, Gaithersburg, MD: National Institute of Standards and Technology. pp 1-52.

National Fire Protection Association (1971), Standard on Protective Ensemble for Structural Fire Fighting, 1997 Edition, Quincy, MA: National Fire Protection Association.

Omega Engineering, Thermocouple Response Timehttp://www.omega.com/temperature/Z/ThermocoupleResponseTime.html

Taylor, B. N. and C. E. Kuyatt, Guidelines For Evaluating and Expressing the Uncertainty of NIST Measurement Results. National Institute of Standards and Technology (U.S.) NIST-TN 1297; September, 20 p. 1994. 